\title{
Energy Savings Estimates of Light Emitting Diodes in Niche Lighting Applications
}

\author{
Prepared for: \\ Building Technologies Program \\ Office of Energy Efficiency and Renewable Energy \\ U.S. Department of Energy
}

Prepared by:

Navigant Consulting Inc.

1801 K Street, NW Suite 500

Washington DC, 20006

January 2011 


\section{Disclaimer}

This report was prepared as an account of work sponsored by an agency of the United States Government. Neither the United States Government, nor any agency thereof, nor any of their employees, nor any of their contractors, subcontractors, or their employees, makes any warranty, express or implied, or assumes any legal liability or responsibility for the accuracy, completeness, or usefulness of any information, apparatus, product, or process disclosed, or represents that its use would not infringe privately owned rights. Reference herein to any specific commercial product, process, or service by trade name, trademark, manufacturer, or otherwise, does not necessarily constitute or imply its endorsement, recommendation, or favoring by the United States Government or any agency, contractor, or subcontractor thereof. The views and opinions of authors expressed herein do not necessarily state or reflect those of the United States Government or any agency thereof.

\section{Copies of this Report}

Electronic (PDF) copies of this report are available to the public from:

Solid-State Lighting Web site

Building Technologies Program

U.S. Department of Energy

Web: http://www.ssl.energy.gov/ 


\section{Foreword}

This analysis of niche markets and applications for light emitting diodes was undertaken on behalf of the U.S. Department of Energy to develop a more complete understanding of the energy savings resulting from the use of LEDs and the factors that are motivating consumers to adopt this new technology.

\section{Comments}

The Department is interested in receiving input on the material presented in this report. If you have suggestions of better data sources and/or comments on the findings presented in this report, please submit your feedback to Dr. James R. Brodrick at the following address:

James R. Brodrick, Ph.D.

Program Manager - Lighting Research and Development

EE-2J / Forrestal Building

U.S. Department of Energy

1000 Independence Avenue, SW

Washington, D.C. 20585 


\section{Acknowledgments}

The authors would like to acknowledge the valuable support, guidance, and input offered in the preparation of this report. James R. Brodrick, Ph.D., of the U.S. Department of Energy, Building Technologies Program provided oversight of the assignment, helping to shape the approach, execution, and documentation. The authors are also grateful to the following list of experts for their respective contributions, guidance, and review, which proved invaluable in preparing the estimates contained in this report.

Adi Abileah

Carl Andersen

Norman Bardsley

Vrinda Bhandarkar

Melissa Bilec

Mike Borgos

Andrew Brix

Amanda Burden

Shawn Conrad

Bob Crase

Ed Ebrahimian

Mike Eckert

Cheryl English

Kelly Gordon

Jim Helmer

Bruce Kinzey

Donald Monahan

John Nelms

Mia Paget

Neil Rettig

Tod Rosinbum

Michael Sills-Trausch

Edward Smalley

Doug Staab

Fred Welsh
PLANAR SYSTEMS, Inc.

Federal Highway Administration

Bardsley Consulting

Strategies Unlimited

The University of Pittsburgh

OSRAM Sylvania, Inc.

The City of Ann Arbor

The City of New York

International Parking Institute

Deposition Sciences, Inc.

The City of Los Angeles

LEDnovation, Inc.

Acuity Brands Lighting

Pacific Northwest National Laboratory

The City of San Jose

Pacific Northwest National Laboratory

Walker Parking Consultants

Progress Energy

Pacific Northwest National Laboratory

LEDnovation, Inc.

The City of Portland

The City of Glendale

Seattle City Light

The City of Broken Bow

Radcliffe Advisors 


\section{Table of Contents}

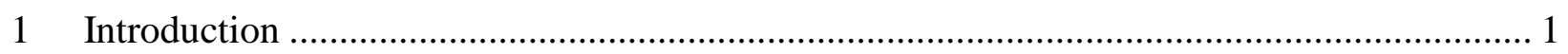

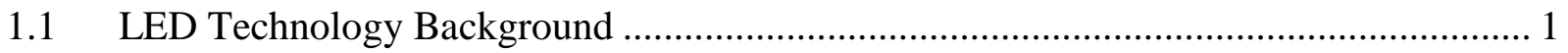

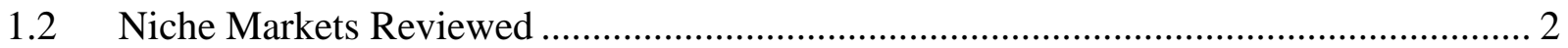

1.3 Methodology for Estimating National Energy Use.......................................................... 3

1.4 Technology Benefits in Addition to Energy Savings....................................................... 5

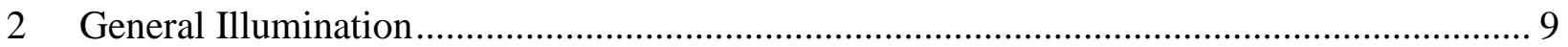

$2.1 \quad$ PAR, BR and R Shaped Lamps........................................................................... 10

2.1.1 PAR, BR and R Shaped Lamp Installed Base ......................................................... 11

2.1.2 PAR, BR and R Shaped Lamp Operating Hours .................................................... 13

2.1.3 PAR, BR and R Shaped Lamp Average Wattages ................................................. 13

2.1.4 PAR, BR and R Shaped Lamp Energy Savings Potential ..................................... 14

2.2 MR16 Replacement Lamps...................................................................................... 14

2.2.1 MR16 Replacement Lamp Installed Base............................................................. 16

2.2.2 MR16 Replacement Lamp Operating Hours .......................................................... 17

2.2.3 MR16 Replacement Lamp Average Wattages......................................................... 17

2.2.4 MR16 Replacement Lamp Energy Savings Potential.............................................. 18

2.3 2-ft by 2-ft Troffer Fixtures......................................................................................... 18

2.3.1 2-ft by 2-ft Troffer Fixture Installed Base ............................................................. 19

2.3.2 2-ft by 2-ft Troffer Fixture Operating Hours ......................................................... 20

2.3.3 2-ft by 2-ft Troffer Fixture Average Wattages ......................................................... 20

2.3.4 2-ft by 2-ft Troffer Fixture Energy Savings Potential ............................................ 21

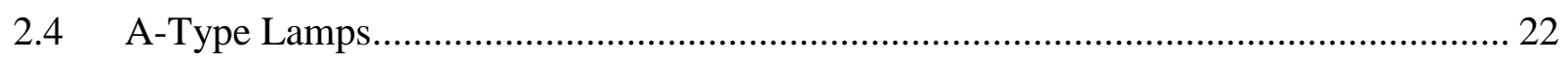

2.4.1 A-Type Lamp Installed Base .............................................................................. 23

2.4.2 A-Type Lamp Operating Hours ........................................................................ 25

2.4.3 A-Type Lamp Average Wattages ....................................................................... 25

2.4.4 A-Type Lamp Energy Savings Potential ................................................................. 25

3 Outdoor Lighting Introduction ..................................................................................... 27

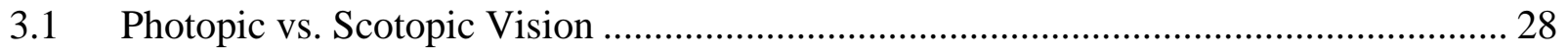

3.2 Roadway Lighting ................................................................................................. 29 


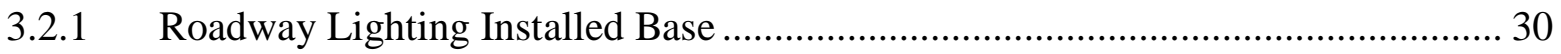

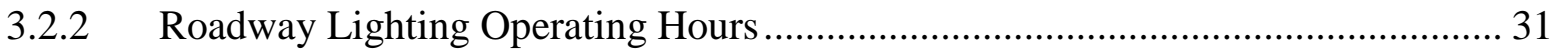

3.2.3 Roadway Lighting Average Wattages ........................................................... 31

3.2.4 Roadway Lighting Energy Savings Potential ................................................. 32

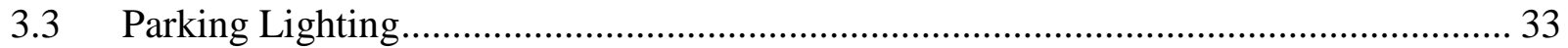

3.3.1 Parking Lighting Installed Base ................................................................... 34

3.3.2 Parking Lighting Operating Hours.............................................................. 35

P.3.3 Parking Lighting Average Wattages ................................................................. 35

3.3.4 Parking Lighting Energy Savings Potential .................................................... 36

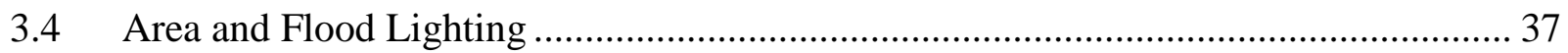

3.4.1 Area and Flood Lighting Installed Base ....................................................... 37

3.4.2 Area and Flood Lighting Operating Hours ..................................................... 38

3.4.3 Area and Flood Lighting Average Wattages .................................................. 38

3.4.4 Area and Flood Lighting Energy Savings Potential ......................................... 39

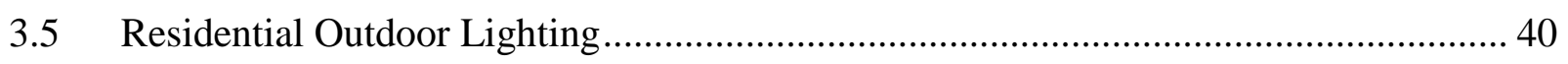

3.5.1 Residential Outdoor Lighting Installed Base ................................................... 40

3.5.2 Residential Outdoor Lighting Operating Hours................................................ 41

3.5.3 Residential Outdoor Lighting Average Wattages ............................................ 41

3.5.4 Residential Outdoor Lighting Energy Savings Potential ..................................... 42

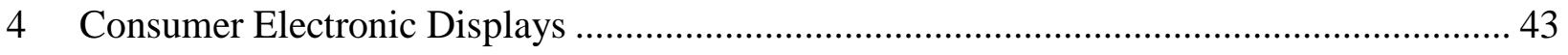

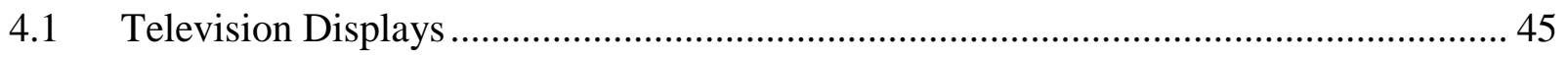

4.1.1 Television Display Installed Base................................................................... 46

4.1.2 Television Display Operating Hours ........................................................... 47

4.1.3 Television Display Average Wattages.......................................................... 47

4.1.4 Television Display Energy Savings Potential.................................................. 49

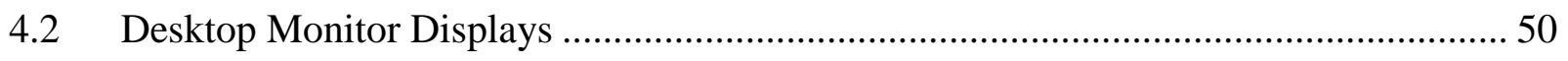

4.2.1 Desktop Monitor Display Installed Base ........................................................ 51

4.2.2 Desktop Monitor Display Operating Hours ....................................................... 52

4.2.3 Desktop Monitor Display Average Wattages ................................................... 53

4.2.4 Desktop Monitor Display Energy Savings Potential .......................................... 53 


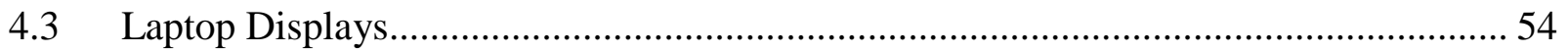

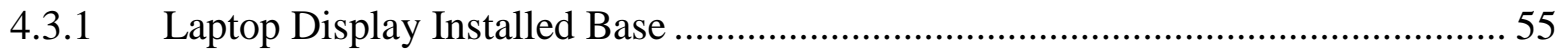

4.3.2 Laptop Display Operating Hours .......................................................................... 56

4.3.3 Laptop Display Average Wattages …………………………………………....... 56

4.3.4 Laptop Display Energy Savings Potential ............................................................ 58

4.4 Mobile Handset Displays ....................................................................................... 58

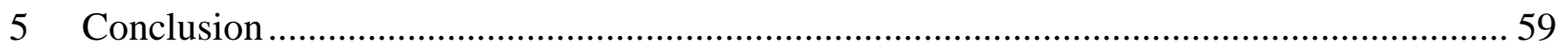

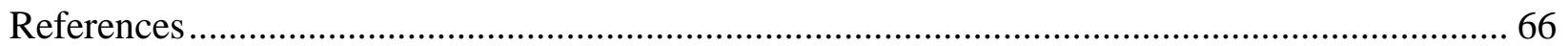




\section{Tables}

Table 1 - Summary of Niche Markets Evaluated in this Report ............................................... 2

Table 2.1 - Key Sources for the PAR, BR and R Shaped Lamp Analysis ................................ 11

Table 2.2 - PAR, BR and R Shaped Lamp Installed Base .................................................... 13

Table 2.3 - Lamp Wattage of PAR, BR and R Shaped Lamps .............................................. 14

Table 2.4 - Energy Consumption and Savings Potential of PAR, BR and R Shaped Lamps ...... 14

Table 2.5 - Key Sources for the MR16 Replacement Lamp Analysis ....................................... 16

Table 2.6 - MR16 Replacement Lamp Installed Base ............................................................. 17

Table 2.7 - Lamp Wattage of MR16 Replacement Lamps ................................................... 18

Table 2.8 - Energy Consumption and Savings Potential of MR16 Replacement Lamps ........... 18

Table 2.9 - Key Sources for the 2-ft by 2-ft Troffer Fixture Analysis ...................................... 19

Table 2.10 - 2-ft by 2-ft Troffer Fixture Installed Base ......................................................... 20

Table 2.11 - System Wattage of 2-ft by 2-ft Troffer Fixtures................................................ 21

Table 2.12 - Energy Consumption and Savings Potential of 2-ft by 2-ft Troffer Fixtures .......... 22

Table 2.13 - Key Sources for the A-Type Lamp Analysis...................................................... 23

Table 2.14 -A-Type Lamp Installed Base ............................................................................. 25

Table 2.15 - Lamp Wattage of A-Type Lamps ..................................................................... 25

Table 2.16 - Energy Consumption and Savings Potential of A-Type Lamps ........................... 26

Table 3.1- Key Sources for the Roadway Lighting Analysis.................................................. 30

Table 3.2 - Roadway Light Installed Base ...................................................................... 31

Table 3.3 - System Wattage of Roadway Lights................................................................ 32

Table 3.4 - Energy Consumption and Savings Potential of Roadway Lights ............................ 32

Table 3.5 - Key Sources for the Parking Lighting Analysis ................................................. 34

Table 3.6 - Parking Light Installed Base ........................................................................... 35

Table 3.7 - System Wattage of Parking Lights .................................................................... 36

Table 3.8 - Energy Consumption and Savings Potential of Parking Lights............................... 36

Table 3.9 - Key Sources for the Area and Flood Lighting Analysis .......................................... 37

Table 3.10 - Area and Flood Lighting Installed Base ........................................................... 38

Table 3.11 -Wattages of Area and Flood Lights ................................................................ 39

Table 3.12 - Energy Consumption and Savings Potential of Area and Flood Lights ................. 39

Table 3.13 - Key Sources for the Residential Outdoor Lighting Analysis ................................ 40

Table 3.14 - Residential Outdoor Lighting Installed Base.................................................... 41

Table 3.15 - Wattages of Residential Outdoor Lights........................................................ 42

Table 3.16 - Energy Consumption and Savings Potential of Residential Outdoor Lights........... 42

Table 4.1 - Key Sources for the Television Displays Analysis............................................... 46

Table 4.2 - Television Installed Base by Display Technology .............................................. 47

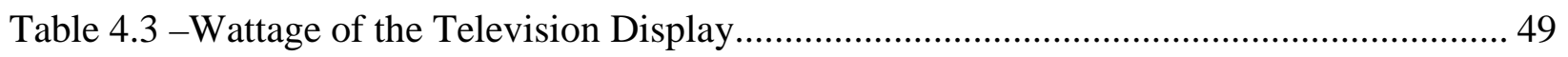

Table 4.4 - Energy Consumption and Savings Potential of Television Displays ....................... 50

Table 4.5 - Key Sources for the Desktop Monitor Display Analysis........................................ 51 
Table 4.6 - Desktop Monitor Display Installed Base ........................................................... 52

Table 4.7 - Total Installed Monitors by Usage Category and Operating Hours ......................... 52

Table 4.8 -Wattage of Desktop Monitor Displays ............................................................... 53

Table 4.9 - Energy Consumption and Savings Potential of Monitor Displays in 2010 .............. 54

Table 4.10 - Key Sources for the Laptop Display Analysis.................................................... 55

Table 4.11 - Laptop Display Installed Base ............................................................................... 55

Table 4.12 - Total Installed Laptops by Usage Category and the Operating Hours ................... 56

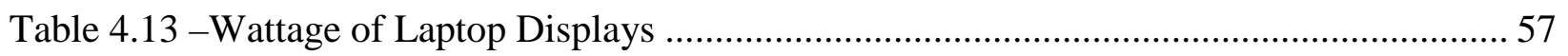

Table 4.14 - Energy Consumption and Savings Potential of Laptop Displays .......................... 58

Table 5.1 - Energy Consumption and Saving in 2010 of Application Evaluated ....................... 62

Table 5.2 - Potential and Cumulative Energy Savings of Applications Evaluated..................... 64

Table 5.3 - 2020 Forecasted Electricity and Primary Energy Savings Potential of Applications

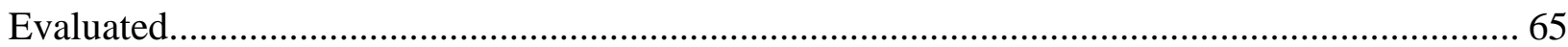




\section{Figures}

Figure ES.1 - 2010 Electricity Savings from the Selected Niche Applications .......................... x

Figure ES.2 -Estimated Potential for Electricity Savings of the Selected Niche Applications .... xi

Figure 1.1 - National Electricity Consumption and Savings Methodology ................................. 3

Figure 3.1 - Photopic and Scotopic V- $\lambda$ Curves................................................................ 29

Figure 4.1 - Display Power Consumption for the Different Screen Sizes and Technologies....... 48

Figure 5.1 - Site Electricity Savings in 2010 Attributable to LED Market Penetration .............. 61

Figure 5.2 - Maximum Site Electricity Savings With 100\% LED Market Penetration ............... 63 


\section{List of Acronyms and Abbreviations}

$\begin{array}{ll}\text { ACEEE } & \text { American Council for an Energy Efficient Economy } \\ \text { ASHRAE } & \text { American Society of Heating, Refrigerating and Air-Conditioning } \\ & \text { Engineers } \\ \text { BR } & \text { bulged reflector } \\ \text { Btu } & \text { British thermal units } \\ \text { CALiPER } & \text { Commercially Available LED Product Evaluation and Reporting } \\ \text { CCFL } & \text { cold cathode fluorescent lamp } \\ \text { CFL } & \text { compact fluorescent lamp } \\ \text { CRI } & \text { color rendering indices } \\ \text { CRT } & \text { cathode ray tube } \\ \text { DLP } & \text { Digital Light Processing }{ }^{2} \\ \text { DOE } & \text { U.S. Department of Energy } \\ \text { EISA 2007 } & \text { Energy Independence and Security Act of 2007 } \\ \text { EPA } & \text { Environmental Protection Agency } \\ \text { EPACT 1992 } & \text { Energy Policy Act of 1992 } \\ \text { EPACT 2005 } & \text { Energy Policy Act of 2005 } \\ \text { ER } & \text { elliptical reflector } \\ \text { FHWA } & \text { Federal Highway Administration } \\ \text { GLS } & \text { general lighting service } \\ \text { HB } & \text { high-brightness } \\ \text { HID } & \text { high intensity discharge } \\ \text { HPS } & \text { high pressure sodium } \\ \text { IPI } & \text { International Parking Institute } \\ \text { IR } & \text { infrared } \\ \text { IRL } & \text { incandescent reflector lamp } \\ \text { K } & \text { Kelvin } \\ \text { LCD } & \text { liquid crystal display } \\ \text { LED } & \text { light emitting diode } \\ \text { lm } & \text { lumens } \\ \text { mg } & \text { milligrams } \\ \text { MR } & \text { multifaceted reflector } \\ \text { NEMA } & \text { National Electrical Manufacturers Association } \\ \text { OLED } & \text { organic LED } \\ \text { PAR } & \text { parabolic aluminized reflector } \\ \text { R } & \text { reflector } \\ \text { SSL } & \text { solid state lighting } \\ \text { TWh } & \text { terawatt-hours } \\ \text { W } & \text { watts } \\ & \end{array}$




\section{Executive Summary}

Light Emitting Diodes (LEDs), a type of Solid State Lighting (SSL), offer the electric lighting market a new and revolutionary light source that saves energy and improves quality, performance, and service. Today, LEDs are competing successfully with conventional lighting sources across a variety of applications due to their ability to offer high quality and cost-effective performance.

This report presents research findings for twelve different niche markets where LEDs are competing or are poised to compete with traditional light sources, such as incandescent, halogen, high intensity discharge (HID), and certain types of fluorescent light sources. This report presents 2010 estimates of the energy saved due to current levels of LED market penetration, and also estimates the "overnight" technical potential energy savings if these markets switched completely to top performing LEDs. It is recognized that the identified twelve markets do not represent an exhaustive list of all applications where LEDs are making progress in the marketplace, but these market applications were selected to reflect current emerging trends and potential for LED growth. It is also recognized that some people use the term "niche" to describe market segments that are small or specialized; however, for the purpose of this report, "niche" merely refers to the various segments which, regardless of their size, comprise the lighting market as a whole.

The markets analyzed in this report are classified into three groups:

General Illumination

- PAR, BR and R Shaped

- MR16

- 2-ft by 2-ft Troffer Fixtures

- General Service A-Type

Outdoor Lighting

- Roadway

- Parking

- Area and Flood

- Residential

Consumer Electronic Displays

- Televisions

- Laptops

- Monitors

- Mobile Handsets 
In all twelve niche applications, LED products are in use and are replacing conventional lighting technologies. For the general illumination applications, LEDs are currently saving 0.38 terawatthours (TWh) of electricity per year in 2010 due to the replacement of incumbent technologies for LEDs. In addition to energy savings, LEDs in general illumination applications provide longer operating life ( $>50,000$ hours), directionality, compact size, and ease of control and dimmability compared to incumbent technologies they replace. If these four general illumination applications switched entirely to LEDs, a potential of 133 TWh per year of electricity could be saved. LEDs are well suited for outdoor white light applications, and have significant energy savings potential in addition to offering limited light pollution and light trespass, cold temperature resilience, highly durable, and are high quality light. In these outdoor applications, LEDs have saved a total of 2.2 TWh of electricity for 2010, and it was estimated that 131 TWh per year of electricity could be saved if all lighting within this sector were to be replaced by LEDs. Lastly, LEDs have become widely prevalent in consumer electronic displays because they offer better contrast and improved color gamut, compact and mechanically robust designs, longer battery life, fast response to controls, as well as increased energy savings. The analysis revealed that LEDs in consumer electronics applications have resulted in about 1.3 TWh of electricity savings for 2010 . However, due to the current high penetration of LED backlighting and the existence of highly efficient competitor technologies, the consumer electronics applications have the lowest energy savings potential. A total of 30.7 TWh per year of electricity savings would be realized if all consumer electronics switched to LED backlit displays.

Figure ES.1 summarizes the on-site electricity savings of the niche applications with the greatest potential for electricity savings from each of the three groups analyzed in this report, as well as the total on-site electricity savings for all twelve niche applications. Also displayed is the energy saving equivalent in terms of household electricity consumption. In 2010, the current penetration of LEDs in the twelve niche applications analyzed in this report resulted in a total realized electricity savings of 3.9 TWh per year, which is equivalent to the electricity needed to power over a quarter million average U.S. households. 


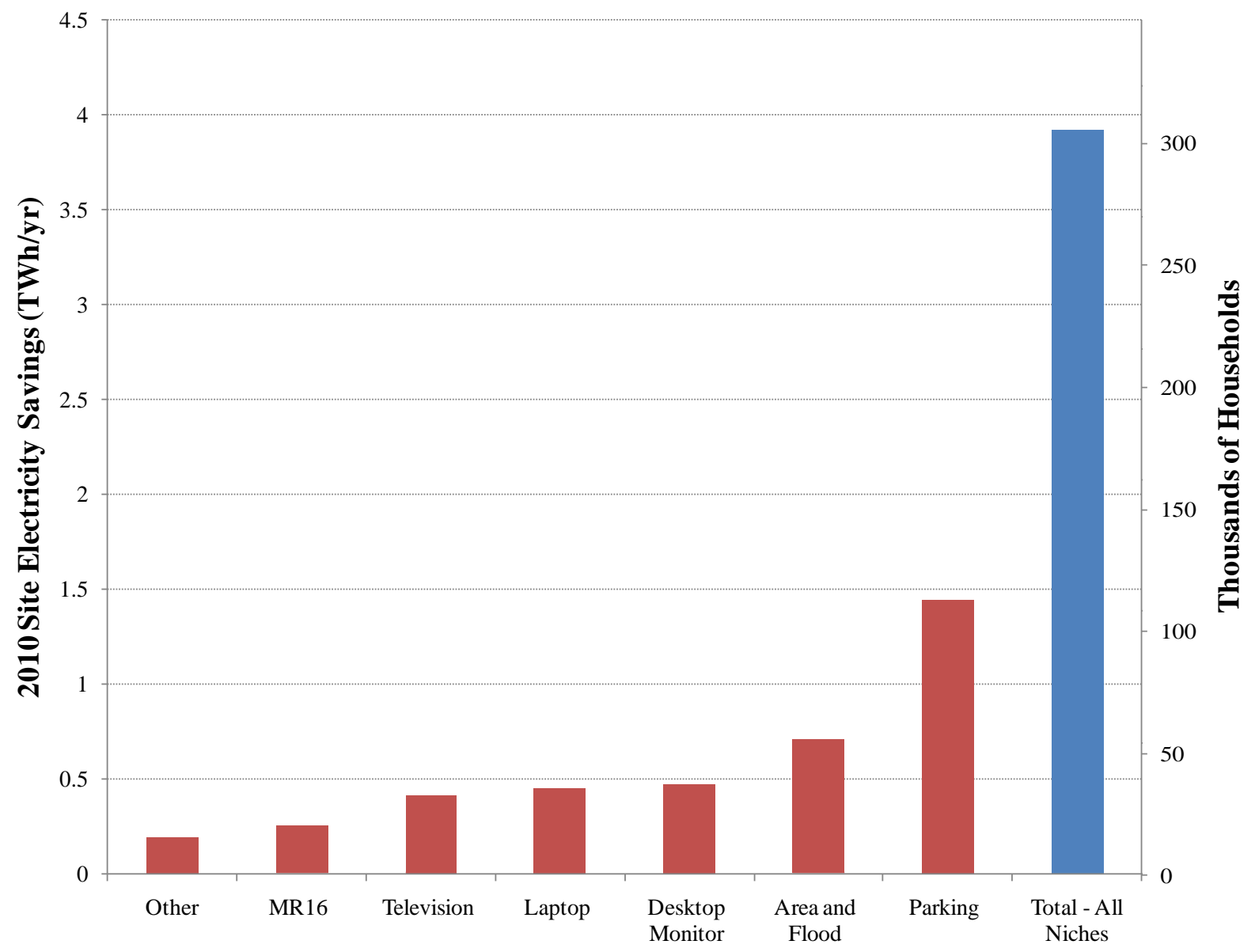

Figure ES.1 - 2010 Electricity Savings from the Selected Niche Applications

As shown in Figure ES.1, the electricity savings attributable to LEDs in 2010 are dominated by outdoor parking lighting, where LEDs have achieved an estimated 4.3\% market penetration. This niche represents about $41 \%$ of the total energy savings from the use of LEDs in 2010. After parking lighting, ${ }^{1}$ the niche market application with the second greatest energy savings in 2010 was area and flood lighting, ${ }^{2}$ which contributed to $20 \%$ of the total site electricity savings in 2010, and has an LED penetration of about $0.72 \%$. LED backlighting in desktop monitors, laptops and televisions, as well as LED MR16 lamps, also demonstrated significant energy savings, in total representing $45 \%$ of the total 2010 savings. Other sectors such as $2-\mathrm{ft}$ by 2 - $\mathrm{ft}$ troffer fixtures and A-type replacement lamps have low levels of LED penetration, and thus contribute less than one percent to the 2010 savings.

\footnotetext{
${ }^{1}$ Parking lighting only includes off-street parking and has been divided into covered parking garage lighting and parking lot lighting.

${ }^{2}$ Within the lighting industry, area and flood lighting often includes both parking and roadway lighting, however, this analysis quantifies these applications separately. In this analysis area and flood lighting are defined as lights that illuminate various outdoor areas such as landscapes, walkways, and common spaces.
} 
Figure ES.2 summarizes the potential on-site electricity savings of the two niche applications with the greatest potential for energy savings as of 2010 from each of the three groups analyzed in this report, as well as the total potential on-site electricity savings for all twelve niche applications. The analysis determined that a total energy savings potential of $263 \mathrm{TWh}$ per year or 2.5 quadrillion British thermal units ("quads") if each switched to LEDs. This savings is equivalent to the electricity needed to power over 21 million U.S. households.

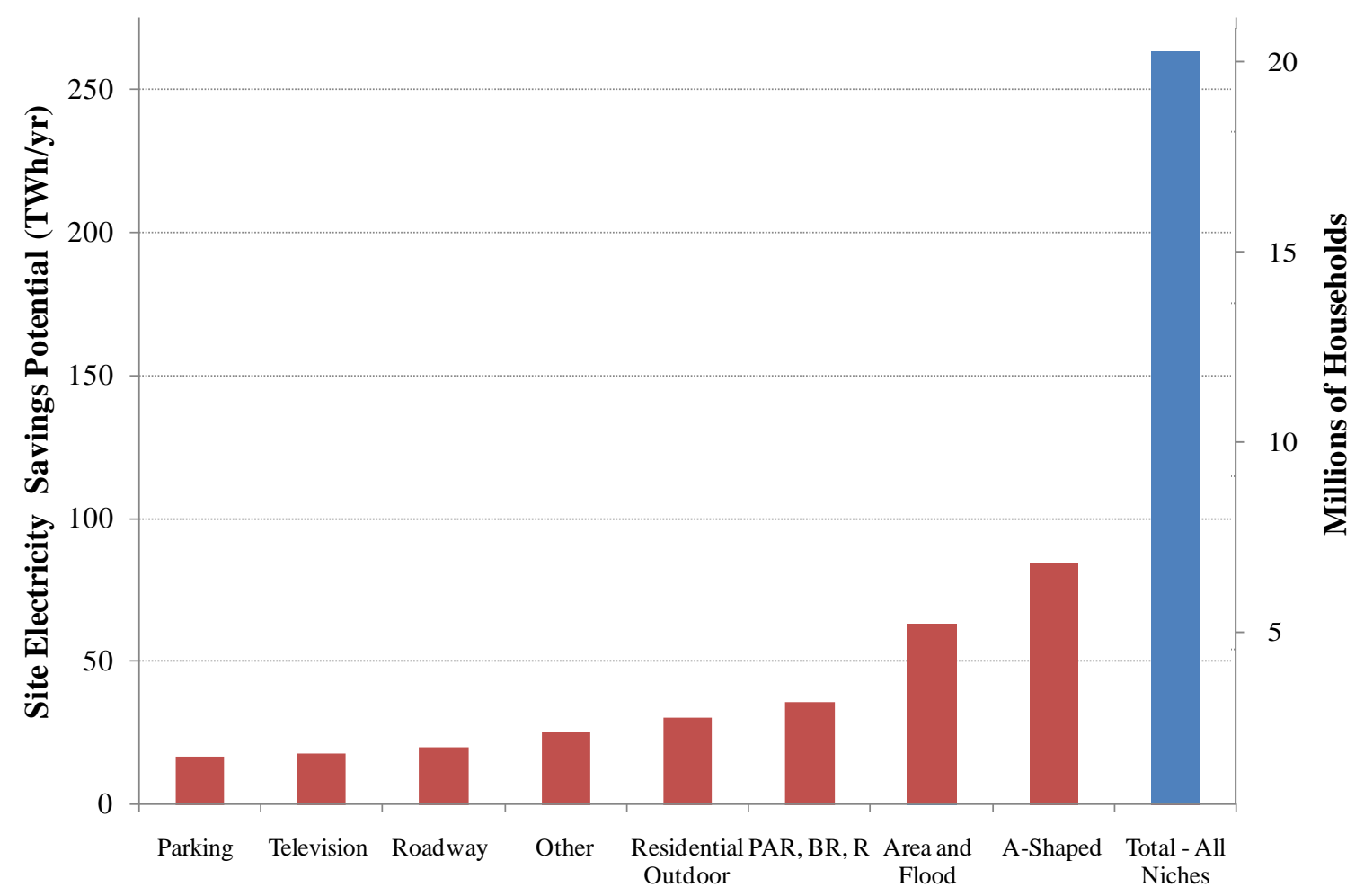

Figure ES.2 -Estimated Potential for Electricity Savings of the Selected Niche Applications

The potential savings estimates, assuming full LED penetration within each of the twelve niche applications are generally understated because it fixes the theoretical replacement LED technology at 2010 performance levels. Over the coming years, researchers and manufacturers will continue to develop and commercialize more energy efficient, higher quality LED devices. This trend means that as more market share is captured in the future, the LED technology adopted will have better performance characteristics, and contribute to even more significant energy savings. The U.S. Department of Energy’s (DOE) SSL 2010 Multi-Year Program Plan predicts that commercial LED luminaire efficacy will increase 155\% over the next decade to 219 lumens per watt $(\mathrm{lm} / \mathrm{W})$. Assuming that the LED replacements within each niche improve according to the DOE's SSL 2010 Multi-Year Program Plan predictions for 2020, LED efficacy increases the total potential energy savings dramatically to $399 \mathrm{TWh}$. This equates to a 
forecasted primary energy savings of approximately 4.3 quads, or the total energy required to power nearly 32 million average U.S. households. 


\section{Introduction}

Light Emitting Diodes (LEDs), a type of solid-state lighting (SSL), are a lighting technology that has great potential to save energy and revolutionize the lighting market. LEDs have penetrated a range of both colored and white light market applications and are successfully competing with a variety of conventional lighting technologies. This report aims to develop a comprehensive understanding of the factors that motivate consumers to adopt LEDs and the energy savings that result from the use of this lighting technology.

\subsection{LED Technology Background}

The first LEDs were produced in the 1950s by British scientists who discovered that the semiconductor gallium arsenide emits low-level infrared light when subjected to a current. This first LED had properties similar to those of a transistor: high tolerance for shock and vibration, and a long operating life. While the efficacy ${ }^{3}$ of the first LEDs was extremely low (approximately 1 lumen per watt $(\mathrm{lm} / \mathrm{W})$ ), researchers have significantly improved the technology over the past four decades. Present-day white LED commercial packages are rapidly becoming more efficacious reaching as high as $124 \mathrm{~lm} / \mathrm{W}$ in $2010,{ }^{4}$ which exceeds the efficacies of most incumbent technologies (DOE (c), 2010).

LEDs produce light using a fundamentally different principle than those used by incandescent, neon, fluorescent, or high-intensity discharge (HID) lamps. Whereas traditional light sources produce light by heating a filament to incandescence or establishing an electrical arc through a gas mixture, LEDs emit light from a small semiconducting chip when a current is applied. LEDs are semiconductors created by bringing together similar materials with slightly different electronic properties to create a "PN junction." In a PN junction, the "P" material contains an excess of positive charges (also called holes) due to the absence of electrons. The "N" material contains an excess of negative charges due to the presence of electrons. When a voltage is applied to this PN junction, the electrons and the holes combine releasing energy that can take the form of visible light.

Unlike incandescent lamps, LEDs emit light in a narrow wavelength band, making the emission appear colored. Since the initial breakthrough in the 1950s, research has focused on developing new LED semiconductor materials that enable LEDs to emit each color in the visible spectrum. Research has also improved the efficacy and power handling capability of LED devices themselves, enabling them to compete with conventional technologies in colored-lighting applications. Past versions of this report have included analyses of white light and colored-light applications. However, colored-light LEDs have matured, reaching market saturation in most applications, and are no longer considered in this analysis.

\footnotetext{
${ }^{3}$ Efficacy is the efficiency metric for light sources, measured in lumens of light output per watt of input power.

${ }^{4}$ A Lumileds cool white LED (LXML-PWC1-0120) reached 124 lm/W in 2010.
} 
For more information on the energy savings of LEDs in colored-light applications, see the September 2008 edition of this report. ${ }^{5}$

This report focuses on energy savings due to white light LEDs. Today, the majority of white light LEDs used for lighting applications emit blue or ultraviolet light onto a phosphor. The phosphor then converts the blue or ultraviolet light into white light. Assembling three or more LED chips that emit in the blue, green, and red spectral zones can also create white light LED packages. In this type of multi-chip design, the individual light emission from each of the chips blends to create a white-light emission from the package. This approach, though more complex than the phosphor method, has the potential to reach high efficacies (DOE, 2010). White light can also be created with just two LEDs (e.g., yellow and blue) when good color rendering is not critical. Alternatively, light from cool white LEDs and a monochromatic orange-red LED can be blended to produce a warm-white light.

\subsection{Niche Markets Reviewed}

The Department of Energy distinguished twelve different niche markets for this study. These markets can be grouped into three categories including indoor lighting, outdoor lighting and consumer electronics displays. This study estimates potential energy savings if these markets were to switch completely to LEDs. The niche markets addressed in this report were selected based on emerging market trends and potential growth for LED usage, as well as to illustrate the benefits of converting to LED technologies. The different market applications evaluated in this report are shown below in Table 1.

Table 1 - Summary of Niche Markets Evaluated in this Report

\begin{tabular}{|l|l|l|}
\hline Niche Market Applications & & \\
\hline Indoor Lighting & Outdoor Lighting & Consumer Electronics Displays \\
\hline PAR, BR and R Shaped & Roadway & Televisions \\
\hline MR16 & Parking & Laptops \\
\hline 2-ft by 2-ft Troffer Fixtures & Area and Flood & Monitors \\
\hline General Service A-type & Residential Outdoor & Mobile Handsets \\
\hline
\end{tabular}

It is recognized that the identified markets do not represent an exhaustive list of all applications where LEDs are making inroads. However, this report has attempted to select LED market applications that best reflect emerging trends, potential for LED growth, and stakeholder interests.

Consumer electronics applications, including televisions, laptops, monitors, and mobile handsets, were added to this report due to their rapid growth and adoption of LED display backlighting.

\footnotetext{
${ }^{5}$ Report available at: http://apps1.eere.energy.gov/buildings/publications/pdfs/ssl/nichefinalreport_october2008.pdf
} 
For each of the twelve LED niche applications, this report addresses the following four fundamental questions:

- How much energy in the year 2010 was consumed by lighting technologies in these applications?

- What is the 2010 estimated market penetration of LED technology?

- What are the electricity savings resulting from the 2010 level of LED market penetration?

- What would the electricity savings be from 100\% LED market penetration?

\subsection{Methodology for Estimating National Energy Use}

This analysis investigates the current and potential reduction in energy consumption due to the penetration of LEDs in niche and emerging applications. In other words, the study examines how much energy the United States is saving now and how much the United States could save with $100 \%$ penetration of LEDs in each market. Energy savings are presented both in terms of onsite electricity savings in terawatt-hours (TWh) and primary energy savings in quadrillion British thermal units (“quads”). ${ }^{6}$ The general methodology used for each of the twelve niche applications is shown below in Figure 1.1.

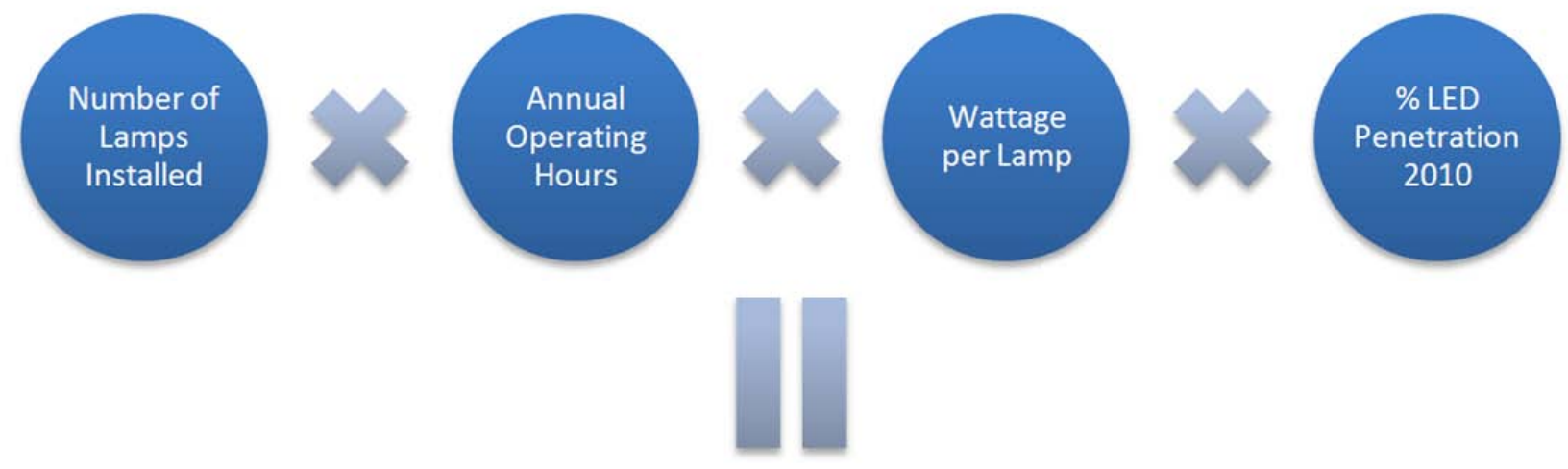

\section{Electricity}

Consumption and

Savings Estimate

Figure 1.1 - National Electricity Consumption and Savings Methodology

Figure 1.1 illustrates the four critical variables used to estimate the 2010 electricity consumption and savings potential for each LED niche application. These include: the number of lamps

\footnotetext{
${ }^{6}$ Primary energy savings are calculated by multiplying electricity savings by the 2009 source-to-site conversion factor (EIA, 2010). The energy savings in terms of equivalent household consumption is estimated by dividing site energy savings by the average residential household electricity consumption (DOE (a), 2009).
} 
installed, annual operating hours, wattage per lamp, and the percentage of LED market penetration. The input values were estimated by reviewing literature and market studies, examining available databases, and conducting interviews with researchers and industry experts. The niche application sections describe the specific sources and any variances on this methodology for each application.

The energy consumption and savings estimate results are highly sensitive to the state of LED technology. The methodology only considers currently available LED technology, and the technical potential analysis only considers the most efficacious, currently available and tested LED technology. However, future advances in LED technology will significantly increase potential energy savings compared to the calculations conducted in this report. LED package and luminaire efficacies are improving rapidly and an ever increasing diversity of applications are becoming available. Commercial available white LED package efficacies have increased from $100 \mathrm{~lm} / \mathrm{W}$ in 2008 to as high as $124 \mathrm{~lm} / \mathrm{W}$ in 2010. ${ }^{7}$ White LED luminaire efficacies are projected to advance from $86 \mathrm{~lm} / \mathrm{W}$ in 2010 to $121 \mathrm{~lm} / \mathrm{W}$ in 2012, and reach $219 \mathrm{~lm} / \mathrm{W}$ in 2020 (DOE (c), 2010).

The 2010 energy consumption and savings of the twelve niche applications analyzed in this report are also highly dependent on the baseline wattages of conventional lamps used compared to that of their LED replacements. The equivalent LED replacement lamp wattages for each of application were determined by matching the lumen output of the conventional system with that of a hypothetical replacement LED system. Best-in-class reported efficacies of products tested by the DOE's Commercially Available LED Product Evaluation and Reporting (CALiPER) program and the Gateway demonstration program were used to create the replacement LED systems. However, these systems are considered hypothetical as in some instances no actual LED luminaire exists that provides an equal lumen output to the conventional technology it is replacing. For example, no tested LED luminaires currently provide the equivalent lumen output of a high wattage metal halide lamp system. However, there are multiple methods to achieving higher lumen outputs in LED systems, including using more LEDs per lamp, driving the LEDs at a higher current, or even replacing the conventional luminaire with more than one LED luminaire. As the pathway chosen is primarily a cost consideration, the potential lumen output of the hypothetical LED system was not limited.

In addition, the total energy consumed by conventional lamps may fall, as might LED energy savings, due to future energy conservation standards ${ }^{8}$ or technical advancement in conventional light sources. For example, on December 19, 2007, the Energy Independence and Security Act of 2007 (EISA 2007) went into effect. EISA 2007 included provisions to set higher efficacy

\footnotetext{
${ }^{7}$ A Lumileds cool white LED (LXML-PWC1-0120) reached 124 lm/W in 2010.

${ }^{8}$ Energy conservation standards will be applicable for fluorescent and incandescent reflector lamps by 2012 and for fluorescent ballasts by 2014 .
} 
requirements for all general service incandescent lamps manufactured after 2014, and an efficacy requirement up to $45 \mathrm{~lm} / \mathrm{W}$ in 2020, effectively phasing out the traditional incandescent lamp. ${ }^{9}$ EISA 2007 will lower the annual energy consumption of the baseline conventional lighting technologies for the twelve applications analyzed in this report, thereby lowering the future energy savings potential of LEDs compared to the calculations conducted in this report.

Energy consumption and potential savings from LEDs also depend on the underlying market dynamics of the twelve niche applications analyzed in this report. Some applications may grow in popularity in the future, such as multifaceted reflector (MR16) lamps, which are more prevalent in new construction than in older buildings. Other applications may decline due to decreasing market demand for the product. These market-specific changes may increase or decrease the potential energy consumption and savings of LEDs according to the overall size of the niche application.

The magnitude of each of these effects - LED advancements, baseline efficacies, and market dynamics - is uncertain, as is the overall impact on energy consumption and savings. Thus, the estimates for energy consumption and savings potential from LEDs presented in this report represent a brief snapshot of the twelve analyzed lighting applications in 2010.

\subsection{Technology Benefits in Addition to Energy Savings}

In addition to yielding more than 42.7 trillion British thermal units (TBtu) per year of primary energy savings in the analyzed markets, and potentially a further 2,865 TBtu per year when LEDs reach saturation in these markets, LED products offer other advantages over conventional lighting products. These advantages include: long operating life, reduced radiated heat, minimal light loss, dimmability and controllability, durability, enhanced performance at low temperatures, safety improvements, smaller package size, uniform illumination, mercury reduction, enhanced product appearance, improved color rendition, and lower lumen depreciation. These benefits are further discussed below.

\section{Long Operating Life}

Commercial and industrial consumers are generally interested in using a light source that is reliable and lasts a long time. Frequent lamp replacements can be costly from a maintenance perspective, and failed lamps could expose lamp operators to liabilities (e.g., busy highways and roadways). In fact, maintenance savings is one of the primary drivers of market adoption of LEDs in several markets, such as roadway and area and flood lights. Presently, LED technology

\footnotetext{
${ }^{9}$ Section 321(a)(3) of EISA 2007 (P.L. 110-140) establishes energy conservation standards for general service and modified spectrum incandescent lamps for rated lumen ranges, maximum rated wattage, and minimum rate lifetime, effective January 1, 2014. In effect, these standards establish minimum wattage requirements for general service lamps. For example, a lamp with the equivalent lumen output of a traditional $100 \mathrm{~W}$ lamp must only consume $72 \mathrm{~W}$, a lamp with the equivalent lumen output of a traditional $75 \mathrm{~W}$ lamp must only consume $53 \mathrm{~W}$, a lamp with the equivalent lumen output of a traditional $60 \mathrm{~W}$ lamp must only consume $43 \mathrm{~W}$, a lamp with the equivalent lumen output of a traditional $40 \mathrm{~W}$ lamp must only consume $29 \mathrm{~W}$.
} 
offers operating lives that are up to fifty times longer than those of incandescent sources. ${ }^{10}$ Researchers indicate that operating life will continue to improve as the technology develops.

\section{Reduced Radiated Heat}

LED conversion efficiency (i.e., efficacy) has improved rapidly and is expected to continue; current LED devices meet or exceed efficacies of fluorescent and HID sources. As a higher proportion of electricity is converted into visible light, a smaller proportion generates waste heat. For example, incandescent sources convert most of the power they use into infrared (IR) radiation (radiated heat), which then dissipates to the surroundings. LEDs do not emit IR (unless

specifically designed to do so); instead, the waste heat generated by the LED must be removed by a heat-conducting material (a "heat sink"). The reduction in heat radiated into conditioned space may reduce the air-conditioning or refrigeration load for some applications.

\section{Minimal Light Loss}

Conventional lamps generally have uniform emission in all directions, which can result in lower fixture efficiencies due to the light is lost as the light is absorbed in the back of the fixture. Light emitted from an LED device is more directional and controlled, meaning that fewer photons are trapped within the lighting fixture. LED sources can be targeted to illuminate particular parts of an object or area. For example, LED MR16 lamps can be targeted to illuminate particular parts of a retail display with higher fixture efficiencies and less light scattering. In outdoor applications, the directional quality of LEDs can also reduce light pollution. In comparison with conventional light sources, through the use of lenses and lighting controls LED roadway and parking lighting or residential outdoor luminaires direct more lumens to the road plane or ground and scatter fewer lumens skyward.

\section{Dimmability and Controllability}

For most applications, LED luminaires can be designed with dimming controls and motion sensors to adjust brightness levels. In consumer electronics, the capability of LEDs to dim each pixel individually creates several advantages over conventional cold cathode fluorescent lamps (CCFL) backlights, including sharp display contrast and improved color gamut. Unlike the conventional CCFL backlight, LEDs can rapidly cycle on and off without degrading the life of the LED, resulting in improved dimming control at the pixel level and reduced annual operating hours. Furthermore, LED A-type replacements have recently become commercially available, and unlike CFL alternatives offer dimming capabilities similar to that of conventional incandescent lamps.

\section{Durability}

The light production mechanism for LED devices is fundamentally different than those of traditional light sources, such as incandescent and fluorescent lamps. LED sources produce light

\footnotetext{
${ }^{10}$ Based on manufacturers’ claims of 50,000-hour LED lifetimes.
} 
by passing a current through thin layers of a semi-conductive material, which causes the recombination of electron-hole pairs in the material to emit light. Inherent in this solid-state light production mechanism is the ability of the source to resist vibration and impact, making it an ideal light source for consumer electronics or roadway lighting. The LED is encased in a tough epoxy plastic resin instead of a fragile glass bulb. Therefore, the device is more resistant to shattering or impact damage in these applications.

\section{Enhanced Performance at Low Temperatures}

LED performance inherently improves as operating temperatures drop. This gives LED outdoor lighting an advantage over other light sources as its efficacy increases when exposed to winter weather conditions. It should also be noted that due to their reduced radiated heat, LEDs do not automatically melt away snow and ice, and this needs to be considered when installing LEDs in winter weather conditions.

\section{Safety Improvements}

For several applications, characteristics specific to LEDs lead to safety enhancements. LED luminaires are made of multiple diodes, and are less likely to fail simultaneously, leading to less downtime for roadway lighting, and thereby enhancing roadway safety.

\section{Smaller Package Size}

Due to their compact size, LED devices are an excellent option where size or weight is a concern. For example, LED lighting allows manufacturers to minimize size and weight of portable consumer electronics such as laptops or mobile handsets. In particular, mobile handsets have taken advantage of this benefit with the vast majority of models incorporating either LED or organic LED (OLED) backlighting technology, while LED backlit televisions are recognized for their remarkably slim design, with Samsung introducing a model that is only 6.5 millimeters thick during the 2010 Consumer Electronics Show (Nystedt, 2010). The small size of LEDs and their mounting surface (generally the conductor cable supplying power) also give LEDs increased design flexibility for use in new applications.

\section{Mercury Reduction}

Fluorescent and compact fluorescent lamps (CFL) contain mercury, a toxic substance that requires special handling for disposal. CFLs contain an average of 4 milligrams (mg) of mercury (EPA ENERGY STAR $\left.{ }^{\circledR}(a), 2010\right)$; in contrast, LEDs contain no mercury and require no special handling for disposal.

\section{Enhanced Product Appearance}

LED lamps are ideal for retail lighting due to their directional control and minimal heat radiation. Additionally, jewelry lit by LED lamps appears to sparkle more brightly because an LED lamp contains multiple diodes which create many reflections off the jewel's facets compared to a single incandescent or fluorescent bulb with equal lumen output. 


\section{Improved Color Rendition}

Most LED outdoor area and streetlights in the market have color temperatures of 3,000 to 15,000 kelvin (K) and can have color rendering indices (CRI) of approximately 90. With these color characteristics, LED outdoor area and streetlights compare favorably with high pressure sodium (HPS) lamps that have color temperatures of approximately 2,000 K, providing a yellow/orange light, and color rendering indices as low as 21 (DOE CALiPER Program (a), 2010). 


\section{General Illumination}

LED sources have begun to penetrate a variety of general illumination applications during the past few years, and recent technical advances have made LEDs cost-effective, on a cost of light basis, for certain sizable applications in general lighting. LED technology is capturing these new applications because it offers a high quality, and increasingly cost-effective lighting service compared to less efficient conventional light sources, such as incandescent. In addition, in energy savings, LEDs offer longer operating life (>50,000 hours), limited light loss and directionality, lower operating costs, improved durability, compact size, and ease of control (DOE (c), 2010).

This analysis evaluates the 2010 impact of LED penetration into four general illumination market applications: PAR, BR and R shaped, MR16, 2-foot by 2-foot (2-ft by 2-ft) troffer fixtures, and A-type replacements. These lamps serve multiple purposes, including illumination for office spaces and households, as well as accent, task, and display lighting in architectural lighting applications such as in museums, art galleries, retail stores, residential settings, landscaping and entertainment venues. In addition, PAR, BR, R and A-type lamps are commonly used in residential outdoor applications. Therefore, the general illumination section has significant overlap with the residential outdoor applications analyzed in Section 3.5 of this report.

LED products for these general illumination applications are currently being manufactured, although the market has yet to adopt them in significant numbers. If LEDs were to become standard technology in these four general illumination market applications, 133 TWh per year of electricity savings could be possible.

In order to accelerate the penetration of energy efficient lighting products, such as LEDs, the U.S. Federal government has developed a variety of legislation aimed at promoting energy efficient lighting products. For example, the Energy Policy Act of 2005 (EPACT 2005) provided a set of tax deductions that peak at $\$ 0.60$ per square foot for installing lighting systems that achieve $40 \%$ lighting power density reduction beyond what is required in American Society of Heating, Refrigerating and Air-Conditioning Engineers (ASHRAE) Standard 90.1-2001. EISA 2007 also mandated increases in the energy efficiency of general service incandescent lamps starting in 2012. In July 2009, DOE published a final rule amending standards for specific general service fluorescent lamps and incandescent reflector lamps. Compliance with these established standards are required starting on July 14, 2012 (DOE (b), 2009). These standards will greatly affect the general illumination market, and help to further the replacement of incandescent, halogen, and in some cases CFL and fluorescents, with LED lamps.

EISA 2007 additionally directed DOE to establish the Bright Tomorrow Lighting Prizes (L Prize) competition. The L Prize rewards manufacturers who develop a superior LED replacement lamp for the standard A-type incandescent $60 \mathrm{~W}$ lamp and the PAR 38 halogen 
lamp. The L Prize has helped incentivize manufacturers to develop high-quality, high efficiency LED lamps by providing a sizeable first mover advantage to successful entrants.

\subsection{PAR, BR and R Shaped Lamps}

In this analysis, PAR, BR and R shaped lamps are considered to include incandescent reflector $(\mathrm{R})$, bulged reflector (BR), halogen parabolic aluminized reflector (PAR), reflector compact fluorescent lamps (CFL) and their qualified LED replacements. These descriptors, "R," "BR" and "PAR," refer to the different shapes of reflector lamps. Generally R and BR lamps are used for accent lighting in areas such as retail displays and museums, as well as for general area downlighting where a smooth distribution of light with a soft-edged beam is desired. While halogen PAR lamps are also used in accent light and general lighting purposes, they produce a harder edge with a more sharply defined lighting beam (Lighting Research Center (c), 1994). Both reflector CFLs and LED lamps have been designed to replace each of these conventional incandescent lamps.

Both reflector CFL and LED replacements have begun to penetrate the PAR, BR and R shaped lamp market. Reflector CFL efficacies, estimated at around 35 to $45 \mathrm{~lm} / \mathrm{W}$ respectively, are much greater than the incandescent or halogen reflector lamps they replace which typically have an efficacy of about 10 to $15 \mathrm{~lm} / \mathrm{W}$. DOE's CALiPER results indicate that the efficacy of LED PAR30 and PAR 38 replacements can range from 40 to $60 \mathrm{~lm} / \mathrm{W}$. However, adopting this fluorescent technology for reflector lamp applications presents several problems. Reflector CFL products are typically bulky and emit light from a larger area compared to an incandescent reflector making it difficult to create an effective directional lighting source. However, LED replacements for reflector lamps have distinct advantages and eliminate several of the issues associated with reflector CFLs due to their inherently small form factor and design flexibility for directional or ambient lighting applications.

This section analyzes the potential for LED replacements in the PAR, BR and R shaped lamps lighting market. The key sources used for the four critical inputs to the analysis are summarized in Table 2.1. 
Table 2.1 - Key Sources for the PAR, BR and R Shaped Lamp Analysis

\begin{tabular}{|l|l|}
\hline Critical Input & Key Sources \\
\hline Installed Base of & IRL Shipments: Historical NEMA IRL Shipments (NEMA (a), 2006) \\
& Penetration of Reflector CFLs: California Residential Lighting and \\
& Appliance Efficiency Saturation Survey (RLW Analytics Inc. (a), \\
& 2000), (RLW Analytics, Inc. (d), 2005) and Single-Family Residential \\
& Existing Construction Stock Assessment (RLW Analytics Inc. (b), \\
& 2007) \\
& Growth rate of IRL Installed Stock: 2010 Annual Energy Outlook: \\
& Commercial and Residential Sector Indicators and Consumption (EIA, \\
& 2010) \\
\hline Annual Operating & DOE's 2009 Energy Conservation Final Rule for General Service \\
& Fluorescent Lamps and Incandescent Reflector Lamps (DOE (b), \\
& 2009) \\
\hline Lamp Wattages & $\begin{array}{l}\text { IRL Wattages: Sylvania, GE and Philips lamp catalog data and 2000- } \\
\text { 2002 NEMA PAR/R Lamp Survey (NEMA (b), 2003) } \\
\text { Reflector CFL Wattages: Single-Family Residential Existing } \\
\text { Construction Stock Assessment (RLW Analytics Inc. (b), 2007) } \\
\text { LED Lamp Wattages: DOE's CALiPER Program Reports (DOE } \\
\text { CALiPER Program (a), 2010) }\end{array}$ \\
\hline $\begin{array}{l}\text { Lighting Technology } \\
\text { Mix }\end{array}$ & Lamp Mix: NEMA PAR/R Lamp Survey (NEMA (b), 2003) \\
\hline
\end{tabular}

\subsubsection{PAR, BR and R Shaped Lamp Installed Base}

The installed base of PAR, BR and R shaped lamps has undergone significant changes in the past two decades due to the enactment of a variety of energy conservation standards. In 1992 the U.S. enacted the Energy Policy Act (EPACT) which set efficacy requirements for widely used incandescent PAR and R lamps. In response to the 1992 EPACT, PAR lamps now primarily utilize halogen technology. These halogen PAR lamps are incandescent lamps that have halogen added to the argon gas fill which results in less lumens depreciation (i.e., the light output does not decrease over time as quickly as that of a standard incandescent PAR lamp). In addition, the 2007 EISA expanded the types of incandescent reflector lamps covered by efficiency standards prescribed in the Energy Policy Act of 1992. The lamps covered now include BR, ER and small diameter R lamps. The minimum efficacy standards established in 1992 now apply to this larger group of reflector lamps. However, several exemptions still remain and include the BR30, BR40 and R20 lamps which are considered in the following analysis.

The inventory for PAR, BR and R shaped lamps was calculated using historical National Electrical Manufacturers Association (NEMA) shipments of IRL products from 2000 to 2005, and then linearly projecting these values forward. The shipments were classified as PAR20, PAR30, PAR38, BR30, BR40 or R20 (NEMA (b), 2003). Using data from DOE's 2009 Energy Conservation Final Rule for General Service Fluorescent Lamps and Incandescent Reflector 
Lamps, the shipment values were further separated into residential and commercial service lamps and were then increased to account for the volume of IRLs that are imported or manufactured by non-NEMA lamp companies (DOE (b), 2009). A 2010 installed stock was then modeled based on a linear regression of these shipment values and typical lifetime values collected from manufacturers' catalogs.

The installed base of reflector CFLs for the residential sector was determined by assuming that the percentage of reflector CFLs from Washington and California State housing survey data is representative of the national value. In addition, it is assumed that reflector CFLs are not present in the commercial sector due to the several problems associated with adapting fluorescent technology to reflector lamp applications. The main problem arises from the fact that a reflector CFL emits light from a larger area than an incandescent lamp's filament does. As a result, it is more difficult to precisely direct reflector CFLs' emitted light with small reflectors and lenses, so the beam spreads of reflector CFL products are wider than those of most incandescent PAR and R lamps (Lighting Research Center (c), 1994). These problems make reflector CFL lighting a poor alternative for commercial spaces, which rely on precise directional light to illuminate museums exhibits, art galleries, retail stores, entertainment venues, and landscapes.

LED reflector lamp products are currently available through several major retailers; however, consumer adoption levels are quite low. The penetration of LED replacement lamps was determined using LED shipment data provided in the 2009 Strategies Unlimited LED Replacement Lamps Market Analysis and Forecast report. The shipments indicate that the installed base of LED replacement lamps has reached approximately 0.90 million units, or $0.20 \%$ of the total U.S. PAR, BR and R shaped lamp installed base. All of these LEDs were assumed to be installed in the commercial sector, which has been more aggressive in upgrading the lamps than the residential sector.

The technology mix and total number of lamps by application and technology type are depicted in Table 2.2. 
Table 2.2 - PAR, BR and R Shaped Lamp Installed Base ${ }^{11}$

\begin{tabular}{|l|c|r|r|r|}
\hline \multirow{2}{*}{\multicolumn{1}{c|}{ Lamp Type }} & \multirow{2}{*}{ Percentage } & \multicolumn{3}{c|}{ Number of Lamps (000's) } \\
\cline { 3 - 5 } & & Residential & \multicolumn{1}{c|}{ Commercial } & \multicolumn{1}{|c|}{ Total Lamps } \\
\hline PAR20 (halogen) & $9.8 \%$ & 33,900 & 19,300 & 53,200 \\
\hline PAR30 (halogen) & $11.1 \%$ & 38,700 & 20,200 & 58,900 \\
\hline PAR38 (halogen) & $16.8 \%$ & 60,800 & 28,900 & 89,700 \\
\hline BR30 (incandescent) & $37.9 \%$ & 180,000 & 21,800 & 202,000 \\
\hline BR40 (incandescent) & $8.2 \%$ & 38,800 & 4,700 & 43,500 \\
\hline R20 (incandescent) & $10.0 \%$ & 48,300 & 5,010 & 53,300 \\
\hline Reflector CFL & $6.0 \%$ & 32,000 & - & 32,000 \\
\hline LED Reflector & $0.2 \%$ & - & 900 & 900 \\
\hline Total & $\mathbf{1 0 0 \%}$ & $\mathbf{4 3 3 , 0 0 0}$ & $\mathbf{1 0 1 , 0 0 0}$ & $\mathbf{5 3 4 , 0 0 0}$ \\
\hline
\end{tabular}

\subsubsection{PAR, BR and R Shaped Lamp Operating Hours}

Operating hours of PAR, BR and R shaped lamps vary significantly for commercial and residential applications, and therefore, these two applications are accounted for separately. DOE’s 2009 Energy Conservation Final Rule for General Service Fluorescent Lamps and Incandescent Reflector Lamps indicates that commercial IRLs operate approximately 3,450 hours per year while residential IRLs operate only 889 hours per year (DOE (b), 2009). These two values were used in this analysis.

\subsubsection{PAR, BR and R Shaped Lamp Average Wattages}

The average wattages for PAR30 and PAR38 lamps were developed from a 2003 NEMA survey, while the PAR20 average wattage was determined using manufacturer reported data in Philips, Osram, and GE lighting catalogs.

EISA 2007 greatly increased regulations of incandescent lamps and many of these lamps are no longer sold in the United States because they cannot obtain the minimum required efficacy. Given the limited number of products that are exempted from this legislation, it is assumed that $65 \mathrm{~W}$ and $45 \mathrm{~W}$ represent the vast majority of BR30, BR40 and R20 lamps. Lastly, a weighted average wattage for reflector CFLs was developed using residential survey data collected by RLW Analytics. The equivalent LED replacement lamp wattages were taken from the tested product with the greatest efficacy as reported by DOE's CALiPER program. LED products from

\footnotetext{
${ }^{11}$ Values in the table may not add up due to rounding.

12 The installed base of PAR, BR and R shaped lamps indicates that roughly $87 \%$ are installed in residences while the remaining $13 \%$ are in commercial buildings. However, only approximately 65\% NEMA shipments are residential. The dramatic split in installed stock arises from the vastly different operating hours assumptions for residential and commercial PAR, BR and R shaped lamps which are described in Section 2.1.2.
} 
this program were matched to the conventional technologies based on lumen output. The average system wattages used in this analysis are provided in Table 2.3.

Table 2.3 - Lamp Wattage of PAR, BR and R Shaped Lamps

\begin{tabular}{|l|c|c|}
\hline Lamp Type & $\begin{array}{c}\text { Average System } \\
\text { Wattage (W) }\end{array}$ & $\begin{array}{c}\text { 2010 LED Replacement } \\
\text { Wattage (W) }\end{array}$ \\
\hline PAR20 & 46 & 13 \\
\hline PAR30 & 67 & 15 \\
\hline PAR38 & 78 & 18 \\
\hline BR30 & 65 & 11 \\
\hline BR40 & 65 & 11 \\
\hline R20 & 45 & 8 \\
\hline Reflector CFL & 18 & 10 \\
\hline
\end{tabular}

\subsubsection{PAR, BR and R Shaped Lamp Energy Savings Potential}

Table 2.4 depicts the total energy consumption of the PAR, BR and R shaped lamp sector, as well as the potential energy savings if the entire U.S. installed base was converted instantaneously to LED lamps. Compared to the baseline savings of 0.11 TWh per year in 2010, a total potential electricity savings of 35.6 TWh per year would be realized if LEDs achieved $100 \%$ market penetration. This equates to an annual primary energy savings of approximately 0.39 quads, or the total annual electricity consumption of nearly three million residential households.

Table 2.4 - Energy Consumption and Savings Potential of PAR, BR and R Shaped Lamps

\begin{tabular}{|l|c|c|c|c|}
\hline Niche Application & $\begin{array}{c}\text { Annual } \\
\text { Electricity } \\
\text { Consumption } \\
\text { in 2010 } \\
\mathbf{( T W h / y r )}\end{array}$ & $\begin{array}{c}\text { Electricity } \\
\text { Savings in } \\
\mathbf{2 0 1 0} \\
\mathbf{( T W h / y r )}\end{array}$ & $\begin{array}{c}\text { Additional } \\
\text { Potential } \\
\text { Electricity } \\
\text { Savings } \\
\text { (TWh/yr) }\end{array}$ & $\begin{array}{c}\text { Total Potential } \\
\text { Electricity } \\
\text { Savings } \\
\text { (TWh/yr) }\end{array}$ \\
\hline $\begin{array}{l}\text { PAR, BR and R } \\
\text { shaped Lamps }\end{array}$ & 45.0 & 0.11 & 35.5 & 35.6 \\
\hline
\end{tabular}

\subsection{MR16 Replacement Lamps}

Similar to the PAR, BR and R shaped lamps discussed in the previous section, multifaceted reflector (MR) or MR16 lamps are primarily halogen incandescent light sources, and are typically low voltage lamps that provide directional light. ${ }^{13}$ Originally, these lamps were used for slide projectors but they are now widely used for accent, task, and display lighting in museums, art galleries, retail stores, residential settings, and entertainment venues. MR16 lamps

\footnotetext{
${ }^{13}$ Most MR16 lamps are operated using voltages lower than 120 volts, typically 12 volts (Lighting Research Center (b), 2002).
} 
are particularly optimal for jewelry and other display applications due to their high color temperature, CRI, and well-controlled, high-intensity beam (Lighting Research Center (b), 2002).

The small form factor and required dimmability and optical control of MR16 lamps are not conducive to CFL technology, making LEDs an ideal replacement. In addition, the efficiencies of these lamps greatly outpace that of the incumbent technologies. LED MR16 lamps have tested efficacies as high as $50 \mathrm{~lm} / \mathrm{W}$ (DOE CALiPER Program (a), 2010), while traditional incandescent MR16 lamps are only capable of efficacies between 15 and $25 \mathrm{~lm} / \mathrm{W}$. The market presence of LED MR16 replacement lamps continues to grow, and a variety of major retail companies including Best Buy and Starbucks are beginning to undertake massive retrofit projects. These two companies are in the process of installing approximately 35,000 (LEDs Magazine (a), 2010) and 129,000 (Girrbach, 2010) LED MR16 lamps respectively.

The following analysis describes the estimated energy savings from the increased use of MR16 LED replacement lamps. The key sources used for the four critical inputs to the analysis are summarized in Table 2.5. 
Table 2.5 - Key Sources for the MR16 Replacement Lamp Analysis

\begin{tabular}{|l|l|}
\hline Critical Input & Key Sources \\
\hline Installed Base of & European MR16 Shipments: Task 3: Review of Sales and Inventory \\
Lamps & Estimates (United Kingdom Department for Environment, Food and \\
& Rural Affairs, 2010) \\
& U.S. Residential MR16 Installed Base: Single-Family Residential \\
& Existing Construction Stock Assessment (RLW Analytics Inc. (b), \\
& 2007) and Single-Family Residential New Construction Characteristics \\
and Practices Study (RLW Analytics Inc. (c), 2007) & MR16 lamp lifetime: Sylvania, GE and Philips lamp catalog data \\
\hline Annual Operating & $\begin{array}{l}\text { U.S. Lighting Market Characterization Volume I: National Inventory } \\
\text { and Energy Consumption Estimate (Navigant Consulting, Inc (b), } \\
\text { 2002) }\end{array}$ \\
\hline Lamp Wattages & $\begin{array}{l}\text { MR16 Commercial Wattage: Sylvania, GE and Philips lamp catalog } \\
\text { data and Task 3: Review of Sales and Inventory Estimates (United } \\
\text { Kingdom Department for Environment, Food and Rural Affairs, 2010) } \\
\text { MR16 Residential Wattage: Sylvania, GE and Philips lamp catalog } \\
\text { data, Single-Family Residential Existing Construction Stock } \\
\text { Assessment and Single-Family Residential New Construction } \\
\text { Characteristics and Practices Study (RLW Analytics Inc. (b), 2007) and } \\
\text { (RLW Analytics Inc. (c), 2007) } \\
\text { LED Lamp Wattages: DOE’s CALiPER Program Report (DOE } \\
\text { CALiPER Program (a), 2010) }\end{array}$ \\
\hline $\begin{array}{l}\text { LED MR16 Penetration: LED Replacement Lamps Market Analysis } \\
\text { and Forecast (Strategies Unlimited, 2009) }\end{array}$ \\
\hline
\end{tabular}

\subsubsection{MR16 Replacement Lamp Installed Base}

The MR16 market mainly consists of incandescent lamps that utilize halogen technology. Very limited domestic market data on MR16s is available, and therefore, the installed stock estimate is based largely on survey data and shipments within the European Union as reported in support of forthcoming European Commission regulations on directional lamps. The U.S. residential stock was determined using two surveys of new and existing household lighting in the Pacific Northwest. For the commercial sector, the European Union shipments were adjusted to reflect the U.S. market by using data provided in the 2009 Strategies Unlimited LED Replacement Lamps Market Analysis and Forecast report. The report indicates the distribution of LED MR16 replacement sales between Europe and North America, and it is assumed that this breakdown is representative of the European Union and U.S. for the entire MR16 market segment. The derived shipment values for the total U.S. MR16 market were then verified by both case study analyses and interviews with manufacturers. 
Then using average MR16 lamp lifetimes and operating hours estimates for the residential and commercial sector, a total installed base was calculated. The commercial stock was then taken to be the difference between the total calculated U.S. stock and the residential stock.

The penetration of LED MR16 replacement lamps to the MR16 installed base was determined using LED MR16 shipment data provided in the 2009 Strategies Unlimited LED Replacement Lamps Market Analysis and Forecast report. The shipments indicate that the U.S. installed base of LED MR16 lamps has reached approximately 2 million units, or $1.67 \%$ of the total MR16 installed base. Furthermore, due to high capital cost and limited number of MR16 residential applications, it is assumed that all LED replacements are for the commercial sector.

The technology mix and total number of lamps by application and technology type are depicted in Table 2.6.

Table 2.6 - MR16 Replacement Lamp Installed Base

\begin{tabular}{|l|c|r|r|r|}
\hline \multirow{2}{*}{ Lamp Type } & \multirow{2}{*}{ Percentage } & \multicolumn{3}{|c|}{ Number of Lamps (000's) } \\
\cline { 3 - 5 } & & Residential & Commercial & Total Lamps \\
\hline MR16 & $98.3 \%$ & 41,800 & 78,400 & 120,000 \\
\hline MR16 LED & $1.7 \%$ & - & 2,000 & 2,000 \\
\hline Total & $\mathbf{1 0 0} \%$ & $\mathbf{4 1 , 8 0 0}$ & $\mathbf{8 1 , 4 0 0}$ & $\mathbf{1 2 2 , 0 0 0}$ \\
\hline
\end{tabular}

\subsubsection{MR16 Replacement Lamp Operating Hours}

Operating hours of MR16 lamps varies significantly for commercial and residential applications, and therefore, these two sectors are accounted for separately. The 2002 U.S. Lighting Market Characterization indicates that commercial low voltage halogen lamps operate approximately 3,270 hours per year, while residential general service halogen lamps operate only 840 hours per year (Navigant Consulting, Inc (b), 2002). It was assumed that the above described operating hours are representative of all commercial and residential MR16 lamps.

\subsubsection{MR16 Replacement Lamp Average Wattages}

MR16 lamps are mainly produced at three wattages: 20, 35 and $50 \mathrm{~W}$. The average commercial wattage was determined using catalog product data together with information provided by the European Commission lighting inventory study. The lighting study suggested that one-third of all low voltage halogen lamps, assumed to be mostly MR16s are rated at $20 \mathrm{~W}$. A large database of higher wattage MR16s was developed and the average wattage of this database was used for the remaining two-thirds of commercial MR16s. The average wattage for residential MR16s was derived directly from the new and existing household surveys previously discussed.

Best-in-class reported efficacies of LED MR16 products tested by the DOE's CALiPER program were used to create the replacement LED wattage. The lumen output required for both residential and commercial MR16 lamp applications was then divided by the tested LED product 
with the highest reported efficacy to determine the necessary LED replacement wattage. The average system wattages used in this analysis are provided in Table 2.7.

Table 2.7 - Lamp Wattage of MR16 Replacement Lamps

\begin{tabular}{|l|c|c|} 
Sector & $\begin{array}{c}\text { Average System } \\
\text { Wattage (W) }\end{array}$ & $\begin{array}{c}\text { 2010 LED Replacement } \\
\text { Wattage (W) }\end{array}$ \\
\hline Residential & 44 & 15 \\
\hline Commercial & 33 & 16 \\
\hline
\end{tabular}

\subsubsection{MR16 Replacement Lamp Energy Savings Potential}

Table 2.8 depicts the total energy consumption of the MR16 lamp market, as well as the potential energy savings if the entire U.S. installed base of MR16 halogen lamps was replaced by LED lamps. Compared to the baseline savings of 0.25 TWh per year in 2010, a total potential electricity savings of 6.3 TWh per year would be realized if LEDs achieved 100\% market penetration. This equates to a primary energy savings of approximately 0.07 quads per year, or the total annual electric consumption of over half a million residential households.

Table 2.8 - Energy Consumption and Savings Potential of MR16 Replacement Lamps

\begin{tabular}{|l|c|c|c|c|}
\hline Niche Application & $\begin{array}{c}\text { Annual } \\
\text { Electricity } \\
\text { Consumption in } \\
\mathbf{2 0 1 0} \text { (TWh/yr) }\end{array}$ & $\begin{array}{c}\text { Electricity } \\
\text { Savings in } \\
\mathbf{2 0 1 0} \\
\text { (TWh/yr) }\end{array}$ & $\begin{array}{c}\text { Additional } \\
\text { Potential } \\
\text { Electricity Savings } \\
\text { (TWh/yr) }\end{array}$ & $\begin{array}{c}\text { Total Potential } \\
\text { Electricity } \\
\text { Savings } \\
\text { (TWh/yr) }\end{array}$ \\
\hline $\begin{array}{l}\text { MR16 Replacement } \\
\text { Lamps }\end{array}$ & 11.2 & 0.25 & 6.0 & 6.3 \\
\hline
\end{tabular}

\subsection{2-ft by 2-ft Troffer Fixtures}

A troffer fixture is typically an inverted metal trough that houses and serves as a reflector for a fluorescent lamp-ballast system. The trough takes the light from the lamp and reflects it in one hemisphere. These fluorescent fixture systems are widely utilized for commercial and industrial establishment because they offer a low cost, highly efficient and long lifetime lighting source. Various types of troffer fixtures are commercially available; however, this analysis examines the commonly used 2-ft by 2-ft system which typically houses two U-shaped fluorescent lamps and less commonly linear fluorescent and CFLs (DOE CALiPER Program (b), 2009).

The CALiPER Round 11 testing results indicate that although LED linear replacement lamps are improving, especially in terms of their efficacy, there are still major performance challenges in the areas of total light output, light distribution, color quality, and reliability. Therefore, this analysis only considers the energy savings from 2-ft by 2-ft replacement LED fixtures, since in most cases LED lamp replacements are not yet competitive with their fluorescent counterparts, in terms of both cost and performance (DOE CALiPER Program (a), 2010). 
These LED replacement fixtures have begun to replace traditional fluorescent troffer systems, but market penetration is still limited. LED 2-ft by 2-ft fixture replacements have CALiPER tested efficacies as high as $79 \mathrm{~lm} / \mathrm{W}$ (DOE CALiPER Program (a), 2010), while a 2-ft by 2-ft fluorescent system can have an efficacy between 40 and $70 \mathrm{~lm} / \mathrm{W}$. LEDs offer several benefits for general illumination compared to fluorescent technology, such as their directionality (i.e., LED sources emit light towards one plane unlike fluorescent technology which is omnidirectional), which results in reduced light loss. DOE's CALiPER Program indicates that LED 2 - $\mathrm{ft}$ by 2 - $\mathrm{ft}$ troffers are increasingly competitive with incumbent technologies with respect to light output levels, light distribution, and efficacy. Therefore, these lamps offer potential for significant energy savings and are superior in applications where dimming is required (DOE CALiPER Program (b), 2009).

This section analyzes the current installed stock and energy savings potential for LED replacements in the 2-ft by 2-ft troffer fixture market. The key sources used for the four critical inputs to the analysis are summarized in Table 2.9.

Table 2.9 - Key Sources for the 2-ft by 2-ft Troffer Fixture Analysis

\begin{tabular}{|l|l|}
\hline Critical Input & Key Sources \\
\hline $\begin{array}{l}\text { Installed Base of } \\
\text { Lamps }\end{array}$ & $\begin{array}{l}\text { Lamp Shipments: Historical NEMA GSFL Shipments (NEMA (a), } \\
\text { 2006) (NEMA (a), 2006) (NEMA (a), 2006) } \\
\text { Lamp Lifetime Estimate: Sylvania, GE and Philips lamp catalog data }\end{array}$ \\
\hline $\begin{array}{l}\text { Annual Operating } \\
\text { Hours }\end{array}$ & $\begin{array}{l}\text { U.S. Lighting Market Characterization - Volume 1: National Lighting } \\
\text { Inventory and Energy Consumption Estimate (Navigant Consulting, Inc } \\
\text { (b), 2002) }\end{array}$ \\
\hline Lamp Wattages & $\begin{array}{l}\text { T12 and T8 2-ft by 2-ft Fixture Wattages: Sylvania, GE and Philips } \\
\text { lamp catalog data } \\
\text { LED Lamp Wattages: Summary of Product Testing Results (DOE } \\
\text { CALiPER Program (a), 2010) }\end{array}$ \\
\hline Lighting Technology & $\begin{array}{l}\text { Lamp Mix: Historical NEMA GSFL Shipments (NEMA (a), 2006) } \\
\text { (NEMA (a), 2006) (NEMA (a), 2006) }\end{array}$ \\
& $\begin{array}{l}\text { LED Penetration: LED Replacement Lamps Market Analysis and } \\
\text { Forecast (Strategies Unlimited, 2009) and Interviews of LEDNovation } \\
\text { (Eckert, 2010) }\end{array}$ \\
\hline
\end{tabular}

\subsubsection{2-ft by 2-ft Troffer Fixture Installed Base}

The 2-ft by 2-ft troffer fixture installed base is assumed to comprise of 2-ft T12 and T8 U-shaped fluorescent lamps, and other 2-ft fluorescents, which includes 2-ft fluorescent linear lamps, and pin-based CFLs. NEMA shipment data from 2001 to 2005 of 2-ft U-shaped lamps were projected to 2010 to determine the total number of installed 2-ft by 2-ft troffers with U-shaped lamps. NEMA data was assumed to represent approximately $90 \%$ of the total U-shaped T12 and T8 market. Therefore, the values were increased to account for the volume of lamps that are 
manufactured by non-NEMA lamp companies (DOE (b), 2009). In addition, interviews with manufacturers indicate that over the past several years, sales of 2-ft by 2-ft fixtures have primarily been comprised of non-U-shaped lamps, namely 2-ft fluorescent linear lamps and pinbased CFLs. Thus the shipments were adjusted to account for these new fixture sales. The adjusted shipment data, coupled with lifetime estimates for each lamp type, was used to calculate the installed stock of all 2-ft fluorescent lamps in 2010.

LED 2-ft by 2-ft fixtures are currently commercially available through several major retailers; however, interviews with LED manufacturers indicated that consumer adoption was quite small. Using data provided in the 2009 Strategies Unlimited LED Replacement Lamps Market Analysis and Forecast report and manufacturer interviews; it was assumed that LEDs represent $0.1 \%$ of the total installed base. The estimated LED penetration rate is lower than other replacement lamps considered in this report because 2-ft by 2-ft LED replacements are truly replacement fixtures and not replacement lamps, effectively limiting penetration to new construction installations (Eckert, 2010). Furthermore, it was assumed that LEDs are only replacing less efficient T12 troffer fixtures. The breakdown of total installed stock for all 2-ft fluorescents and LED 2-ft by 2-ft troffers is shown below in Table 2.10.

Table 2.10 - 2-ft by 2-ft Troffer Fixture Installed Base ${ }^{14}$

\begin{tabular}{|l|c|c|}
\hline Lamp Type & Percentage & $\begin{array}{c}\text { Number of Troffer } \\
\text { Fixtures (000's) }\end{array}$ \\
\hline 2-ft U-shaped T12 & $17.3 \%$ & 9,200 \\
\hline 2-ft U-shaped T8 & $74.1 \%$ & 39,300 \\
\hline Other 2-ft fluorescent & $8.5 \%$ & 4,510 \\
\hline 2-ft by 2-ft LED Fixture & $0.1 \%$ & 50 \\
\hline Total & $\mathbf{1 0 0 \%}$ & $\mathbf{5 3 , 1 0 0}$ \\
\hline
\end{tabular}

\subsubsection{2-ft by 2-ft Troffer Fixture Operating Hours}

The operating hours for 2 -ft by 2-ft troffer fixtures was derived from estimates provided in the U.S. Lighting Market Characterization report. The report indicates that T12 and T8 lamps operate for approximately 10.5 hours per day or 3,833 hours annually (Navigant Consulting, Inc (b), 2002).

\subsubsection{2-ft by 2-ft Troffer Fixture Average Wattages}

To determine the power consumption of the entire system, it was necessary to collect the typical power ratings for the lamp and ballast components.

For the U-shaped T12 and T8 lamps a database of standard and low wattage products was developed to determine an average wattage for each lamp at both the standard and low wattage

\footnotetext{
${ }^{14}$ Values in the table may not add up due to rounding.
} 
lamp types. The product database revealed that U-shaped T12 lamps are almost only available at 40 and $34 \mathrm{~W}$ for the standard and low wattage rating respectively, while T8 lamps are offered only at 32 and $31 \mathrm{~W}$. A similar database was also created for other 2-ft fluorescent lamps (linear 2-ft and CFLs) which indicated that these lamps typically operate at about $17 \mathrm{~W}$. However, a 2ft by 2-ft fluorescent system contains two 2-ft fluorescent lamps, a ballast, and a fixture (the troffer). Therefore, these lamp wattages do not represent the total power consumptions of a 2-ft by 2 -ft fluorescent system.

Ballasts are used to limit the current flow to the lamp, and typically drive the lamp at wattage lower than its specified power rating to increase electricity savings (Lighting Reseach Center (a), 2003). Ballasts are also designed to function with multiple lamp configurations (e.g., a two 32 W T8 or three $32 \mathrm{~W}$ T8 lamp system), and therefore, the ballast product specifications include information on the input wattage for each system configuration the ballast is qualified to run. A product database of ballasts rated to run the determined wattages for U-shaped T12 and T8 and other 2-ft fluorescent lamps was then created. A weighted average wattage for 2-ft by 2-ft troffer fixture system was determined using the input wattages provided in the ballast database.

The LED replacement 2-ft by 2-ft LED troffer efficacies were taken from the best-in class products tested by DOE's CALiPER program and were then used to determine the replacement wattages for 2-ft by 2-ft U-shaped T12 and T8 systems. The average system wattages used in this analysis are provided in Table 2.11 .

Table 2.11 - System Wattage of 2-ft by 2-ft Troffer Fixtures

\begin{tabular}{|l|c|c|}
\hline Fixture Type & $\begin{array}{c}\text { Average System } \\
\text { Wattage (W) }\end{array}$ & $\begin{array}{c}\text { 2010 LED Replacement } \\
\text { Wattage (W) }\end{array}$ \\
\hline 2-ft U-shaped T12 & 70 & 45 \\
\hline 2-ft U-shaped T8 & 59 & 46 \\
\hline Other 2-ft fluorescent & 36 & 21 \\
\hline
\end{tabular}

\subsubsection{2-ft by 2-ft Troffer Fixture Energy Savings Potential}

Table 2.12 below indicates that 2-ft by 2-ft troffer fixtures consumed 12 TWh of electricity in 2010. Given the 2010 baseline LED penetration of $0.1 \%$, this represents an electricity reduction of approximately 0.005 TWh per year. Furthermore, if LED 2-ft by 2-ft fixtures were to immediately replace the entire installed stock, there would be an electricity savings of 6.6 TWh per year. The total potential electricity savings equates to an annual primary energy savings of approximately 0.07 quads or the total annual electricity consumption of over a half a million residential households. 
Table 2.12 - Energy Consumption and Savings Potential of 2-ft by 2-ft Troffer Fixtures

\begin{tabular}{|l|c|c|c|c|}
\hline $\begin{array}{l}\text { Niche } \\
\text { Application }\end{array}$ & $\begin{array}{c}\text { Annual } \\
\text { Electricity } \\
\text { Consumption in } \\
\mathbf{2 0 1 0}(\mathbf{T W h} / \mathbf{y r})\end{array}$ & $\begin{array}{c}\text { Electricity } \\
\text { Savings in } \\
\mathbf{2 0 1 0} \\
\mathbf{( T W h / y r )}\end{array}$ & $\begin{array}{c}\text { Additional Potential } \\
\text { Electricity Savings } \\
\text { (TWh/yr) }\end{array}$ & $\begin{array}{c}\text { Total Potential } \\
\text { Electricity } \\
\text { Savings } \\
\text { (TWh/yr) }\end{array}$ \\
\hline $\begin{array}{l}\text { 2-ft by 2-ft } \\
\text { Troffer Fixtures }\end{array}$ & 12.0 & 0.005 & 6.6 & 6.6 \\
\hline
\end{tabular}

\subsection{A-Type Lamps}

General lighting service (GLS) or A-type lamps have the largest installed stock of any lighting type, and are used in ambient lighting application where the light is designed to diffuse in all directions. These lamps are most prevalent in the residential sector, and over the past decade the A-type market has drastically changed due to the increasing penetration of CFLs.

The CFL market experienced an upsurge of shipments in 2007, and incandescent shipments have steadily declined from 2004 to the present. Since 2007, CFL shipments have gradually declined but large scale penetration in the United States has increased (D\&R International, Ltd., 2010). The steady decrease of CFLs in the market after the surge in 2007 could be due to multiple factors, such as increased market penetration (CFL has a typical lifetime of 12,000 hours compared to 1,000 hours for a standard incandescent) or consumer preferences (DOE (c), 2010). Therefore, as consumers purchase additional CFLs to replace incandescent bulbs, purchases could be made less frequently due to the longer lifetime.

LED A-type replacements have recently become commercially available, and have the potential of offering energy savings and lamp lifetimes beyond that of CFLs, as well as dimming capabilities similar to conventional incandescent lamps. In addition, LED A-type replacements display efficacies as high as $67 \mathrm{~lm} / \mathrm{W}$ (DOE CALiPER Program (a), 2010) which is similar to that of CFLs, while incandescent A-type lamps only produce efficacies of about $15 \mathrm{~lm} / \mathrm{W}$ (DOE (c), 2010). However, LEDs still face a variety of barriers to reach significant penetration, most notably their high initial cost. As LED A-type technology improves, these lamps will likely gain support from state, local and utility energy efficiency programs. Currently, these programs typically encourage consumers to change out incandescent lighting for replacement CFLs and work with retailers to offer significantly discounted CFLs. LED penetration will also be propelled due to EISA 2007, which will regulate the use of A-type incandescent lamps by imposing minimum efficacy requirements.

This section addresses the potential for LED replacements in the general service A-type lamp market, which includes standard incandescent A-type lamps, commonly known as Edison bulbs, CFLs and LED replacement lamps. Furthermore, this analysis only considers spiral/twister, mini-spiral/twisters and spring CFL types as equivalent incandescent A-type replacements. All 
other CFL types are not considered in the analysis. The key sources used for creating inputs to the analysis are summarized in Table 2.13.

\section{Table 2.13 - Key Sources for the A-Type Lamp Analysis}

\begin{tabular}{|c|c|}
\hline Critical Input & Key Sources \\
\hline $\begin{array}{l}\text { Installed Base of } \\
\text { Lamps }\end{array}$ & $\begin{array}{l}\text { Incandescent Shipments: Historical IRL NEMA Shipments (NEMA } \\
\text { (a), 2006) and NEMA shipments index data (NEMA (c), 2010) } \\
\text { Saturation of CFLs, Residential Sector: Multistate CFL Modeling } \\
\text { Effort (NMR Group, Inc., } 2010 \text { (a)), Northwest Energy Efficiency } \\
\text { Alliance Survey Results (RLW Analytics Inc. (c) and (d), 2007), Puget } \\
\text { Sound Area Residential Compact Fluorescent Lighting Market } \\
\text { Saturation Study (Energy Market Innovations, Inc., 2007) } \\
\text { Saturation of CFLs, Commercial Sector: California Commercial End- } \\
\text { Use Survey Results (Itron, Inc., 2006) } \\
\text { CFL and Incandescent Lamp Lifetime Hours: Sylvania, GE and Philips } \\
\text { lamp catalog data }\end{array}$ \\
\hline $\begin{array}{l}\text { Annual Operating } \\
\text { Hours }\end{array}$ & $\begin{array}{l}\text { Lighting Market Characterization Vol. 1, Final Evaluation Report: } \\
\text { Upstream Lighting Program, Vol. } 1 \text { (Navigant Consulting, Inc (b), } \\
\text { 2002), Residential Lighting Markdown Impact Evaluation }\end{array}$ \\
\hline Lamp Wattages & $\begin{array}{l}\text { Incandescent and CFL Wattages: Multistate CFL Modeling Effort } \\
\text { (NMR Group, Inc., } 2010 \text { (a)), Northwest Energy Efficiency Alliance } \\
\text { Survey Results (RLW Analytics Inc. (c) and (d), 2007), Puget Sound } \\
\text { Area Residential Compact Fluorescent Lighting Market Saturation } \\
\text { Study (Energy Market Innovations, Inc., 2007), California Commercial } \\
\text { End-Use Survey Results (Itron, Inc., 2006) } \\
\text { LED Lamp Wattages: Summary of Product Testing Results (DOE } \\
\text { CALiPER Program (a), 2010) }\end{array}$ \\
\hline $\begin{array}{l}\text { Lighting Technology } \\
\text { Mix }\end{array}$ & $\begin{array}{l}\text { Commercial Sector Lamp Mix: California Commercial End-Use } \\
\text { Survey Results (Itron, Inc., 2006), } \\
\text { Residential Sector CFL Penetration: ENERGY STAR CFL Market } \\
\text { Profile (D\&R Internation, Ldt., 2010), Multistate CFL Modeling Effort } \\
\text { (NMR Group, Inc., } 2010 \text { (a)), The Market for CFLs in Massachusetts } \\
\text { (NMR Group, Inc., } 2010 \text { (b)) } \\
\text { LED Penetration: LED Replacement Lamps Market Analysis and } \\
\text { Forecast (Strategies Unlimited, 2009) }\end{array}$ \\
\hline
\end{tabular}

\subsubsection{A-Type Lamp Installed Base}

To determine the U.S. installed stock of CFLs in the residential sector, the average number of CFLs per household was calculated using onsite survey data for several U.S. states. States were then binned based on their energy efficiency efforts, as reported by the American Council for an Energy Efficient Economy (ACEEE) State Energy Efficiency Scorecard, ${ }^{15}$ and average

\footnotetext{
${ }^{15}$ The ACEEE 2010 State Energy Efficiency Scorecard ranks States based on the extent of utility or state sponsored CFL programs.
} 
saturation values for each bin were determined (ACEEE, 2010). Using U.S. Census estimates for the number of households within each state, the installed base of residential CFLs was determined by multiplying the total number of households in each bin by the saturation values. ${ }^{16}$

The installed base of CFLs for the commercial sector was determined using the California Commercial End-Use Survey data, which indicated the percentage of lamps that are CFLs within California's commercial buildings. The CFL counts in California were then scaled by commercial floor space to determine the total U.S. installed base.

The installed stock for incandescent A-type lamps in the residential and commercial sector was developed using annual NEMA shipments from 2001 through 2005, and were projected to 2010 using NEMA index data (NEMA (c), 2010). Using data from DOE's 2009 Energy Conservation Final Rule for General Service Fluorescent Lamps and Incandescent Reflector Lamps, the shipment values were then increased to account for the volume of incandescent lamps that are manufactured by non-NEMA lamp companies (DOE (b), 2009). These shipments were summed and adjusted based on expected lifetime and operating hours of incandescent lamps.

The penetration of LED replacement lamps was determined using LED shipment data provided in the 2009 Strategies Unlimited LED Replacement Lamps Market Analysis and Forecast report. The shipments indicate that the installed base of LED A-type replacement lamps has reached approximately 0.24 million units, or $0.01 \%$ of the total U.S. general service A-type installed base. The penetration of LEDs into the residential and commercial sectors is determined based on the distribution for the CFL installed base, where approximately $91 \%$ is classified as residential lamps, and the remaining $9 \%$ is in commercial applications.

The technology mix and total number of lamps by application and technology type are depicted in Table 2.14.

\footnotetext{
${ }^{16}$ Another CFL installed base calculation method using statewide CFL socket saturation studies weighted and scaled to develop a national average, was used to verify the accuracy of the above described method.
} 
Table 2.14 -A-Type Lamp Installed Base ${ }^{17}$

\begin{tabular}{|l|c|r|r|r|}
\hline \multirow{2}{*}{ Lamp Type } & \multirow{2}{*}{ Percentage } & \multicolumn{3}{|c|}{ Number of Lamps (millions) } \\
\cline { 3 - 5 } & & Residential & Commercial & Total Lamps \\
\hline Incandescent & $63.2 \%$ & 1,680 & 33.3 & 1,710 \\
\hline CFL & $36.6 \%$ & 897 & 92.5 & 990 \\
\hline LED & $0.01 \%$ & 0.22 & 0.02 & 0.24 \\
\hline Total & $\mathbf{1 0 0} \%$ & $\mathbf{2 , 5 8 0}$ & $\mathbf{1 2 6}$ & $\mathbf{2 , 7 0 0}$ \\
\hline
\end{tabular}

\subsubsection{A-Type Lamp Operating Hours}

Because operating hours of general service A-type lamps are disparate for commercial and residential applications, separate methods are used to account for each market sector. The 2002 U.S. Lighting Market Characterization shows that standard incandescent lamps and CFLs in commercial applications respectively operate approximately 3,723 and 3,541 hours per year, while studies based on onsite surveys in California and the Northeast indicate incandescent Atype lamps and CFLs respectively operate approximately 821 and 764 hours per year in residential applications.

\subsubsection{A-Type Lamp Average Wattages}

Incandescent A-type lamps and CFLs are produced at various wattages for use in commercial and residential applications. The average wattages for both incandescent A-type lamps and CFLs were determined using onsite survey data for several U.S. regions. A weighted average for each was then determined based on the sample size of each survey.

For LED A-type replacement lamps the equivalent wattages were determined using data from products tested by DOE's CALiPER program. The lumen outputs required for both incandescent A-type and CFL applications were used to develop the replacement LED wattage (DOE CALiPER Program (a), 2010). The average wattages used in the analysis are shown in Table 2.15 .

Table 2.15 - Lamp Wattage of A-Type Lamps

\begin{tabular}{|l|c|c|}
\hline Lamp Type & $\begin{array}{c}\text { Average System } \\
\text { Wattage (W) }\end{array}$ & $\begin{array}{c}\text { 2010 LED Replacement } \\
\text { Wattage (W) }\end{array}$ \\
\hline Incandescent & 66 & 13 \\
\hline CFL & 18 & 14 \\
\hline
\end{tabular}

\subsubsection{A-Type Lamp Energy Savings Potential}

Table 2.16 depicts the total energy consumption of general service A-type lamps and the potential energy savings if the entire nationwide installed base was converted instantaneously to LED replacement lamps. Compared to the baseline savings of $0.015 \mathrm{TWh}$ per year in 2010, a

\footnotetext{
${ }^{17}$ Values in the table may not add up due to rounding.
} 
potential electricity savings of 84.1 TWh per year would be realized if LEDs achieved complete and immediate market penetration. This equates to an annual primary energy savings of approximately 0.91 quads, or the total annual electricity consumption of nearly seven million residential households.

Table 2.16 - Energy Consumption and Savings Potential of A-Type Lamps

\begin{tabular}{|l|c|c|c|c|}
\hline $\begin{array}{l}\text { Niche } \\
\text { Application }\end{array}$ & $\begin{array}{c}\text { Annual Electricity } \\
\text { Consumption in } \\
\mathbf{2 0 1 0}(\mathbf{T W h} / \mathbf{y r})\end{array}$ & $\begin{array}{c}\text { Electricity } \\
\text { Savings in } \\
\mathbf{2 0 1 0}(\mathbf{T W h} / \mathbf{y r})\end{array}$ & $\begin{array}{c}\text { Additional } \\
\text { Potential } \\
\text { Electricity } \\
\text { Savings (TWh/yr) }\end{array}$ & $\begin{array}{c}\text { Total Potential } \\
\text { Electricity } \\
\text { Savings } \\
\text { (TWh/yr) }\end{array}$ \\
\hline A-type & 118.7 & 0.015 & 84.1 & 84.1 \\
\hline
\end{tabular}




\section{Outdoor Lighting Introduction}

The outdoor white light analysis includes lamps that are used for roadway lighting, parking facilities, other area and flood lighting applications, as well as lighting outside residences. These lamps serve multiple purposes including providing proper illumination for pedestrian and automobile traffic, creating a sense of personal security, and attracting attention and business to the spaces. Typically, HID lamps for non-residential installations, and incandescent lamps for residential installations, have been relied upon in these applications due to their ability to affordably achieve illumination requirements. However, in the past several years newer technologies, such as induction (electrodeless fluorescent) lamps, plasma (electrodeless HID) and LEDs, have begun to make inroads into these markets.

Lighting designed for outdoor applications must address multiple issues such as proper light distribution, glare, light pollution, energy usage, and lifetime. Lifetimes are of particular interest to facility managers as they directly affect maintenance costs, which can be an important part of the economic equation as outdoor lights are often spread out over a large geographic region and owned by one organization. For example, the city of Oakland maintains over 36,000 streetlights contained within 56 square miles (City of Oakland Public Works Agency, 2009). In Oakland's case, maintenance costs range from $15 \%$ to $25 \%$ of the annual costs for operations of its streetlights with traditional technologies (Cook, 2008).

LEDs are particularly advantageous in outdoor lighting applications because their inherent characteristics address many of the key issues associated with these types of lighting. LEDs offer extremely long lifetimes, are directional light sources, and thus able to limit light pollution and light trespass, are highly efficacious, function well in cold temperatures, are greatly resilient to vibration, and are able to provide a high quality light. However, the major obstacle to greater market penetration continues to be the initial cost of LED luminaires. A review of DOE SSL Gateway Demonstrations revealed that the initial cost of outdoor LED luminaires is between three to seven times more than equivalent HID luminaires. ${ }^{18}$

In order to obviate the cost hurdle, the Federal government has provided financial incentives directly to facility owners that install energy efficient lighting. For example, EPACT 2005 provided a set of tax deductions, which are applicable to most indoor spaces as well as parking garages that peak at $\$ 0.60$ per square foot, for installing lighting systems that achieve $40 \%$ lighting power density reduction beyond what is required in ASHRAE Standard 90.1-2001. These tax deductions were extended by EISA 2007. EISA 2007 also mandated minimum efficiency standards for ballasts in metal halide lamp fixtures, which are commonly used in

\footnotetext{
${ }^{18}$ More information on the Gateway Demonstrations can be found at http://www1.eere.energy.gov/buildings/ssl/gatewaydemos.html
} 
commercial outdoor lighting applications, as well as general service lamps, which are used in residential outdoor applications.

Finally, the American Recovery and Reinvestment Act of 2009 awarded \$3.2 billion through the Energy Efficiency and Conservation Block Grant Program to cities, counties, states, territories, and Indian tribes. A sizeable portion of these funds have been used to transition roadway lights, parking facility lights, and outdoor area lights to LEDs. ${ }^{19}$

\subsection{Photopic vs. Scotopic Vision}

The perceived level of light, as depicted by photopic, scotopic, and mesopic vision, is highly relevant to outdoor lighting and deserves its own section in this analysis. According to some experts, the energy efficiency benefits of LED outdoor lights cannot be determined simply by comparing efficacy, the energy efficiency measure for lamps. Studies in Raleigh, North Carolina and the City of Los Angles indicate that comparing the perceived brightness of LED sources and high and low pressure sodium lamps at night have shown that LEDs can achieve the same level of perceived brightness with lower lumen output than sodium lamps (Responsible Purchasing Network, 2009). This affect could be explained by the eye's response to light in outdoor "night time" conditions.

Light, measured in lumens, is defined according to the visual sensation it produces in "daytime" conditions. However, the visibility of light varies with external conditions. During "daytime” or indoor lighting conditions, where there is a high level of ambient light, the eye uses its cone sensors to perceive light. This type of vision is referred to as photopic (photon-rich) vision. During "night time" conditions, where there is a low level of ambient light, the eye uses its rod sensors to perceive light. This type of vision is referred to as scotopic (scarcity of photons) vision. The rods have a different color response than the cones in the eye, as shown in the photopic and scotopic V- $\lambda$ curves, Figure 3.1. Under outdoor lighting at night, the eye operates in an intermediate range, called mesopic vision, using both rods and cones.

The energy savings estimates given in this report could possibly be greater if the visible light output of light sources under outdoor lighting conditions were taken into account. Assuming equal quantities of “daytime” lumens produced, light sources rich in blue light, such as LEDs or metal halide lamps produce more visible lumens at night than light sources rich in yellow light such as high or low pressure sodium lamps (Bullough, 2001). However, the commercial applicability of these additional energy savings is limited until regulatory bodies and the lighting industry change specifications and design requirements to take the efficacy of light sources under nighttime conditions into account.

\footnotetext{
${ }^{19}$ More on the EECBG Program and funding allocations can be found at: http://www1.eere.energy.gov/wip/eecbg.html
} 


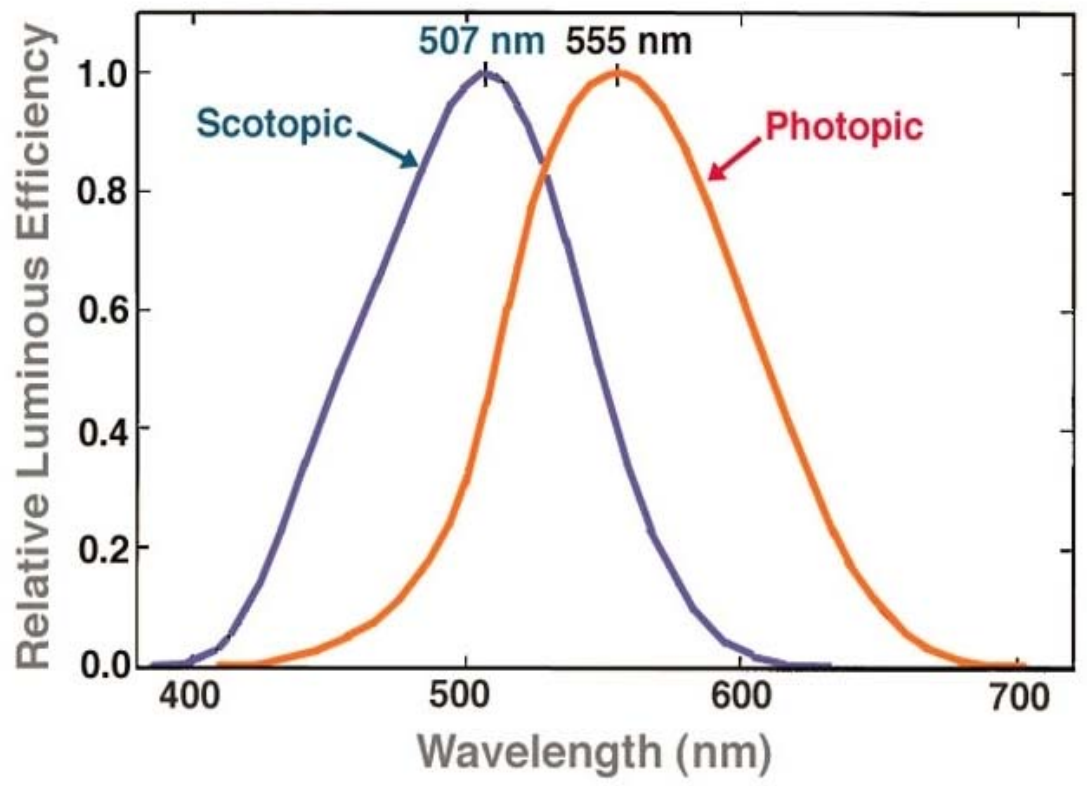

Figure 3.1 - Photopic and Scotopic V- $\lambda$ Curves

(Source: Kalloniatis, 2005)

\subsection{Roadway Lighting}

In this analysis roadway lights are divided into street lights and highway lights. Street lights are considered those lights that illuminate local and collector roads, while highway lights illuminate interstates, freeways, and expressways. The key sources used for the four critical inputs to the analysis are summarized in Table 3.1. 
Table 3.1- Key Sources for the Roadway Lighting Analysis

\begin{tabular}{|l|l|}
\hline Critical Input & Key Sources \\
\hline Lnstalled Base of & No. of Street Lamps: City Departments of Transportation \& Planning \\
& Interviews (City Governments, 2010), Municipal Solid-State Street and \\
& Area Lighting Consortium Survey (DOE (e), 2010) \\
& No. of Highway Lamps: State Departments of Transportation \\
& Interviews (State Governments, 2010), U.S. Census Bureau (U.S. \\
Census Bureau (a), 2010), Federal Highway Administration Interview \\
(Andersen, 2010)
\end{tabular}

\subsubsection{Roadway Lighting Installed Base}

The installed base of roadway lights in 2010 was 52.6 million lamps, which includes 26.5 million street lighting lamps and 26.1 million highways lighting lamps.

The national inventory is estimated from data collected through interviews with City Departments of Transportation as well as data provided by the Municipal Solid-State Street Lighting Consortium. The lighting data provided by these sources included the number, the type, and the application for every roadway light owned by the city. Combined, these two sources provided street lighting inventory data for a total of 25 local governments. The lighting data was placed into different bins based on the city's population from where it came. This bin method was utilized because it was found that the streetlight density (defined as streetlights per person) varies greatly between cities with widely different populations but is fairly consistent among cities of similar size. Within each bin, the average streetlight density was calculated. The average streetlight density was then extrapolated to a national installed base, based on the total population contained by each bin. 
The highway lighting value is based on interviews with State Departments of Transportation and the Federal Highway Administration (FHWA). These interviews provided the technology mix of highway lamps for a sample set of states that was considered representative of the entire United States. The total number of U.S. highway lamps is based on FHWA estimates for total U.S. lighted highway miles and the average roadway spacing between lamps. The total number of lamps by application and technology type are depicted in Table 3.2.

Table 3.2 - Roadway Light Installed Base

\begin{tabular}{|l|l|c|c|}
\hline \multirow{4}{*}{ Application } & \multicolumn{1}{|c|}{ Lamp Type } & Percentage & $\begin{array}{c}\text { Number of Lights } \\
\text { (000's) }\end{array}$ \\
\hline \multirow{4}{*}{ Street Lighting } & Incandescent & $0.1 \%$ & 18 \\
\cline { 2 - 4 } & Mercury Vapor & $15.9 \%$ & 4,200 \\
\cline { 2 - 4 } & Low Pressure Sodium & $0.4 \%$ & 100 \\
\cline { 2 - 4 } & High Pressure Sodium & $80.9 \%$ & 21,500 \\
\cline { 2 - 4 } & Metal Halide & $2.5 \%$ & 700 \\
\cline { 2 - 4 } & LED & $0.2 \%$ & 60 \\
\cline { 2 - 4 } & Total & $\mathbf{1 0 0 \%}$ & $\mathbf{2 6 , 5 0 0}$ \\
\hline Highway Lighting & Induction & $8.5 \%$ & 100 \\
\cline { 2 - 4 } & Low Pressure Sodium & $0.4 \%$ & 22,500 \\
\cline { 2 - 4 } & High Pressure Sodium & $86.1 \%$ & 1,300 \\
\cline { 2 - 4 } & Metal Halide & $5.0 \%$ & $\mathbf{2 6 , 1 0 0}$ \\
\cline { 2 - 4 } & Total & $\mathbf{1 0 0 \%}$ & 100 \\
\hline
\end{tabular}

\subsubsection{Roadway Lighting Operating Hours}

Operating hours were provided by two sets of sources. Interviews were conducted with city planning departments, utilities, and State Departments of Transportation in order to acquire a sampling of typical operating hours. The FHWA also provided an estimate for roadway lighting operating hours for the entire United States. Based on these sources it was determined that 12 hours per day, or 4,380 hours per year, is a reasonable estimate for roadway lighting operating hours.

\subsubsection{Roadway Lighting Average Wattages}

Though similar luminaire types and lamp technologies are used in both applications, highway system wattages are typically far greater than streetlight system wattages. This is because the spacing between luminaires and mounting heights of highway lights are both larger than for streetlights. The average system wattages for roadway lighting installed base were developed from the same datasets used in the installed base calculation, the Municipal Consortium dataset, the interviews with City Departments of Transportation, and the interviews with State Departments of Transportation. 
The equivalent LED replacement lamp wattages were determined by matching the lumen output of the conventional system with that of a hypothetical replacement LED system. Best-in-class reported efficacies of products tested by the DOE's CALiPER program and the Gateway demonstration program were used to create the replacement LED systems. To determine the conventional system's lumen output the typical ballast input power, lamp efficacy, and fixture efficiency was drawn from manufacturer catalogues. The average wattages used in this analysis are provided in Table 3.3.

Table 3.3 - System Wattage of Roadway Lights

\begin{tabular}{|l|l|c|c|}
\hline \multirow{3}{*}{ Application } & \multicolumn{1}{|c|}{ Lamp Type } & $\begin{array}{c}\text { Average System } \\
\text { Wattage (W) }\end{array}$ & $\begin{array}{c}\text { 2010 LED } \\
\text { Replacement } \\
\text { Wattage (W) }\end{array}$ \\
\hline \multirow{5}{*}{ Street Lighting } & Incandescent & 100 & 12 \\
\cline { 2 - 4 } & Mercury Vapor & 291 & 82 \\
\cline { 2 - 4 } & High Pressure Sodium & 178 & 118 \\
\cline { 2 - 4 } & Low Pressure Sodium & 90 & 84 \\
\cline { 2 - 4 } & Metal Halide & 310 & 183 \\
\cline { 2 - 4 } & LED & 74 & 104 \\
\hline \multirow{5}{*}{ Highway Lighting } & Induction & 176 & 178 \\
\cline { 2 - 4 } & High Pressure Sodium & 270 & 185 \\
\cline { 2 - 4 } & Low Pressure Sodium & 199 & 140 \\
\cline { 2 - 4 } & Metal Halide & 237 & \\
\hline
\end{tabular}

\subsubsection{Roadway Lighting Energy Savings Potential}

Table 3.4 depicts the total energy consumption of the roadway lighting sector as well as the potential energy savings if the entire U.S. installed base was converted overnight to LED fixtures. Compared to the baseline savings of 0.06 TWh per year in 2010, a potential electricity savings of 20.2 TWh per year would be realized if LEDs achieved 100\% market penetration. This equates to a primary energy savings of approximately 0.22 quads per year, or the total annual electricity consumption of over one and a half million residential households.

Table 3.4 - Energy Consumption and Savings Potential of Roadway Lights

\begin{tabular}{|c|c|c|c|c|}
\hline Niche Application & $\begin{array}{c}\text { Annual } \\
\text { Electricity } \\
\text { Consumption in } \\
2010(\mathrm{TWh} / \mathrm{yr})\end{array}$ & $\begin{array}{c}\text { Electricity } \\
\text { Savings in } \\
2010 \\
(\mathrm{TWh} / \mathrm{yr})\end{array}$ & $\begin{array}{c}\text { Additional } \\
\text { Potential } \\
\text { Electricity } \\
\text { Savings (TWh/yr) }\end{array}$ & $\begin{array}{c}\text { Total Potential } \\
\text { Electricity } \\
\text { Savings } \\
\text { (TWh/yr) }\end{array}$ \\
\hline Street Lights & 23.1 & 0.06 & 9.9 & 10.0 \\
\hline Highway Lights & 29.7 & 0 & 10.2 & 10.2 \\
\hline
\end{tabular}


The past version of this report noted that there were virtually no LED installations in roadway lighting applications in 2007 (Navigant Consulting, Inc (a), 2008). Thus, the entirety of the 2010 electricity savings being reported is due to LED retrofits and new installations from the past two years. Streetlights comprise the entirety of these installations as color quality is generally not considered as important for highway lighting, allowing HPS to remain the dominant technology.

\subsection{Parking Lighting}

In this analysis, parking lighting only includes off-street parking and has been divided into covered parking garage lighting and parking lot lighting. Parking garages and lots face unique issues concerning their lighting. The near constant vehicle traffic creates particularly harsh operating conditions, with high levels of vibration. And public safety concerns demand that lamps produce a high quality light with a low probability of failure.

LEDs are becoming a popular option in parking applications as their long lifetime helps facility managers reduce costly lamp replacements. Some facilities also view LEDs relatively high CRIs as welcome replacements for the poor quality of light that some incumbent technologies emit.

The parking lighting analysis relies primarily on a survey conducted among International Parking Institute (IPI) members to characterize the inventory of parking lot and garage lights and estimate the potential savings of LEDs. The IPI is the largest parking organization and well represents the entire U.S. parking sector, with membership representing parking professionals, law enforcement officers, urban planners, architects, builders, engineers, university/college administrators, airport authorities, facility managers of corporate complexes, facility managers of sports complexes, and city officials. In August of 2010, the IPI surveyed these members on a variety of lighting issues relevant to this report. All of the key sources used for the four critical inputs to the analysis are summarized in Table 3.5. 
Table 3.5 - Key Sources for the Parking Lighting Analysis

\begin{tabular}{|l|l|}
\hline Critical Input & Key Sources \\
\hline Lnstalled Base of & $\begin{array}{l}\text { No. of Lamps: International Parking Institute Survey (International } \\
\text { Parking Institute, 2010) } \\
\text { No. of Parking Spaces: Parking Infrastructure: Energy, Emissions, } \\
\text { and Automobile Life-Cycle Environmental Accounting (Chester, et al, } \\
\text { 2010) } \\
\text { No. of Spaces per Lamp: Walker Parking Consultants Interview } \\
\text { (Monahan, 2010) }\end{array}$ \\
\hline $\begin{array}{l}\text { Annual Operating } \\
\text { Hours }\end{array}$ & $\begin{array}{l}\text { International Parking Institute Survey (International Parking Institute, } \\
\text { 2010) }\end{array}$ \\
\hline Lamp Wattages & $\begin{array}{l}\text { Lamp Wattages: International Parking Institute Survey (International } \\
\text { Parking Institute, 2010) } \\
\text { LED Lamp Wattages: DOE’s CALiPER Program Reports (DOE } \\
\text { CALiPER Program (a), 2010) }\end{array}$ \\
\hline $\begin{array}{l}\text { Lighting Technology } \\
\text { Mix }\end{array}$ & $\begin{array}{l}\text { Lamp Mix: International Parking Institute Survey (International } \\
\text { Parking Institute, 2010) }\end{array}$ \\
\hline
\end{tabular}

\subsubsection{Parking Lighting Installed Base}

The installed base of parking lights is very sensitive to the total number of parking spaces. There is no commonly accepted number of total U.S. off-street parking spaces and often cited estimates range from 105 million to 2 billion. In this analysis, a middle ground value of 505 million total spaces was used, as determined from a recent University of California study, and based on the authors' estimates of square foot of commercial space and a workspace for each vehicle (Chester, et al, 2010). The number of parking spaces includes 395 million surface lot spaces (non -single family residential) and 110 million garage spaces. It is assumed that all of these spaces are lighted.

The inventory of parking lights in the U.S. was determined using typical design values of 3 and 20 parking spaces per luminaire for garage and lot lighting, respectively, as provided by Walker Parking Consultants (Monahan, 2010). The technology mix of lamps was based on the IPI member survey. The total number of lamps by application and technology type are depicted in Table 3.6. 
Table 3.6 - Parking Light Installed Base

\begin{tabular}{|l|l|c|c|}
\hline \multirow{4}{*}{ Application } & \multicolumn{1}{|c|}{ Lamp Type } & Percentage & $\begin{array}{c}\text { Number of Lights } \\
\text { (000's) }\end{array}$ \\
\hline \multirow{5}{*}{ Garage Lighting } & Incandescent & $1.6 \%$ & 600 \\
\cline { 2 - 4 } & Halogen & $2.2 \%$ & 800 \\
\cline { 2 - 4 } & Fluorescent & $45.9 \%$ & 16,600 \\
\cline { 2 - 4 } & Induction & $7.4 \%$ & 2,700 \\
\cline { 2 - 4 } & Mercury Vapor & $0.1 \%$ & 44 \\
\cline { 2 - 4 } & High Pressure Sodium & $23.2 \%$ & 8,500 \\
\cline { 2 - 4 } & Metal Halide & $15.3 \%$ & 5,600 \\
\cline { 2 - 4 } & LED & $4.1 \%$ & 1,500 \\
\cline { 2 - 4 } & Total & $\mathbf{1 0 0 \%}$ & $\mathbf{3 6 , 4 0 0}$ \\
\hline \multirow{5}{*}{ Lot Lighting } & Incandescent & $2.6 \%$ & 400 \\
\cline { 2 - 4 } & Halogen & $0.1 \%$ & 16 \\
\cline { 2 - 4 } & Mercury Vapor & $2.4 \%$ & 400 \\
\cline { 2 - 4 } & High Pressure Sodium & $36.0 \%$ & 5,700 \\
\cline { 2 - 4 } & Metal Halide & $54.2 \%$ & 700 \\
\cline { 2 - 4 } & LED & $4.6 \%$ & $\mathbf{1 5 , 8 0 0}$ \\
\cline { 2 - 4 } & Total & $\mathbf{1 0 0 \%}$ & \\
\hline
\end{tabular}

\subsubsection{Parking Lighting Operating Hours}

As operating hours directly affect a lamp's lifetime, maintenance and parking professionals have made a concerted effort to limit operating hours. Sensor technologies are gaining attention for their ability to provide light only when and where it is needed. Currently, 60\% of IPI members utilize some form of a sensor technology (International Parking Institute, 2010). Based on the IPI survey, 13 hours per day or 4,745 hours per year, and 18 hours per day or 6,570 hours per year are used for the parking lot and garage lamps, respectively.

\subsubsection{Parking Lighting Average Wattages}

The average system wattages were developed from the IPI member survey. Because parking garage lamps and parking lot lamps are dissimilar in their spacing, mounting heights, and illumination requirements, they have dissimilar wattages. As a result, garage system wattages are significantly lower than lot system wattages.

The equivalent LED replacement lamp wattages were determined by matching the lumen output of the conventional system with that of a hypothetical replacement LED system. Best-in-class reported efficacies of products tested by the DOE's CALiPER program and the Gateway demonstration program were used to create the replacement LED systems. To determine the conventional system's lumen output the typical ballast input power, lamp efficacy, and fixture efficiency was drawn from manufacturer catalogues. The average system wattages used in this analysis are provided in Table 3.7. 
Table 3.7 - System Wattage of Parking Lights

\begin{tabular}{|l|l|c|c|}
\hline \multirow{4}{*}{ Application } & \multicolumn{1}{|c|}{ Lamp Type } & $\begin{array}{c}\text { Average System } \\
\text { Wattage (W) }\end{array}$ & $\begin{array}{c}\text { 2010 LED } \\
\text { Replacement } \\
\text { Wattage (W) }\end{array}$ \\
\hline \multirow{5}{*}{ Garage Lighting } & Incandescent & 86 & 18 \\
\cline { 2 - 4 } & Halogen & 107 & 27 \\
\cline { 2 - 4 } & Fluorescent & 82 & 68 \\
\cline { 2 - 4 } & Induction & 106 & 68 \\
\cline { 2 - 4 } & Mercury Vapor & 185 & 71 \\
\cline { 2 - 4 } & $\begin{array}{l}\text { High Pressure } \\
\text { Sodium }\end{array}$ & 183 & 138 \\
\cline { 2 - 4 } & Metal Halide & 152 & 91 \\
\cline { 2 - 4 } & LED & 54 & n/a \\
\hline \multirow{5}{*}{ Lot Lighting } & Incandescent & 150 & 22 \\
\cline { 2 - 4 } & Halogen & 150 & 26 \\
\cline { 2 - 4 } & Mercury Vapor & 421 & 119 \\
\cline { 2 - 4 } & High Pressure & 340 & 245 \\
\hline & Sodium & 307 & 199 \\
\cline { 2 - 4 } & Metal Halide & 72 & n/a \\
\cline { 2 - 4 } & LED & & \\
\hline
\end{tabular}

\subsubsection{Parking Lighting Energy Savings Potential}

Table 3.8 depicts the total energy consumption of the parking lighting sector as well as the potential energy savings if the entire U.S. installed base was converted overnight to LED lamps. Compared to the baseline savings of 1.4 TWh per year in 2010, a total potential electricity savings of 16.9 TWh per year would be realized if LEDs achieved 100\% market penetration. This equates to an annual primary energy savings of approximately 0.18 quads, or the total annual electricity consumption of over 1 million residential households.

Table 3.8 - Energy Consumption and Savings Potential of Parking Lights

\begin{tabular}{|l|c|c|c|c|}
\hline $\begin{array}{l}\text { Niche } \\
\text { Application }\end{array}$ & $\begin{array}{c}\text { Annual } \\
\text { Electricity } \\
\text { Consumption in } \\
\mathbf{2 0 1 0}(\mathbf{T W h} / \mathbf{y r})\end{array}$ & $\begin{array}{c}\text { Electricity } \\
\text { Savings in } \\
\mathbf{2 0 1 0}(\mathbf{T W h} / \mathbf{y r})\end{array}$ & $\begin{array}{c}\text { Additional } \\
\text { Potential } \\
\text { Electricity } \\
\text { Savings (TWh/yr) }\end{array}$ & $\begin{array}{c}\text { Total Potential } \\
\text { Electricity } \\
\text { Savings } \\
\text { (TWh/yr) }\end{array}$ \\
\hline Garage Lighting & 28.1 & 0.6 & 7.7 & 8.3 \\
\hline Lot Lighting & 23.0 & 0.8 & 7.8 & 8.6 \\
\hline
\end{tabular}

The past version of this report noted that there were no LED installations in parking applications in 2007 (Navigant Consulting, Inc (a), 2008). Thus, the entirety of the 2010 electricity savings reported above are due to LED retrofits and new installations from the past two years. Garage 
lighting has led the transition to LEDs in the parking sector, with some garage lighting manufacturers noting that nearly $30 \%$ of current sales are LEDs.

\subsection{Area and Flood Lighting}

Area and flood lighting is the largest outdoor sector in this analysis. These lights illuminate various outdoor areas such as landscapes, walkways, and common spaces. Area and flood lights that are used in parking and roadway applications were excluded from this analysis so that they were not counted twice in this report. All of the key sources used for the four critical inputs to the analysis are summarized in Table 3.9.

\section{Table 3.9 - Key Sources for the Area and Flood Lighting Analysis}

\begin{tabular}{|l|l|}
\hline Critical Input & Key Sources \\
\hline Lamstalled Base of & $\begin{array}{l}\text { Lighting Fixture Shipments: U.S. Census Bureau, Electric Light } \\
\text { Fixture Current Industrial Reports (U.S. Census Bureau (b), 2010) } \\
\text { Fixture Lifetime: Municipal Solid-State Street and Area Lighting } \\
\text { Consortium Survey (DOE (e), 2010) }\end{array}$ \\
\hline $\begin{array}{l}\text { Annual Operating } \\
\text { Hours }\end{array}$ & $\begin{array}{l}\text { Energy Savings Estimates of Light Emitting Diodes in Niche Lighting } \\
\text { Applications (Navigant Consulting, Inc (a), 2008) }\end{array}$ \\
\hline Lamp Wattages & $\begin{array}{l}\text { Area and Flood Lighting Wattages: U.S. Lighting Market } \\
\text { Characterization - Volume 1: National Lighting Inventory and Energy } \\
\text { Consumption Estimate (Navigant Consulting, Inc (b), 2002), NEMA } \\
\text { HID Lamp Survey (NEMA (d), 2004), Sylvania, GE and Philips lamp } \\
\text { catalog data } \\
\text { LED Lamp Wattages: DOE’s CALiPER Program Reports (DOE } \\
\text { CALiPER Program (a), 2010) }\end{array}$ \\
\hline $\begin{array}{l}\text { Lighting Technology } \\
\text { Mix }\end{array}$ & $\begin{array}{l}\text { Technology Mix: U.S. Lighting Market Characterization - Volume 1: } \\
\text { National Lighting Inventory and Energy Consumption Estimate }\end{array}$ \\
\hline
\end{tabular}

\subsubsection{Area and Flood Lighting Installed Base}

The installed base of area and flood lights in 2010 was approximately 118 million lamps, which includes 63.5 million area lamps and 54.5 million flood lighting lamps. ${ }^{20}$ The installed stock for area and flood lights was estimated using annual fixture shipment data from the U.S. Census Bureau for 1971 to 2001. ${ }^{21}$ After 2001, the U.S. Census Bureau discontinued tracking these fixtures, so fixture shipments for 2002 to 2010 were projected forward using a linear trend. The estimated installed stock assumes a typical lifetime of approximately 20 years for area and flood

\footnotetext{
${ }^{20}$ Parking lot luminaires are categorized as area fixtures in the Census Bureau's shipments. The lamps determined to be in this sector from the analysis in Section 3.2 were deducted from the total installed base for the Area and Flood Lighting sector, so that they were not counted twice.

${ }^{21}$ The U.S. Census Bureau did not distinguish between flood and area luminaires for non-HID technologies. For simplicity, this analysis considered half of these technologies to be flood lighting subsector and half to be in the area lighting subsector.
} 
lighting luminaires. The technology mix of area and flood lights was estimated from the 2002 U.S. Lighting Market Characterization report in conjunction with recent manufacturer reported sales trends. The total number of lamps by application and technology type are depicted in Table 3.10 .

Table 3.10 - Area and Flood Lighting Installed Base

\begin{tabular}{|c|c|c|c|}
\hline Application & Lamp Tуре & Percentage & $\begin{array}{c}\text { Number of Lamps } \\
\text { (000's) }\end{array}$ \\
\hline \multirow[t]{9}{*}{ Area Lighting } & Incandescent & $2.3 \%$ & 1,200 \\
\hline & Halogen & $19.0 \%$ & 8,600 \\
\hline & Fluorescent & $5.8 \%$ & 3,600 \\
\hline & Induction & $0.3 \%$ & 200 \\
\hline & Mercury Vapor & $12.7 \%$ & 6,700 \\
\hline & High Pressure Sodium & $22.1 \%$ & 10,700 \\
\hline & Metal Halide & $36.9 \%$ & 18,900 \\
\hline & LED & $0.9 \%$ & 600 \\
\hline & Total & $100 \%$ & 50,400 \\
\hline \multirow[t]{9}{*}{ Flood Lighting } & Incandescent & $3.6 \%$ & 1,600 \\
\hline & Halogen & $18.6 \%$ & 8,000 \\
\hline & Compact Fluorescent & $0.2 \%$ & 74 \\
\hline & Fluorescent & $7.9 \%$ & 3,400 \\
\hline & Mercury Vapor & $8.4 \%$ & 3,600 \\
\hline & High Pressure Sodium & $21.4 \%$ & 9,200 \\
\hline & Metal Halide & $39.7 \%$ & 17,100 \\
\hline & LED & $0.2 \%$ & 74 \\
\hline & Total & $100 \%$ & 43,200 \\
\hline
\end{tabular}

\subsubsection{Area and Flood Lighting Operating Hours}

It is assumed that the typical outdoor area and flood lamp is run throughout the night, for 12 hours per day, amounting to 4,380 hours per year (Navigant Consulting, Inc (a), 2008).

\subsubsection{Area and Flood Lighting Average Wattages}

The average system wattages for the installed base of area and flood lights were developed from the NEMA HID lamp survey data from 2004. As the market has changed significantly since this survey was conducted, this data was augmented with more recent manufacturer sales data.

The equivalent LED replacement lamp wattages were determined by matching the lumen output of the conventional system with that of a hypothetical replacement LED system. Best-in-class reported efficacies of products tested by the DOE's CALiPER program and the Gateway demonstration program were used to create the replacement LED systems. To determine the conventional system's lumen output the typical ballast input power, lamp efficacy, and fixture 
efficiency was drawn from manufacturer catalogues. The average system wattages used in this analysis are provided in Table 3.11 .

Table 3.11 -Wattages of Area and Flood Lights

\begin{tabular}{|l|l|c|c|}
\hline \multirow{4}{*}{ Application } & \multicolumn{1}{|c|}{ Lamp Type } & $\begin{array}{c}\text { Average System } \\
\text { Wattage (W) }\end{array}$ & $\begin{array}{c}\text { 2010 LED } \\
\text { Replacement } \\
\text { Wattage (W) }\end{array}$ \\
\hline \multirow{5}{*}{ Area Lighting } & Incandescent & 202 & 23 \\
\cline { 2 - 4 } & Halogen & 150 & 26 \\
\cline { 2 - 4 } & Fluorescent & 160 & 61 \\
\cline { 2 - 4 } & Induction & 287 & 178 \\
\cline { 2 - 4 } & Mercury Vapor & 254 & 69 \\
\cline { 2 - 4 } & High Pressure Sodium & 285 & 183 \\
\cline { 2 - 4 } & Metal Halide & 451 & 255 \\
\cline { 2 - 4 } & LED & 67 & n/a \\
\hline \multirow{5}{*}{ Flood Lighting } & Incandescent & 202 & 23 \\
\cline { 2 - 4 } & Halogen & 150 & 26 \\
\cline { 2 - 4 } & Compact Fluorescent & 53 & 36 \\
\cline { 2 - 4 } & Fluorescent & 159 & 61 \\
\cline { 2 - 4 } & Mercury Vapor & 254 & 69 \\
\cline { 2 - 4 } & High Pressure Sodium & 294 & 194 \\
\cline { 2 - 4 } & Metal Halide & 460 & 264 \\
\cline { 2 - 4 } & LED & 67 & $\mathrm{n} / \mathrm{a}$ \\
\hline
\end{tabular}

\subsubsection{Area and Flood Lighting Energy Savings Potential}

Table 3.12 depicts the total energy consumption of area and flood lights in the United States as well as the potential energy savings if the entire installed stock was converted overnight to LED lamps. Compared to the baseline savings of 0.71 TWh per year in 2010, a potential electricity savings of 63.1 TWh per year would be realized if LEDs achieved 100\% market penetration. This equates to a primary energy savings of approximately 0.69 quads per year, or the total annual electricity consumption of over 5 million residential households.

Table 3.12 - Energy Consumption and Savings Potential of Area and Flood Lights

\begin{tabular}{|l|c|c|c|c|}
\hline $\begin{array}{l}\text { Niche } \\
\text { Application }\end{array}$ & $\begin{array}{c}\text { Annual } \\
\text { Electricity } \\
\text { Consumption in } \\
\mathbf{2 0 1 0}(\mathbf{T W h} / \mathbf{y r})\end{array}$ & $\begin{array}{c}\text { Electricity } \\
\text { Savings in 2010 } \\
\mathbf{( T W h / y r )}\end{array}$ & $\begin{array}{c}\text { Additional } \\
\text { Potential } \\
\text { Electricity } \\
\text { Savings } \\
\text { (TWh/yr) }\end{array}$ & $\begin{array}{c}\text { Total Potential } \\
\text { Electricity } \\
\text { Savings } \\
\text { (TWh/yr) }\end{array}$ \\
\hline Area Lighting & 67.3 & 0.63 & 33.2 & 33.9 \\
\hline Flood Lighting & 60.0 & 0.08 & 29.1 & 29.2 \\
\hline
\end{tabular}




\subsection{Residential Outdoor Lighting}

In this analysis, residential outdoor lighting is defined as lighting designed to illuminate walkways, steps, driveways, porches, decks, or the landscape areas of a residential single-family housing unit. As previously indicated, many of the applications evaluated in the general illumination section of this report include lamps used in residential outdoor applications. However, due to significant interest in the impact of LEDs on the residential outdoor lighting market, the analysis below describes the estimated electricity savings from the use of LED luminaires in these applications. The key sources used for the four critical inputs to the analysis are summarized in Table 3.13.

\section{Table 3.13 - Key Sources for the Residential Outdoor Lighting Analysis}

\begin{tabular}{|c|c|}
\hline Critical Input & Key Sources \\
\hline $\begin{array}{l}\text { Installed Base of } \\
\text { Lamps }\end{array}$ & $\begin{array}{l}\text { Total Number of Occupied U.S. Households: American Housing } \\
\text { Survey (U.S. Census Bureau (a), 2010) } \\
\text { Percent of Households with Outdoor Lighting: California Statewide } \\
\text { Residential Appliance Saturation Study (RLW Analytics Inc. (a), 2000) } \\
\text { (RLW Analytics, Inc. (d), 2005), Single Family Residential New } \\
\text { Construction Characteristics and Practices Study (RLW Analytics Inc. } \\
\text { (c), 2007), Single Family Residential Existing Construction Stock } \\
\text { Assessment (RLW Analytics Inc. (b), 2007) }\end{array}$ \\
\hline $\begin{array}{l}\text { Annual Operating } \\
\text { Hours }\end{array}$ & $\begin{array}{l}\text { NSTAR Residential High Use Program Operating Hours Realization } \\
\text { Rate Study (Xenergy Inc., 2003) }\end{array}$ \\
\hline Lamp Wattages & $\begin{array}{l}\text { Incumbent Lamp Wattages: Single Family Residential New } \\
\text { Construction Characteristics and Practices Study (RLW Analytics Inc. } \\
\text { (c), 2007), Single Family Residential Existing Construction Stock } \\
\text { Assessment (RLW Analytics Inc. (b), 2007) } \\
\text { LED Replacement Wattages: DOE CALiPER Program and Catalog } \\
\text { Product Listings (DOE CALiPER Program (a), 2010) }\end{array}$ \\
\hline $\begin{array}{l}\text { Lighting Technology } \\
\text { Mix }\end{array}$ & $\begin{array}{l}\text { Outdoor Household Lamp Technology Mix: California Statewide } \\
\text { Residential Appliance Saturation Study (RLW Analytics Inc. (a), 2000) } \\
\text { (RLW Analytics, Inc. (d), 2005), Single Family Residential New } \\
\text { Construction Characteristics and Practices Study (RLW Analytics Inc. } \\
\text { (c), 2007), Single Family Residential Existing Construction Stock } \\
\text { Assessment (RLW Analytics Inc. (b), 2007) }\end{array}$ \\
\hline
\end{tabular}

\subsubsection{Residential Outdoor Lighting Installed Base}

The U.S. installed base of residential outdoor lighting was estimated using data from four recent residential lighting studies conducted in California and the Pacific Northwest. These studies included lamp inventory data for outdoor and porch applications for 2000, 2005, and 2007. The 2010 installed stock was extrapolated from this data assuming a constant growth rate over time. 
LED lamps were not included in these studies, and it is assumed that the 2010 penetration of LEDs in residential outdoor lighting is negligible.

Using the studies described above, an installed base per residence was derived. It was assumed that this value is indicative of the entire United States. The U.S. Census Bureau's American Housing Survey provided the total number of single-family homes in the United States. The resulting installed stock is shown in Table 3.14.

Table 3.14 - Residential Outdoor Lighting Installed Base

\begin{tabular}{|l|c|c|}
\hline Lamp Type & Percentage & $\begin{array}{c}\text { Number of Lamps } \\
\text { (000's) }\end{array}$ \\
\hline Compact Fluorescent & $12.1 \%$ & 46,000 \\
\hline Halogen Standard & $10.6 \%$ & 40,300 \\
\hline Halogen Quartz Tube & $2.4 \%$ & 9,200 \\
\hline Incandescent & $75.2 \%$ & 286,500 \\
\hline Total & $\mathbf{1 0 0 \%}$ & $\mathbf{3 8 2 , 0 0 0}$ \\
\hline
\end{tabular}

\subsubsection{Residential Outdoor Lighting Operating Hours}

The NSTAR, Residential High Use Program Operating Hours Realization Rate Study was used to estimate the operating hours for outdoor residential lighting in the United States. The study metered 59 homes during the months of May through August in 2002, and incorporated data from previous long term metering studies to develop annual operating hours for outdoor residential lighting. This study indicates that lighting for this application operates approximately 4.5 hours a day, or 1,620 hours per year (Xenergy Inc., 2003).

\subsubsection{Residential Outdoor Lighting Average Wattages}

The data from a survey of new and existing residential studies was used to characterize the power consumption of each outdoor lighting technology (RLW Analytics, Inc., 2007a and 2007b). This analysis assumes that the average outdoor power consumption for each lamp technology, as determined by these two surveys, is representative of the entire U.S. residential outdoor lighting installed stock. The general lamp types considered in this analysis include compact fluorescent, halogen standard, halogen quartz tube, and incandescent. ${ }^{22}$

The equivalent LED replacement lamp wattages were determined by matching the lumen output of the conventional system with that of a hypothetical replacement LED system. Best-in-class

\footnotetext{
${ }^{22}$ Halogen Quartz Tube is categorized outside of Halogen Standard because its average power consumption is significantly higher than the other halogen lamps documented in the two surveys. In addition, since fluorescent lamps only represent $2 \%$ of all outdoor residential installed stock, they are included in the Compact Fluorescent category. HID lamps were represented in the housing surveys, but they represented an insignificant proportion of outdoor lamps.
} 
reported efficacies of products tested by the DOE's CALiPER program and the Gateway demonstration program were used to create the replacement LED systems. The CALiPER results indicate that LED residential outdoor replacement lamps are capable of efficacies as high as $66 \mathrm{~lm} / \mathrm{W}$ compared to incandescent lamps which have efficacies of approximately 10 to 15 $\mathrm{lm} / \mathrm{W}$. Table 3.15 below details the average power consumption for the installed technologies and the resulting replacement LED lamp power consumptions.

Table 3.15 - Wattages of Residential Outdoor Lights

\begin{tabular}{|l|c|c|}
\hline Lamp Type & $\begin{array}{c}\text { Average System } \\
\text { Wattage (W) }\end{array}$ & $\begin{array}{c}\text { 2010 LED Replacement } \\
\text { Wattage (W) }\end{array}$ \\
\hline Compact Fluorescent & 17 & 8 \\
\hline Halogen Standard & 86 & 19 \\
\hline Halogen Quartz Tube & 180 & 46 \\
\hline Incandescent & 67 & 10 \\
\hline
\end{tabular}

\subsubsection{Residential Outdoor Lighting Energy Savings Potential}

Table 3.16 depicts the total energy consumption of outdoor residential lights in the United States as well as the potential energy savings if the entire installed stock was converted overnight to LED lamps. Compared to the negligible baseline energy savings in 2010, a potential electricity savings of 30.3 TWh per year would be realized if LEDs achieved 100\% market penetration. This equates to a primary energy savings of approximately 0.33 quads per year, or the total annual electricity consumption of nearly two and a half a million residential households.

Table 3.16 - Energy Consumption and Savings Potential of Residential Outdoor Lights

\begin{tabular}{|l|c|c|c|c|}
\hline Niche Application & $\begin{array}{c}\text { Annual } \\
\text { Electricity } \\
\text { Consumption in } \\
\mathbf{2 0 1 0} \text { (TWh/yr) }\end{array}$ & $\begin{array}{c}\text { Electricity } \\
\text { Savings in } \\
\mathbf{2 0 1 0} \\
\mathbf{( T W h / y r )}\end{array}$ & $\begin{array}{c}\text { Additional } \\
\text { Potential } \\
\text { Electricity } \\
\text { Savings } \\
\text { (TWh/yr) }\end{array}$ & $\begin{array}{c}\text { Total Potential } \\
\text { Electricity } \\
\text { Savings } \\
\text { (TWh/yr) }\end{array}$ \\
\hline $\begin{array}{l}\text { Residential } \\
\text { Outdoor }\end{array}$ & 37.7 & 0 & 30.3 & 30.3 \\
\hline
\end{tabular}




\section{Consumer Electronic Displays}

DOE's SSL Program is committed to accelerating the development and market growth of solidstate lighting sources, such as LEDs, for general illumination. The scope of DOE's SSL Program does not include consumer electronics; however, by supporting domestic research, development, demonstration and commercialization activities related to SSL DOE, also has a direct impact on advancement of LEDs in non-general illumination applications. In 2009, approximately 55\% of the high-brightness (HB) LED market was comprised of electronic devices such as mobile phones, laptops, and portable media players, and displays including monitors and televisions (Bhandarkar, 2010). Therefore, due to the prevalence and success of LEDs in consumer electronics, the electricity savings from LED backlighting in televisions, laptops, monitors and mobile handsets are investigated in the following sections.

LED backlighting works by emitting light onto an electronic liquid crystal display (LCD). The display then modifies the light passing through each pixel to create the desired image. This is contrary to a true LED display, such as a digital billboard, where the image is directly produced by the LEDs. In consumer electronics, the LED is typically located behind the display, thus the term "backlighting," and can span the entire area of the display or simply the perimeter of the display.

As was found in this analysis, LED backlit displays are more energy efficient than conventional technologies. This is largely because the light transmission efficiency of conventional LCD panels is typically not greater than $5-14 \%$ with up to $86-95 \%$ of the light produced by the backlight structure being converted into heat across the LCD panel. LED backlit LCDs have a much improved light transmission efficiency, and with the future development of high efficiency RGB Field Sequential Backlighting, inefficient color filters can be eliminated from LED backlit designs significantly increasing their energy savings (Lazarev, 2009).

This analysis considers multiple display technologies, some that utilize backlighting techniques and some where the illumination component is incorporated into the actual display. The display technologies considered are briefly described below:

- Cathode Ray Tube (CRT) - The CRT is a cathodoluminescent display where light is generated by exciting a luminescent material with energetic electrons. CRT is the oldest display technology still in use today.

- Digital Light Processing ${ }^{\circledR}$ (DLP) - DLP is rear projection technology that relies on a light source and an array of mirrors to produce an image on the screen. Traditionally, the light source is a high-pressure metal halide arc lamp; however, LEDs and LASERs are also being used (Texas Instruments, 2009).

- Plasma - Plasma displays utilize a gas discharge in each pixel. The discharge generates a local ultraviolet emission, which activates a phosphor emitting a red, green, or blue light 
which creates an image when all of the pixels are combined. Only the pixels that are activated draw power from the system.

- Liquid Crystal Display (LCD) - LCDs operate by applying a varying electric voltage to a layer of liquid crystal, thereby changing its optical properties. A backlight behind the LCD generates the light and can either be a cold cathode fluorescent lamp (CCFL), LED or OLED. What is typically referred to today as an LED or OLED display, is in actuality an LED or OLED backlit LCD display.

As consumer electronics have become more prevalent nationwide and are used more hours per day, power management of these devices has become extremely important. The Environmental Protection Agency's (EPA) ENERGY STAR ${ }^{\circledR}$ program is a labeling initiative that recognizes the top energy performing products available on the market in order to aid consumers when purchasing. The ENERGY STAR ${ }^{\circledR}$ program is continually increasing its efficiency standards, placing LED backlit televisions, laptops, monitors and mobile handsets at an advantage due to their potential for electricity savings beyond that of conventional backlighting technologies.

LEDs have reached significant penetration levels in televisions, laptop, monitor and mobile handset consumer electronics applications not solely because of their capacity for electricity savings. The additional non-energy benefits are as follows:

- Solid state lighting displays in consumer electronic devices offer long lifetimes, upwards of 50,000 hours.

- LED-based displays offer better contrast and improved color gamut. In the case of local dimming configuration, a contrast of 2,000,000:1 can be achieved. LEDs allow for local dimming control over groups of pixels. Unlike a conventional CCFL backlight, where pixels are either on or off and the illumination level is constant, each LED pixel in local dimming mode can be individually dimmed to generate higher contrast, better images, and power savings.

- LEDs do not produce heat in the form of infrared radiation, although they do produce heat at the semiconductor junction within the device. The absence of infrared radiation allows LED fixtures to be positioned in locations where heating from conventional sources is problematic. This allows for greater ease in integrating LEDs with consumer electronic devices compared to other backlighting technologies.

- LEDs are very small and thin, having dimensions of less than 2 by 2 millimeters. As a result, LEDs offer compact, flexible and mechanically robust designs which present a tremendous range of application for consumer electronics. In particular, mobile handsets have taken advantage of this benefit with the vast majority of models incorporating either LED or OLED backlighting technology; and LED backlit televisions are recognized for their remarkably slim design, with Samsung introducing a model that is only 6.5 millimeter thick during the 2010 Consumer Electronics Show (Nystedt, 2010). 
- As a byproduct of its high-efficiency, LED backlighting places a smaller burden on the battery, and thus, allows a longer battery life of portable consumer electronic devices.

- LEDs use low driving voltage (typically $3.5 \mathrm{~V}$, compared to hundreds for CCFLs). This makes it much easier to make the complementary components of the electronic device, such as drivers and controllers.

- LEDs have a very fast response to controls. This allows for LED backlit displays to have an improved display response time and results in crisper images when motion levels are high.

\subsection{Television Displays}

This analysis considers the most prevalent television display technologies which include CRT, DLP, Plasma and LCD. ${ }^{23}$ Televisions are some of the greatest energy consumers of all personal electronic devices, and their energy consumption has grown significantly due to increasing television use and ownership, as well as the increasing adoption of more sophisticated television display technologies at larger screen sizes (Chian Myau Soon, 2007).

The rising awareness of televisions' excessive energy consumption has led to the creation of both labeling programs and efficiency regulations. In California, televisions now consume $10 \%$ of all residential electricity use. Therefore, the California Energy Commission has passed energy efficiency standards for new televisions measuring 58 inches (1,400 square inches) and smaller with the standards going into effect beginning in 2011. This California efficiency standard, places LED backlit TVs at an advantage due to their potential for electricity savings beyond that of conventional backlighting technologies.

In 2009, global LED television sales comprised 3.6 million units, about $2 \%$ of the total market (DisplaySearch (a), 2010). In 2010 this value jumped, with LED televisions comprising nearly $15 \%$ of sales. OLED televisions entered the commercial market in 2007 , and in the first quarter of 2010 approximately 100,000 units were sold worldwide. This represents a negligible portion of the global television market, and therefore this technology is not considered in the analysis (DisplaySearch (b)).

The following analysis describes the estimated energy savings from the increased use of LED backlit LCD televisions. The key sources used for the four critical inputs to the analysis are summarized in Table 4.1.

\footnotetext{
${ }^{23}$ For a brief description of each display technology see Section 0.
} 
Table 4.1 - Key Sources for the Television Displays Analysis

\begin{tabular}{|l|l|}
\hline Critical Input & Key Sources \\
\hline Installed Base of & No. of Residential Televisions: U.S. Census Bureau \\
& No. of Commercial Televisions: Commercial Miscellaneous Electric \\
Loads (TIAX LLC(a), 2010) & Televisions per household: Energy Consumption of Consumer \\
& Electronics in U.S. Residences (TIAX LLC(b), 2007)
\end{tabular}

\subsubsection{Television Display Installed Base}

Based on the 2010 U.S. Census Bureau's estimate for the total number of households and approximation of 2.3 total televisions per household, the total number of residential televisions was determined to be approximately 299 million in 2010. TIAX estimates that there are 16 million televisions are installed in commercial buildings in the United States. This results in a total 2010 installed base of approximately 315 million total televisions.

The California Appliance Energy Efficiency Rulemaking for Televisions provided the technology breakdown of televisions in California in 2008, which was assumed to be representative of the entire U.S. This breakdown did not include LED backlit televisions, since they represented a negligible percentage of the market until 2009. Therefore, using market penetration rates of LED backlit televisions and total U.S. television shipment data, both provided by iSuppli, an installed base for 2010 was modeled. Table 4.2 summarizes the installed stock characterization for televisions. 
Table 4.2 - Television Installed Base by Display Technology ${ }^{24}$

\begin{tabular}{|l|r|r|r|r|}
\hline \multirow{2}{*}{ Display Technology } & \multirow{3}{*}{ Percentage } & \multicolumn{3}{|c|}{ Number of Televisions (000's) } \\
\cline { 3 - 5 } & & Residential & \multicolumn{1}{c|}{ Commercial } & \multicolumn{1}{c|}{ Total } \\
\hline Cathode Ray Tube & $60.9 \%$ & 182,100 & 9,800 & 191,900 \\
\hline Digital Light Processing & $2.0 \%$ & 6,000 & 300 & 6,300 \\
\hline Plasma & $5.1 \%$ & 15,200 & 800 & 16,100 \\
\hline LCD - CCFL & $29.9 \%$ & 89,400 & 4,800 & 94,100 \\
\hline LCD - LED & $2.1 \%$ & 6,200 & 300 & 6,500 \\
\hline Total & $\mathbf{1 0 0 \%}$ & $\mathbf{2 9 8 , 8 0 0}$ & $\mathbf{1 6 , 0 0 0}$ & $\mathbf{3 1 4 , 8 0 0}$ \\
\hline
\end{tabular}

\subsubsection{Television Display Operating Hours}

Televisions typically have three functionality modes: on, standby and off. During the standby and off modes the display illumination function is inactive, and thus all further analysis only considers the on-mode.

Data from TIAX indicates that residential televisions are in the on-mode for approximately 4.5 hours per day, or 1,642 hours per year. In commercial buildings, television usage varies considerably depending on the type of building. For example, televisions in food service buildings (e.g., restaurants and bars) are in the on-mode during all hours the building is open, while televisions usage in lodging mimics the residential sector, and is significantly less. For this analysis, televisions in commercial establishments are assumed to operate in the on-mode for 8 hours per day, or 2,920 hours per year.

\subsubsection{Television Display Average Wattages}

The power consumed by a television in the on-mode is a factor of five components: display, interfacing (the connection between the television cable and the television), processing, storage, and sound (Hans-Paul Siderius, 2007).

The power consumption of the non-display components is fairly consistent, ranging from 18 to $29 \mathrm{~W}$, depending on the sophistication of the picture being processed and the capabilities of the television. In order to determine the power consumption of display function, the total television power consumption was first determined, and then the average power consumption for the remaining components, $23.5 \mathrm{~W}$, was subtracted from this value.

The typical power consumption for each television type was derived from a database of 562 units that was developed using television specifications provided by CNET, EPA, and the Natural Resources Defense Council. Figure 4.1 below illustrates the distribution of display power

\footnotetext{
${ }^{24}$ Values in the table may not add up due to rounding.
} 
consumption for the technologies considered. The final database includes 56 CRT, 55 DLP, 329 CCFL, 35 LED, and 87 plasma televisions from a variety of manufacturers.

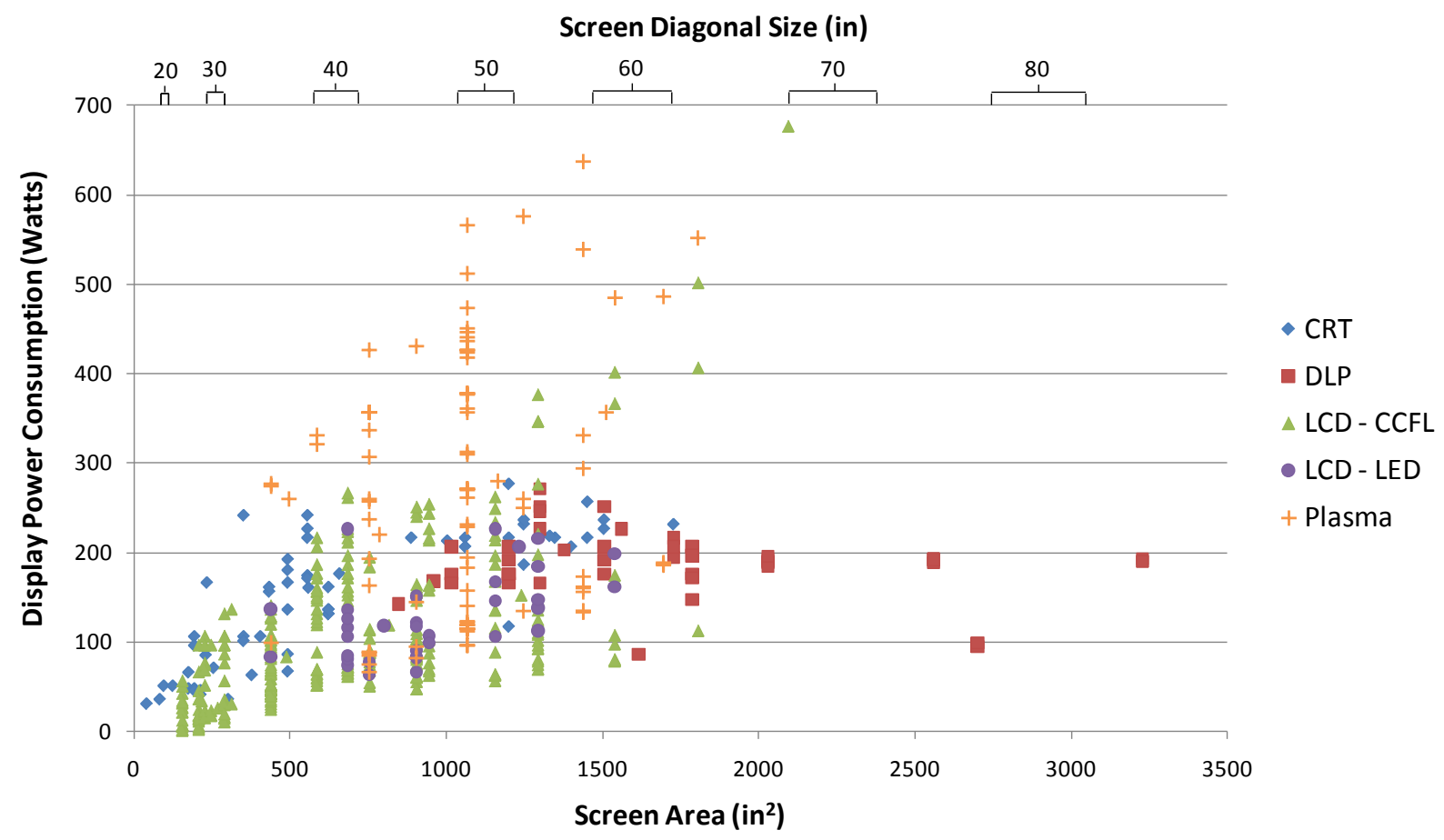

\section{Figure 4.1 - Display Power Consumption for the Different Screen Sizes and Technologies}

As indicated by Figure 4.1, the display power consumption is highly dependent on the screen size for all television technologies except DLP. As would be expected, an increase in the size of the television screen typically requires a higher powered lamp, all else remaining the same. DLP televisions do not follow this pattern as they are projection televisions, so a larger image is accomplished through altering the mechanics and optics of the projection technology rather than increasing the light output.

The average installed screen size in the U.S. differs greatly across the different television technologies. For example, most CRTs are small ${ }^{25}$ since the technology is bulky, while plasma televisions are rarely produced at sizes below a 30" screen diagonal as it is not cost effective. The average screen area for each television is shown below in Table 4.3 along with the average power consumption from the display.

\footnotetext{
${ }^{25}$ Within the sample database, 70\% of the CRTs are less than 40 ”, while only $50 \%$ of LCD - CCFL, 9\% of LCD LED, 7\% Plasma and none of the DLP are less than this diagonal size.
} 
Table 4.3 -Wattage of the Television Display ${ }^{26}$

\begin{tabular}{|c|c|c|c|c|}
\hline Display Technology & $\begin{array}{l}\text { Average Screen } \\
\text { Diagonal (in) }^{27}\end{array}$ & $\begin{array}{l}\text { Average } \\
\text { Screen Area } \\
\left(\text { in }^{2}\right)^{28}\end{array}$ & $\begin{array}{c}\text { Average } \\
\text { Display } \\
\text { Wattage (W) }\end{array}$ & $\begin{array}{c}\text { Display Power } \\
\text { Density } \\
\left(\mathrm{W} / \mathrm{in}^{2}\right)^{*}\end{array}$ \\
\hline Cathode Ray Tube & 30 & 430 & 130 & 0.29 \\
\hline $\begin{array}{l}\text { Digital Light } \\
\text { Processing }\end{array}$ & 54 & 1,400 & 190 & - \\
\hline LCD - CCFL & 36 & 550 & 83 & 0.15 \\
\hline LCD - LED & 40 & 680 & 85 & 0.13 \\
\hline Plasma & 48 & 980 & 260 & 0.27 \\
\hline
\end{tabular}

* Calculating display power density is unnecessary for DLP televisions since display power consumption does not vary with screen size.

The display power density, presented in Table 4.3, provides a comparison metric for the backlighting energy use among the different technologies. The metric is determined by normalizing the backlighting power consumption of each individual television unit in the database based on its corresponding screen area. As can be seen, LED televisions have the lowest display power density of $0.13 \mathrm{~W} / \mathrm{in}^{2}$, signifying that they are the most efficient backlighting option, however CCFL television are a close second at $0.15 \mathrm{~W} / \mathrm{in}^{2}$.

\subsubsection{Television Display Energy Savings Potential}

An estimate of the total television display electricity consumption was developed using the installed stock, operating hours and display wattages described in the previous sections.

Assuming that the installed stock of LED backlit televisions replaced CRT televisions, in 2010 the U.S. has already achieved an energy consumption reduction of 0.41 TWh per year.

In the additional savings potential analysis, the LED televisions were sized based on the average size of each television technology they replaced. For example, LED televisions that replaced plasma televisions, which have an average screen size of 48 inches, also had an average screen size of 48 inches. Using this replacement assumption, if LED backlighting replaced all other technologies a potential electricity savings of $18 \mathrm{TWh}$ could be realized per year. This equates to a primary energy savings of approximately 0.20 quads per year, or the total annual electric consumption of over one million residential households. The results of the estimated total television display electricity consumption are shown below in Table 4.4.

\footnotetext{
${ }^{26}$ The Average Display Illumination Wattages shown in Table 4.3 do not represent the total power consumption of each television display technology, and only convey the wattage associated with the image illumination function.

27 The average screen diagonal for CRT, LCD - CCFL, and Plasma was determined from the 2009 California, TV Appliance Energy Efficiency Rulemaking, (California Energy Commission, 2009). For DLP it was determined from 2006 TIAX, Energy Consumption by Consumer Electronics in U.S. Residences, (TIAX LLC(b), 2007), and LCD LED was determined by a weighted average of the 133 LED TVs reviewed through CNET.

${ }^{28}$ Average screen area was determined by considering the aspect ratio used for the different technologies, this is assumed to be 4:3 for CRT and DLP (since these represent technologies designed for standard TV image formats) and 16:9 for LCD - CCFL, LCD - LED, and plasma (designed for wide-screen TV image formats).
} 
Table 4.4 - Energy Consumption and Savings Potential of Television Displays

\begin{tabular}{|l|c|c|c|c|}
\hline $\begin{array}{l}\text { Niche } \\
\text { Application }\end{array}$ & $\begin{array}{c}\text { Electricity } \\
\text { Consumption in } \\
\mathbf{2 0 1 0} \mathbf{( T W h} / \mathbf{y r})\end{array}$ & $\begin{array}{c}\text { Electricity } \\
\text { Savings in 2010 } \\
\text { (TWh/yr) }\end{array}$ & $\begin{array}{c}\text { Potential } \\
\text { Electricity Savings } \\
\text { (TWh/yr) }\end{array}$ & $\begin{array}{c}\text { Total Potential } \\
\text { Electricity } \\
\text { Savings } \\
\text { (TWh/yr) }\end{array}$ \\
\hline $\begin{array}{l}\text { Television } \\
\text { Displays }\end{array}$ & 64.7 & 0.4 & 17.6 & 18.0 \\
\hline
\end{tabular}

It should be noted that this is a theoretical analysis and there are multiple limitations to its applicability. This analysis examines replacing solely the display technology within a television, but in reality this is not feasible. The display component is integrated into the whole television design and displays are not interchangeable. For example, plasma televisions are designed specifically for the gas discharge illumination, and an LED would not be compatible with its internal design. Additionally, this analysis defines the electricity savings in 2010 as the difference between the installed LED television's energy consumption and the replaced CRT display's energy consumption. Based on the display power density, CRTs are the most inefficient display technology. As the market naturally moves away from this antiquated technology, energy will be saved no matter the display technology chosen as replacement (though LEDs are the most efficient option).

Furthermore, most consumers tend to replace their old CRT televisions with one that has a larger screen area. Due to the significance of this trend towards larger screen areas, the television manufacturer Sharp Electronics predicts that the average screen diagonal could approach 60 inches by 2015 compared to 46 inches in 2010 (Sharp Electronics Corporation, 2009). Since energy consumption of a television is function of the viewing area, less energy is saved when consumers purchase LED televisions with larger screen areas. Thus the 2010 electricity savings is likely overstated.

\subsection{Desktop Monitor Displays}

A monitor is a stand-alone device used most commonly as the display component of a desktop computer. For the displays, monitors commonly utilize CRT or LCD technologies, with CCFL and LED being the two backlighting options for LCD. Currently, the desktop monitor market is dominated by CCFL backlighting technologies. However, LEDs compare favorably and have the potential to offer even further improvements to luminance, power efficiency, color gamut and product lifetime.

The first LED-backlit monitor was introduced in 2006; however, due to the high cost and performance bottlenecks, the market did not begin to grow in earnest until 2008 (Steele, 2010). In 2008, total shipments of desktop monitor LED backlit panels totaled only 8,000 units, and in early 2009 all major monitor manufacturers announced that all of their new model lines would use LED backlights (LEDs Magazine (c), 2010). This push enabled the global shipments of 
desktop monitors with LED backlit panels to reach over 1.3 million units in 2009, representing nearly one percent of all LCD monitor panels shipped (DisplaySearch (c), 2010). Due to LEDbacklights energy efficient nature, the market penetration is expected to increase greatly with the ENERGYSTAR 5.0 specifications, effective July 1, 2009 for monitor appliances. In addition, OLED backlit monitors are commercially available, but are not considered in this analysis due to the limited product availability and the lack of existing data on the market penetration.

The following analysis describes the estimated electricity savings from the use of LED backlit desktop monitors. The key sources used for the four critical inputs to the analysis are summarized in Table 4.5 .

Table 4.5 - Key Sources for the Desktop Monitor Display Analysis

\begin{tabular}{|l|l|}
\hline Critical Input & Key Sources \\
\hline Installed Base of & $\begin{array}{l}\text { No. of Residential Monitors: U.S. Census Bureau Survey, Energy } \\
\text { Consumption of Consumer Electronics in U.S. Residences (TIAX } \\
\text { LLC(b), 2007) } \\
\text { No. of Commercial Monitors: Commercial Miscellaneous Electric } \\
\text { Loads (TIAX LLC(a), 2010), After-hours power status of office } \\
\text { equipment in the USA (Webber, et al, 2006) }\end{array}$ \\
\hline $\begin{array}{l}\text { Annual Operating } \\
\text { Hours }\end{array}$ & $\begin{array}{l}\text { Commerical Monitor Operating Hours: After-hours power status of } \\
\text { office equipment in the USA (Webber, et al, 2006) } \\
\text { Residential Monitor Operating Hours: Energy Consumption of } \\
\text { Consumer Electronics in U.S. Residences (TIAX LLC(b), 2007) }\end{array}$ \\
\hline Display Wattages & $\begin{array}{l}\text { Wattage of Non-Backlighting Monitor Components: An Energy } \\
\text { Efficiency Index for Televisions (Hans-Paul Siderius, 2007) } \\
\text { Wattage for Desktop Monitors: CNET and ENERGY STAR } ® \text { Product } \\
\text { Lists }\end{array}$ \\
\hline $\begin{array}{l}\text { Display Technology } \\
\text { Mix }\end{array}$ & $\begin{array}{l}\text { Monitor Technology Mix: Commercial Miscellaneous Electric Loads } \\
\text { (TIAX LLC(a), 2010) } \\
\text { LED Monitor Shipments: LCDs Face LED Backlight Supply Shortage } \\
\text { as Shipments More than Double in 2010 (iSuppli (a), 2010) }\end{array}$ \\
\hline
\end{tabular}

\subsubsection{Desktop Monitor Display Installed Base}

The total number of desktop monitors is assumed to be equivalent to the installed stock of desktop computers. The U.S. Census Bureau's Current Population Survey indicates that, approximately 120 million PCs were used in households. Additionally, TIAX reports that roughly 150 million PCs are used in commercial buildings. In the residential sector $70 \%$ of all household PCs were classified as desktops, while in the commercial sector this value was approximately 35\%. Furthermore, it is assumed that approximately 10 million office laptops also utilize external monitors. According to these values the total installed base of desktops was found to be 147 million, 84 million in households and 63 million the commercial sector. 
TIAX indicates that the installed stock of desktop monitors consists of about $40 \% 17$ inch CRT, 15\% 15 inch LCD - CCFL, 35\% 17 inch LCD - CCFL and 10\% 19 inch LCD - CCFL. Based on shipment data, it is estimated that LED backlit monitors reached a market penetration of $1.7 \%$ in 2010. The total number of lamps by application and technology type are depicted in Table 4.6.

Table 4.6 - Desktop Monitor Display Installed Base ${ }^{29}$

\begin{tabular}{|l|c|c|}
\hline Monitor Type & Percentage & $\begin{array}{c}\text { Number of Desktop Monitor } \\
\text { Displays (000's) }\end{array}$ \\
\hline LCD - CCFL - 15 in & $15.0 \%$ & 22,000 \\
\hline LCD - CCFL - 17 in & $35.0 \%$ & 51,400 \\
\hline LCD - CCFL - 19 in & $10.0 \%$ & 14,700 \\
\hline CRT - 17 in & $38.3 \%^{30}$ & 56,300 \\
\hline LED - 17 in & $1.7 \%$ & 2,500 \\
\hline Total & $\mathbf{1 0 0 \%}$ & $\mathbf{1 4 6 , 9 0 0}$ \\
\hline
\end{tabular}

\subsubsection{Desktop Monitor Display Operating Hours}

Monitors are typically considered to have three functionality modes: on, sleep, and off. During the sleep and off modes the monitor backlighting display is inactive, and since this analysis estimates the electricity consumption due to the monitor backlighting, all further analysis only considers the on-mode.

To estimate the average amount of time that a desktop monitor is in on-mode, this analysis separated desktop monitors into two different usage categories: residential and commercial. This distinction is made because the hours of operation for each vary significantly. Data from TIAX was used to determine the residential monitor operating hours, while Lawrence Berkeley National Laboratory provided estimates for commercial monitors. Table 4.7 below summarizes these results.

\section{Table 4.7 - Total Installed Monitors by Usage Category and Operating Hours}

\begin{tabular}{|l|c|c|}
\hline $\begin{array}{l}\text { Monitor Usage } \\
\text { Category }\end{array}$ & $\begin{array}{c}\text { Units } \\
\text { (000's) }\end{array}$ & $\begin{array}{c}\text { Operating } \\
\text { hours } \\
\text { (hrs/yr) }\end{array}$ \\
\hline Residential & 84,400 & 1,870 \\
\hline Commercial & 62,500 & 2,870 \\
\hline
\end{tabular}

\footnotetext{
${ }^{29}$ Values in the table may not add up due to rounding.

${ }^{30}$ It is assumed that currently all LED backlit monitors are replacing CRT monitors; therefore, the total number of CRT monitors is reduced from approximately $40 \%$ of the total installed stock, to $38 \%$.
} 


\subsubsection{Desktop Monitor Display Average Wattages}

As compared to televisions, desktop monitors are far simpler devices. On average, only $3 \mathrm{~W}$ are allocated to monitor functions other than the image display. The non-display energy consumption is assumed to be constant for all monitor technologies and screen sizes. To determine the energy consumption of the monitor display, or the light-emitting technology, these $3 \mathrm{~W}$ are subtracted from the total power consumption of the device.

A database of 379 units on the market in 2010 was developed to determine the typical electricity consumption of each monitor type. The final database includes 50 CRT, 224 CCFL, and 105 LED desktop monitors from a variety of manufacturers. ${ }^{31}$

The power consumption of the display is directly related to the screen size for all monitor technologies. The sample set was normalized based on screen size to create a power density that allows for a standard measure of comparison. Though monitors are available in a variety screen sizes, the majority of installed desktop monitors have a 17 inch diagonal. Table 4.8 indicates the power consumption of the three most popular types of monitors. LED desktop monitors represent the most energy efficient option, with the lowest power density, at $0.11 \mathrm{~W} / \mathrm{in}^{2}$, as well as the lowest average display power consumption, at $13 \mathrm{~W}$.

\section{Table 4.8 -Wattage of Desktop Monitor Displays}

\begin{tabular}{|l|c|c|c|c|}
\hline $\begin{array}{l}\text { Desktop } \\
\text { Monitor } \\
\text { Technology }\end{array}$ & $\begin{array}{c}\text { Average Screen } \\
\text { Diagonal (in) }\end{array}$ & $\begin{array}{c}\text { Average } \\
\text { Screen Area } \\
\text { (in }^{\mathbf{2}}\end{array}$ & $\begin{array}{c}\text { Average } \\
\text { Display } \\
\text { Wattage (W) }\end{array}$ & $\begin{array}{c}\text { Display Power } \\
\text { Density (W/in }\end{array}$ \\
\hline CRT & 17 & 141 & 93 & 0.68 \\
\hline LCD - CCFL & 17 & 141 & 16 & 0.13 \\
\hline LCD - LED & 17 & 141 & 13 & 0.11 \\
\hline
\end{tabular}

\subsubsection{Desktop Monitor Display Energy Savings Potential}

Table 4.9 depicts the total energy consumption for the 147 million monitor displays in the United States, as well as the potential energy savings if the entire stock was converted overnight to containing LED backlights. In 2010, about 1.7\% of the national installed base of monitor displays utilizes LED backlit technology, and assuming they are replaced CRT monitors, this has resulted in an electricity savings of about 0.47 TWh. An additional electricity savings of 11.6 TWh is achievable if LED backlights reached $100 \%$ market penetration. This equates to a primary energy savings of approximately 0.13 quads per year, or the total annual electric consumption of nearly one million residential households.

\footnotetext{
31 The final monitor database utilizes monitor specification data provided by CNET and ENERGYSTAR. These databases were accessed in July, 2010.

${ }^{32}$ The average screen diagonal for CRT, and LCD - CCFL are determined from TIAX LLC, 2006. The average installed screen diagonal for LCD - LED monitors is unknown, so it is assumed to be 17 inches.
} 
Table 4.9 - Energy Consumption and Savings Potential of Monitor Displays in 2010

\begin{tabular}{|l|c|c|c|c|}
\hline $\begin{array}{l}\text { Niche } \\
\text { Application }\end{array}$ & $\begin{array}{c}\text { Electricity } \\
\text { Consumption in } \\
\mathbf{2 0 1 0}(\mathbf{T W h} / \mathbf{y r})\end{array}$ & $\begin{array}{c}\text { Electricity } \\
\text { Savings in 2010 } \\
\mathbf{( T W h / y r )}\end{array}$ & $\begin{array}{c}\text { Potential } \\
\text { Electricity } \\
\text { Savings } \\
\mathbf{( T W h / y r )}\end{array}$ & $\begin{array}{c}\text { Total Potential } \\
\text { Electricity } \\
\text { Savings } \\
\text { (TWh/yr) }\end{array}$ \\
\hline $\begin{array}{l}\text { Monitor } \\
\text { Displays }\end{array}$ & 15.2 & 0.47 & 11.1 & 11.6 \\
\hline
\end{tabular}

\subsection{Laptop Displays}

A laptop is a portable computer with a LCD screen that uses either a CCFL or LED for backlighting. In this analysis, laptops include both notebook and netbook PCs which are smaller and have limited operating capabilities.

When laptops were first introduced, CCFL backlighting was the only practical option. This remained the case until 2007 when Sony developed the first LED backlit laptop (Elliott, 2007). LED-backlighting offers significant benefits such as reduced power consumption, brighter images, better contrast, and longer battery life as well as thinner and lighter designs, and they are being actively pursued by laptop manufacturers. For instance, Apple adopted LED backlighting for all its laptops starting in 2008. The total industry market penetration has rapidly grown from about 3.5\% of total laptop shipments in 2007 to over 50\% in 2009 and is expected to reach $100 \%$ by 2012 (DisplaySearch (d), 2010). This growth has been greatly supported by the increasing popularity of ultra-portable netbooks PCs, which solely use LED backlighting technology in order to meet their low-cost, lightweight and small screen diagonal specifications (less than 10.2 inches). The key sources used for the four critical inputs to the analysis are summarized in Table 4.10. 
Table 4.10 - Key Sources for the Laptop Display Analysis

\begin{tabular}{|l|l|}
\hline Critical Input & Key Sources \\
\hline $\begin{array}{l}\text { Installed Base of } \\
\text { Displays }\end{array}$ & $\begin{array}{l}\text { No. of Residential Laptops: U.S. Census Bureau Survey, Energy } \\
\text { Consumption of Consumer Electronics in U.S. Residences (TIAX } \\
\text { LLC(b), 2007) } \\
\text { No. of Commercial Laptops: Commercial Miscellaneous Electric Loads } \\
\text { (TIAX LLC(a), 2010), After-hours power status of office equipment in } \\
\text { the USA (Webber, et al, 2006) }\end{array}$ \\
\hline $\begin{array}{l}\text { Annual Operating } \\
\text { Hours }\end{array}$ & $\begin{array}{l}\text { ENERGY STAR Computer Specification (EPA ENERGY STAR (b), } \\
\text { 2005) }\end{array}$ \\
\hline Display Wattages & ENERGY STAR® Product Lists \\
\hline $\begin{array}{l}\text { Display Technology } \\
\text { Mix }\end{array}$ & $\begin{array}{l}\text { LED Laptop Shipments: Consumer Portable PCs Limit Volume } \\
\text { Decline, But Shipment Value Suffers, According to IDC (IDC, 2009) } \\
\text { LED Market Penetration Rate: Key Component Shortages Limiting } \\
\text { Growth of LED Backlight Units for LCD TV (DisplaySearch (d), 2010) }\end{array}$ \\
\hline
\end{tabular}

\subsubsection{Laptop Display Installed Base}

The national inventory of laptop displays was estimated from previous estimates of the installed base of personal computers developed by TIAX, LLC, for the commercial buildings sector, and the U.S. Census Bureau, for the residential sector. According to these sources, the total installed base of personal computers, which includes both laptops and desktops, was approximately 270 million units. In the residential sector $30 \%$ of all household PCs were classified as laptops, while in the commercial sector this value was far greater, approximately 65\%. According to these values the total installed base of laptops was found to be 134 million.

In order to determine the penetration of LED backlit laptops, PC and laptop shipment data from 2007 to 2010 was used in conjunction with annual LED backlit laptop market penetration rates. The total number of lamps by application and technology type are depicted in Table 4.11.

Table 4.11 - Laptop Display Installed Base ${ }^{33}$

\begin{tabular}{|l|c|c|c|c|}
\hline $\begin{array}{l}\text { Display } \\
\text { Technology }\end{array}$ & Percentage & $\begin{array}{c}\text { Total Laptop } \\
\text { Displays } \\
\text { (000's) }\end{array}$ & $\begin{array}{c}\text { Residential } \\
\text { Laptop } \\
\text { Displays } \\
\text { (000's) }\end{array}$ & $\begin{array}{c}\text { Commercial } \\
\text { Laptop } \\
\text { Displays } \\
\text { (000's) }\end{array}$ \\
\hline LED & $40.5 \%$ & 54,100 & 14,700 & 39,500 \\
\hline CCFL & $59.5 \%$ & 79,500 & 21,500 & 58,000 \\
\hline Total & $\mathbf{1 0 0 \%}$ & $\mathbf{1 3 3 , 7 0 0}$ & 36,200 & $\mathbf{9 7 , 5 0 0}$ \\
\hline
\end{tabular}

\footnotetext{
${ }^{33}$ Values in the table may not add up due to rounding.
} 


\subsubsection{Laptop Display Operating Hours}

Monitors are typically considered to have four operational modes: active, idle, sleep, and off. The laptop display consumes negligible amounts of electricity during the sleep and off modes, and therefore they were not considered in this analysis. Active and idle modes are defined by the EPA as the following:

- Active mode represents a state when the computer is undertaking some intensive computing operation, such as opening a program, downloading e-mail, manipulating a graphic, finding a web-site, saving a file, or searching a directory (EPA ENERGY STAR $\left.{ }^{\circledR}(b), 2005\right)$.

- Idle state accounts for any situation where time is being logged in "System Idle Process" under the Windows Task Manager, or where there is no hard drive activity and CPU utilization is less that $10 \%$. A typical example of this scenario is when a user is viewing a document on the computer screen (not making changes) with no email or data transfer occurring (EPA ENERGY STAR® (b), 2005).

Data provided by the EPA was used to determine the household and office laptop operating hours. The Table 4.12 below summarizes these results.

\section{Table 4.12 - Total Installed Laptops by Usage Category and the Operating Hours}

\begin{tabular}{|l|c|c|}
\hline \multirow{2}{*}{$\begin{array}{l}\text { Laptop Usage } \\
\text { Category }\end{array}$} & \multicolumn{2}{|c|}{ Operating hours (hrs/yr) } \\
\cline { 2 - 3 } & Active Mode & Idle Mode \\
\hline Residential & 507 & 2,930 \\
\hline Commercial & 250 & 5,890 \\
\hline
\end{tabular}

\subsubsection{Laptop Display Average Wattages}

The power consumption of a laptop varies depending on its operational mode in addition to the subsystems that are engaged in those modes, such as the central processing unit, the graphics card, and backlight, among others. During active mode, with a high brightness setting, a CCFL backlight consumes about $20 \%$ of the total power input. While in idle mode, when fewer subsystems are utilized, it consumes about 30\%. It should be noted that reducing the brightness setting can have a large impact on the backlighting energy use; however, for simplicity and ease of comparison between technologies, this analysis only examines electricity consumption of laptop displays with a high brightness setting.

A database of 92 units was developed using the ENERGY STAR ${ }^{\circledR}$ product test data for laptop PCs. ${ }^{34}$ It is important to note that the ENERGY STAR ${ }^{\circledR}$ database biases the analysis towards

\footnotetext{
${ }^{34}$ The final monitor database utilizes laptop specification data provided for ENERGYSTAR ${ }^{\circledR}$ qualified products. This database was accessed in July, 2010.
} 
energy efficient products, and therefore, these low power consuming laptops are not a perfectly representative sample of the installed stock. The final database includes 41 CCFL, and 51 LED backlit display laptops from a variety of manufacturers.

Interestingly, the database revealed that an LED backlit laptop is likely to consume more energy than a CCFL backlit laptop of comparable size. This is likely because CCFL backlighting is more commonly used in economy laptops which run at a lower system operating power. LED backlighting is more prevalent in high-end, or "executive”, laptops which often run at a higher system operating power (Chian Myau Soon, 2007). In other words, the power consumption for non-display components in an LED backlit laptop is greater than that in a CCFL backlit laptop. As laptop displays function much like monitor displays, the backlighting power consumption in LED laptops was determined by assuming that the difference in power density for CCFL and LED desktop monitors (see Table 4.8) was equivalent to the difference in CCFL and LED backlit laptops.

In addition, the backlighting power consumption is highly dependent on the screen size and there is a wide range of screen areas for available products. Based on an assessment of the bestselling laptop screen sizes from a variety of retailers, it was found that the average screen diagonal for a CCFL backlit laptop is approximately 15.6 inches and 14.1 inches for LED. ${ }^{35}$ Although these screen sizes characterize the currently sold products, it is assumed they are representative of the screen sizes for the U.S. installed stock of laptops. The average screen size for an LED backlit laptop is smaller as it has saturated the market for screen sizes less than 10.1 inches (LEDs Magazine (b), 2009). The average screen areas are shown below in Table 4.13, along with the display power densities and average backlighting power consumption for each laptop display option.

Table 4.13 -Wattage of Laptop Displays

\begin{tabular}{|c|c|c|c|c|c|c|}
\hline \multirow{2}{*}{$\begin{array}{l}\text { Display } \\
\text { Technology }\end{array}$} & \multirow{2}{*}{$\begin{array}{c}\text { Average } \\
\text { Screen } \\
\text { Diagonal (in) }\end{array}$} & \multirow{2}{*}{$\begin{array}{l}\text { Average } \\
\text { Screen } \\
\text { Area } \\
\left(\text { in }^{2}\right)\end{array}$} & \multicolumn{2}{|c|}{$\begin{array}{c}\text { Average Display } \\
\text { Wattage (W) }\end{array}$} & \multicolumn{2}{|c|}{$\begin{array}{c}\text { Display Power Density } \\
\left(\mathrm{W} / \mathrm{in}^{2}\right)\end{array}$} \\
\hline & & & $\begin{array}{l}\text { Active } \\
\text { Mode }\end{array}$ & $\begin{array}{l}\text { Idle } \\
\text { Mode }\end{array}$ & $\begin{array}{l}\text { Active } \\
\text { Mode }\end{array}$ & $\begin{array}{l}\text { Idle } \\
\text { Mode }\end{array}$ \\
\hline CCFL & 15.6 & 104 & 7.8 & 4.2 & 0.075 & 0.041 \\
\hline LED & 14.1 & 84 & 5.1 & 2.8 & 0.060 & 0.032 \\
\hline
\end{tabular}

The display power density, shown in Table 4.13, is a metric used to normalize the backlighting power consumption of each unit based on its screen area. LED laptop backlights have a smaller power density during active mode and idle mode, resulting in an average LED power consumption for both modes that is less than the incumbent CCFL backlighting technology.

\footnotetext{
${ }^{35}$ The top five bestselling laptops for each backlighting technology were taken from BestBuy.com, $\underline{\text { Amazon.com, }}$

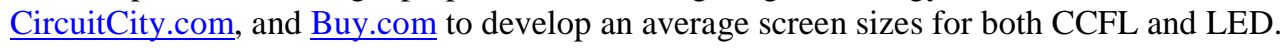




\subsubsection{Laptop Display Energy Savings Potential}

Table 4.14 depicts the total energy consumption of laptop displays, as well as the potential energy savings if the entire stock was converted overnight to LED backlit laptops. The estimated 2010 electricity consumption for the backlighting the 134 million laptop displays in the United States was 2.75 TWh. About $41 \%$ of the national installed base of laptop displays utilized LED backlighting technology, saving an estimated 0.45 TWh of electricity in 2010. Unlike the television market segments where consumers are moving towards larger screen areas, the laptop market is moving towards smaller more portable displays. To account for this market trend, it was assumed that 14.1 inch LED laptops are replacing 15.6 inch CCFL backlit laptops. This assumption results in an additional electricity savings of 0.66 TWh if LED backlights reached $100 \%$ market penetration, which is partially due to the smaller screen size of the replacement laptops. This equates to a primary energy savings of approximately 0.01 quads per year, or the total annual electric consumption of nearly ninety thousand residential households.

Table 4.14 - Energy Consumption and Savings Potential of Laptop Displays

\begin{tabular}{|l|c|c|c|c|}
\hline $\begin{array}{l}\text { Niche } \\
\text { Application }\end{array}$ & $\begin{array}{c}\text { Electricity } \\
\text { Consumption in } \\
\mathbf{2 0 1 0} \text { (TWh/yr) }\end{array}$ & $\begin{array}{c}\text { Electricity } \\
\text { Savings in 2010 } \\
\text { (TWh/yr) }\end{array}$ & $\begin{array}{c}\text { Potential } \\
\text { Electricity } \\
\text { Savings } \\
\text { (TWh/yr) }\end{array}$ & $\begin{array}{c}\text { Total Potential } \\
\text { Electricity Savings } \\
\text { (TWh/yr) }\end{array}$ \\
\hline $\begin{array}{l}\text { Laptop } \\
\text { Displays }\end{array}$ & 2.75 & 0.45 & 0.66 & 1.11 \\
\hline
\end{tabular}

\subsection{Mobile Handset Displays}

LEDs in mobile phones are used for backlighting full-color LCD screens, backlighting keypads, and for other functions such as multicolor ringer lights and flash lamps for camera phones (Bhandarkar, 2010). Mobile phones are the largest market segment for HB LEDs, and constituted approximately $40 \%$ of all HB LED sales in 2009. The rapid adoption of LEDs in mobile phone backlighting is due to low power consumption, thinner form factors, and superior display color and contrast. And in 2008 these combined factors resulted in a 93\% market adoption of LED backlit mobile phones (SEMI, 2010). Therefore, due to the dominant market position of LEDs in mobile phone displays, this application is not considered in the analysis. 


\section{Conclusion}

In the last few years, LEDs have emerged as a competitive lighting technology, capturing market share in several niche applications from incandescent, halogen, high intensity discharge, and certain types of fluorescent light sources. Although LED light sources have higher upfront costs, this is offset by reduced electricity and maintenance cost over the lamp's lifetime. For example, the DOE's Gateway demonstration at the InterContinental Hotel in San Francisco involved replacing 237 halogen lamps with LED MR16 and PAR30 lamps, saving the hotel approximately $\$ 20,700$ over three years. This lifetime cost savings was achieved despite the fact that the LED MR16 and PAR30 lamps cost nearly eight times more than the conventional halogen lamps they replaced (DOE (d), 2010). Substitutions like these are taking place, without subsidies or coupon schemes, because LEDs can make financial sense and have the ability to offer customers a better quality, more reliable lighting service.

The niche applications evaluated in this report cut across general illumination and outdoor white light installations, as well as consumer electronics. For the baseline year of 2010, it was found that in all three niche sectors LED lamps are being used and replacing conventional lighting technologies. For general illumination applications, approximately $0.11 \mathrm{TWh}$ of electricity were saved in 2010 because of the LED PAR, BR and R shaped lamps that have replaced incandescent and halogen technologies. LED MR16 lamps have saved even more electricity, approximately 0.25 TWh per year, since the flexible form factor and inherent directionality of LEDs give them distinct advantages in this type of lighting application. Energy savings have also been realized through LED 2-ft by 2-ft troffer fixtures and A-type replacements, each saving approximately 0.005 and 0.015 TWh per year respectively. Indoor general illumination applications have the greatest potential of all the applications studied in this report to save substantial amounts of energy. If these four general illumination applications switched entirely to LEDs, a potential of 133 TWh per year of electricity could be saved, equivalent to the annual electricity consumption of over ten million typical U.S. households.

For outdoor white light installations, LED products are available in all sectors examined: parking facilities, roadway lighting, area and flood lighting, as well as lighting outside residences. LEDs are particularly advantageous in outdoor lighting applications because their inherent characteristics well address many of the key issues associated with outdoor lighting. LEDs offer extremely long lifetimes, are directional light sources, and thus able to limit light pollution and light trespass, are highly efficacious, function well in cold temperatures, are not affected by vibration, and are able to provide a high quality light. In 2010, approximately $0.058 \mathrm{TWh}$ of electricity were saved because of the installation of LED street and highway lamps that have replaced incumbent technologies. LED parking lot and garage lamps have saved more electricity than any outdoor application, approximately 1.4 TWh per year. Energy savings have also been 
realized through area and flood lighting replacements, which combined save approximately 0.71 TWh per year. Outdoor residential is the only market application with a negligible LED penetration and energy savings for 2010. If the four outdoor white light applications switched entirely to LEDs, a potential of 131 TWh per year of electricity could be saved, equivalent to the annual electricity consumption of over 10 million typical U.S. households.

LED backlighting is the most energy efficient of all backlighting technologies available, and in consumer electronics, LED backlighting has reached significant penetration levels in televisions, laptop, monitor and mobile handset applications. Due to the assumption LED desktop monitors are replacing conventional cathode ray tube monitors; this application has resulted in the greatest electricity savings of all consumer electronics application, approximately 0.47 TWh per year. Laptop LED backlighting has also contributed to significant energy reductions with nearly 0.45 TWh being saved in 2010. Lastly, energy savings have also been realized through the adoption of LED backlit televisions, saving approximately 0.41 TWh per year. If the consumer electronics market switched entirely to LED backlighting, a total of 30.7 TWh per year of electricity savings would be realized, equal to the annual electricity consumption of about two and a half million households.

Figure 5.1 presents the baseline energy savings in 2010 from the ten niche applications considered in this analysis where LEDs have some level of market penetration. The outdoor residential market has an assumed market penetration of $0 \%$, due to the lack of significant market adoption as of 2010, while the 2010 energy savings for mobile handsets was determined inconsequential since LED backlighting has reached near full saturation. 


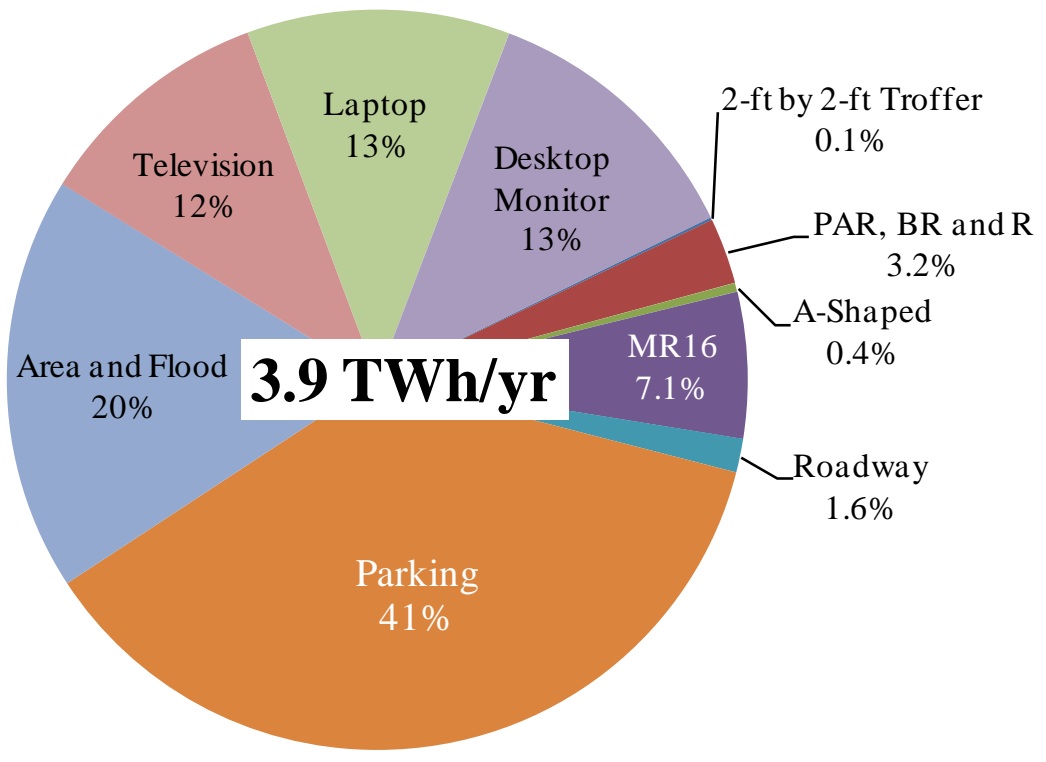

Figure 5.1 - Site Electricity Savings in 2010 Attributable to LED Market Penetration

It is clear that LEDs in parking lot and garage applications have resulted in the greatest energy savings in 2010, providing approximately $41 \%$ of the total realized electricity savings. Within this sector LED penetration has reached about $4.3 \%$ of the total installed base. Interestingly the penetration of LEDs into parking applications does not represent the greatest adoption rate. After mobile handsets where LED penetration is essentially 100\%, LED backlit laptops now represent approximately $41 \%$ of the total laptop installed base. However, significantly greater energy savings are realized by switching from incumbent parking lighting technologies (such as high pressure sodium) to LEDs, compared to laptop applications where LEDs are competing with efficient cold cathode fluorescent backlighting.

The second most significant energy saving niche market in 2010 was area and flood lighting, which contributed to $20 \%$ of the total site electricity savings in 2010, and has an LED penetration of about $0.72 \%$. Again, LED penetration into laptop, television and desktop monitor backlighting are all much greater, however, within these applications LEDs are competing against more efficient technologies and have achieved high levels of penetration due to the numerous additional benefits LEDs provide. LED backlighting in desktop monitors, laptops, and televisions, as well as LED MR16 lamps also demonstrated significant energy savings together representing $45 \%$ of the total 2010 savings. Other sectors such as 2 -ft by 2 -ft troffer fixtures and 
A-type replacement lamps have low levels of LED penetration, and thus contribute less than one percent to the 2010 savings.

Table 5.1 summarizes the 2010 energy savings in detail, both on-site electricity consumption and primary energy consumption. The outdoor residential sector was the only application to have an estimate of 0\% LED penetration in 2010, thus it contributes no savings to the total of $3.9 \mathrm{TWh}$. Energy savings estimates are also not provided for mobile handsets because within this sector the analysis determined that LED backlighting is the dominate technology and is not competing to replace incumbent technologies.

Table 5.1 - Energy Consumption and Saving in 2010 of Application Evaluated

\begin{tabular}{|c|c|c|c|c|}
\hline Application & $\begin{array}{c}\text { Annual } \\
\text { Electricity } \\
\text { Consumption } \\
\text { (TWh) }\end{array}$ & $\begin{array}{c}\text { LED } \\
\text { Market } \\
\text { Penetration }\end{array}$ & $\begin{array}{c}\text { Electricity } \\
\text { Savings } 2010 \\
\text { (TWh) }\end{array}$ & $\begin{array}{c}\text { Primary Energy } \\
\text { Savings } 2010 \\
\text { (TBtu) }\end{array}$ \\
\hline \multicolumn{5}{|c|}{ General Illumination Replacements } \\
\hline 2-ft by 2-ft Troffer & 12 & $0.10 \%$ & 0.005 & 0.1 \\
\hline PAR, BR and R Shaped & 45 & $0.20 \%$ & 0.113 & 1.2 \\
\hline MR16 & 11.2 & $1.67 \%$ & 0.25 & 2.7 \\
\hline A-Type & 118.7 & $0.01 \%$ & 0.015 & 0.16 \\
\hline \multicolumn{5}{|c|}{ Outdoor White Light Applications } \\
\hline Roadway & 52.8 & $0.01 \%$ & 0.058 & 0.6 \\
\hline Parking & 51.1 & $4.30 \%$ & 1.44 & 15.7 \\
\hline Area and Flood & 127.3 & $0.70 \%$ & 0.71 & 7.7 \\
\hline Residential Outdoor & 37.7 & $0.00 \%$ & 0 & 0.0 \\
\hline \multicolumn{5}{|c|}{ Consumer Electronics Applications } \\
\hline Television & 64.7 & $2.10 \%$ & 0.41 & 4.5 \\
\hline Laptop & 2.75 & $41.00 \%$ & 0.45 & 4.9 \\
\hline Desktop Monitor & 15.2 & $1.70 \%$ & 0.47 & 5.1 \\
\hline Total $^{36}$ & $500.8 \mathrm{TWh}$ & - & $3.9 \mathrm{TWh}$ & 42.7 TBtu \\
\hline
\end{tabular}

The next figure, Figure 5.2, apportions the electricity savings if these twelve niche markets convert entirely to LED technology. This total represents the combined 2010 energy savings and potential energy savings if the remainder of each market converts to LED luminaires or backlighting.

\footnotetext{
${ }^{36}$ These energy savings totals do not include the Outdoor Residential applications values since it has significant overlap with the General Illumination applications.
} 


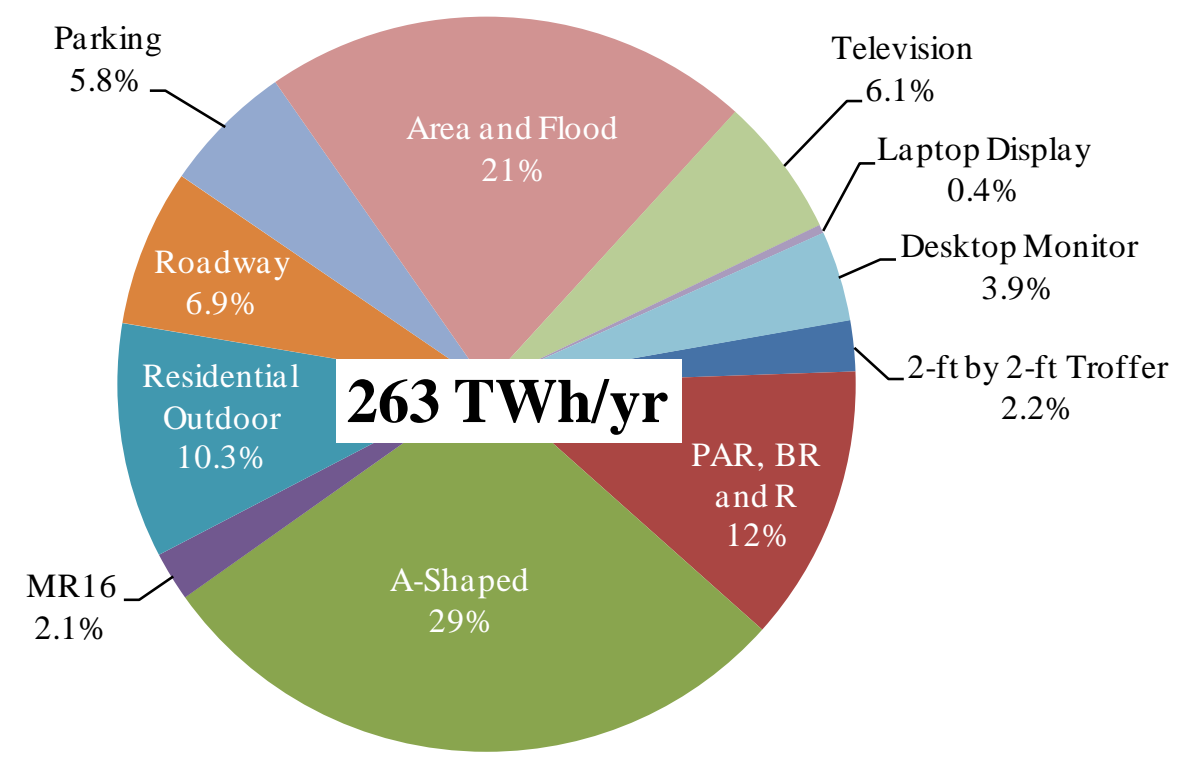

Figure 5.2 - Maximum Site Electricity Savings With 100\% LED Market Penetration ${ }^{37}$

Table 5.2 presents the energy savings potential from converting the remainder of each market entirely to LEDs. It also presents the cumulative energy savings that results from the energy savings in 2010 combined with the technical potential energy savings. There are significant opportunities for energy savings across the niche markets analyzed within the general illumination, outdoor white light and consumer electronics sectors. A total of 133 TWh per year of potential site electricity savings are available in the PAR, BR and R shaped, MR16, 2-ft by 2ft fixture and A-type markets. Similarly, 131 TWh per year of site electricity savings are available if the installed base of roadway, parking, area and flood and outdoor residential lights switched to LEDs. In the consumer electronics market, 30.7 TWh per year of site electricity savings are available in the television, laptop and desktop monitor applications. If these opportunities are fully realized, combined with the savings already captured today, a national electricity consumption of 263 TWh per year could be avoided which is equivalent to a primary energy savings of 2.5 quads. This amount represents approximately 2.5 percent of total national energy consumption in 2010.

\footnotetext{
${ }^{37}$ The pie chart includes the Outdoor Residential to indicate the relative electricity savings. However, the total maximum site electricity savings with 100\% LED market penetration reported in the center of the graphic does not include Outdoor Residential applications because it has significant overlap with the General Illumination applications.
} 
Table 5.2 - Potential and Cumulative Energy Savings of Applications Evaluated

\begin{tabular}{|c|c|c|c|c|}
\hline Application & $\begin{array}{l}\text { Electricity } \\
\text { Savings } \\
\text { Potential } \\
\text { (TWh) }\end{array}$ & $\begin{array}{l}\text { Primary } \\
\text { Energy } \\
\text { Savings } \\
\text { Potential } \\
\text { (TBtu) }\end{array}$ & $\begin{array}{c}\text { Theoretical } \\
\text { Maximum } \\
\text { Electricity } \\
\text { Savings (TWh) }\end{array}$ & $\begin{array}{c}\text { Theoretical } \\
\text { Maximum } \\
\text { Primary Energy } \\
\text { Savings (TBtu) }\end{array}$ \\
\hline \multicolumn{5}{|c|}{ General Illumination Replacements } \\
\hline 2-ft by 2-ft Troffer & 6.6 & 71.4 & 6.6 & 71.4 \\
\hline PAR, BR and R Shaped & 35.5 & 386.2 & 35.6 & 387.2 \\
\hline MR16 Replacement & 6.0 & 65.3 & 6.3 & 68.0 \\
\hline A-Tyре & 84.1 & 914.8 & 84.1 & 914.8 \\
\hline \multicolumn{5}{|c|}{ Outdoor White Light Applications } \\
\hline Roadway & 20.1 & 218.6 & 20.2 & 219.7 \\
\hline Parking & 15.5 & 168.6 & 16.9 & 183.8 \\
\hline Area and Flood & 62.4 & 678.4 & 63.1 & 686.2 \\
\hline Residential Outdoor & 30.3 & 329.6 & 30.3 & 329.6 \\
\hline \multicolumn{5}{|c|}{ Consumer Electronics Applications } \\
\hline Television & 17.6 & 191.4 & 18.0 & 195.8 \\
\hline Laptop & 0.7 & 7.2 & 1.1 & 12.1 \\
\hline Desktop Monitor & 11.1 & 120.7 & 11.6 & 126.2 \\
\hline Total & 259.5 TWh & 3,152 TBtu & 263.4 TWh & 2,865 TBtu \\
\hline
\end{tabular}

In a way, this savings estimate is understated, because it fixes the theoretical replacement LED technology at 2010 performance levels. Over the coming years, researchers and manufacturers will continue to develop and commercialize more energy efficient, higher quality LED devices. This trend means that as more market share is captured in the future, the LED technology adopted will have better performance characteristics, and contribute to even more significant energy savings.

Table 5.3 provides a rough estimate of what the future potential from LED penetration energy savings could look like. The DOE’s SSL 2010 Multi-Year Program Plan predicts that LED luminaire efficacy will increase $155 \%$ over the next decade to $219 \mathrm{~lm} / \mathrm{W}$, and LED package efficacy will make a similar rise of $81 \%$ to $234 \mathrm{~lm} / \mathrm{W}$. Assuming the increase in luminaire efficacy is representative of the general illumination and outdoor white light sectors, and the increase in package efficacy characterizes that of the consumer electronics market, the potential energy savings increases dramatically to $399 \mathrm{TWh}$. This equates to a forecasted primary energy savings of approximately 4.3 quads, or the total annual electricity consumption of nearly 32 million residential households. 
Table 5.3 - 2020 Forecasted Electricity and Primary Energy Savings Potential of Applications Evaluated

\begin{tabular}{|l|c|c|}
\hline \multicolumn{1}{|c|}{ Application } & $\begin{array}{c}\text { 2020 Forecasted } \\
\text { Electricity Savings } \\
\text { Potential (TWh) }\end{array}$ & $\begin{array}{c}\text { 2020 Forecasted } \\
\text { Primary Energy } \\
\text { Savings Potential } \\
\text { (TBtu) }\end{array}$ \\
\hline General Illumination Replacements \\
\hline 2-ft by 2-ft Troffer & 9.9 & 107 \\
\hline PAR, BR and R shaped & 41.3 & 449 \\
\hline MR16 Replacement & 9.3 & 101 \\
\hline A-Type & 105.1 & 1,143 \\
\hline Outdoor White Light Applications \\
\hline Roadway & 40.0 & 435 \\
\hline Parking & 37.7 & 410 \\
\hline Area and Flood & 102.1 & 1,110 \\
\hline Residential Outdoor & 34.8 & 378 \\
\hline Consumer Electronics Applications \\
\hline Television & 38.9 & 424 \\
\hline Laptop & 1.8 & 20 \\
\hline Desktop Monitor & 13.2 & 144 \\
\hline Total & $\mathbf{3 9 9 . 3 ~ T W h}$ & $\mathbf{4 , 3 4 3 ~ T B t u}$ \\
\hline
\end{tabular}




\section{References}

ACEEE. (2010). The 2010 State Energy Efficiency Scorecard. American Council for an Energy Efficient Economy.

Andersen, C. K. (2010, May). U.S. Department of Transportation, Federal Highway Administration. [Interview].

Bhandarkar, V. (2010, July 14). Outlook for the Worldwide High-Brightness LED Market. Retrieved October 25, 2010, from Strategies Unlimited:

http://semiconwest.org/cms/groups/public/documents/web_content/ctr_038417.pdf

Bullough. (2001). Driving in Snow: Effect of Headlamp Color at Mesopic and Photopic Light Levels. Detroit, Michigan: Lighting Research Center.

California Energy Commission. (2009). 2009 Appliance Efficiency Rulemaking. California Energy Commission.

Chester, et al. (2010). Parking Infrastructure: Energy, Emissions, and Automobile Life-Cycle Environmental Accounting. IOP Publishing.

Chian Myau Soon. (2007). White Light Emitting Diodes as Liquid Crystal Display Backlighting. Massachusetts Institute of Technology.

City Governments. (2010). Ann Arbor, MI; Bellevue, WA; Blair, NE; Broken Bow, NE; Glendale, AZ; Kansas City, MO; Los Angeles, CA; Pittsburgh, PA; Raleigh, NC. [Interview]. City of Oakland Public Works Agency. (2009). Street Light Facts. Retrieved November 1, 2010, from Electrical Services Division: http://www.oaklandpw.com/Page246.aspx

Cook, e. a. (2008). PG\&E Emerging Technologies Program Application Assessment Report \#0714. Oakland, CA: Emerging Technologies Coordinating Council.

D\&R Internation, Ldt. (2010). ENERGY STAR CFL Market Profile.

D\&R International, Ltd. (2010). ENERGY STAR CFL Market Profile: Data Trends and Market Insights. Washington DC: U.S. DOE.

DisplaySearch (a). (2010). LCD TVs to Exceed 180 Million Units in 2010. Retrieved October 2010, from http://www.displaysearch.com/pdf/100223_lcdtv_tvs_to_exceed_180_million_units_in_2010.pd $\mathrm{f}$ 
DisplaySearch (b). (n.d.). Q1’10 Shipments Show Global TV Market Continues to Recover. Retrieved October 2010, from http://www.displaysearch.com/pdf/100602_q1_10_shipments_show_global_tv_market_continue s_to_recover.pdf

DisplaySearch (c). (2010). 34 Billion LEDs for TFT LCD Backlights in 2012, Up 300\% from 2008 to a 20\% Share of the LED Market. Retrieved October 2010, from

http://www.displaysearch.com/cps/rde/xchg/displaysearch/hs.xsl/090622_34_billion_leds_for_tft _lcd_backlights_in_2012_up_from_2008\%20.asp

DisplaySearch (d). (2010). Key Component Shortages Limiting Growth of LED Backlight Units for LCD TVs. Retrieved October 2010, from

http://www.displaysearch.com/cps/rde/xchg/displaysearch/hs.xsl/100719_key_component_short ages_limiting_growth_of_led_backlight_units_for_lcd_tvs.asp

DOE (a). (2009). 2009 Building Energy Databook. Washington DC: DOE.

DOE (b). (2009). DOE's 2009 Energy Conservation Final Rule for General Service Fluorescent Lamps and Incandescent Reflector Lamps. Washington DC: DOE.

DOE (c). (2010). Solid-State Lighting Research and Development: 2010 Multi-Year Program Plan. Washington DC: DOE.

DOE (d). (2010). Demonstration Assessment of Light-Emitting Diode (LED) Retrofit Lamps. U.S. DOE Solid-State Lighting Technology Demonstration GATEWAY Program.

DOE (e). (2010). Municipal Solid-State Street Lighting Consortium. Retrieved from Member Lighting Inventory Survey: http://www1.eere.energy.gov/buildings/ssl/consortium.html

DOE CALiPER Program (a). (2010). Solid-State Lighitng CALiPER Program: Summary Results: Rounds 1 through 11. Retrieved from http://www1.eere.energy.gov/buildings/ssl/reports.html

DOE CALiPER Program (b). (2009). Performance of T12 and T8 Fluorescent Lamps and Troffers and LED Linear Replacement Lamps. Washington DC: U.S. DOE.

Eckert, M. (2010, September). LEDnovation, Inc. [Interview].

EIA. (2010). Annual Energy Outlook 2010. Retrieved from http://www.eia.doe.gov/oiaf/archive/aeo10/aeoref_tab.html

Elliott, M. (2007). LED laptops: Thinner, lighter, longer, better. Retrieved October 25, 2010, from Cnet News: http://news.cnet.com/8301-17938_105-9671130-1.html 
Energy Market Innovations, Inc. (2007). Puget Sound Area Residential Compact Fluorescent Lighting Market Saturation Study.

EPA ENERGY STAR® (a). (2010). Frequently Asked Questions Information on Compact Fluorescent Light Bulbs (CFLs) and Mercury. U.S. EPA.

EPA ENERGY STAR ${ }^{\circledR}$ (b). (2005). Summary of Assumptions for EPA ENERGY STAR® Savings Estimates ENERGY STAR Preliminary Draft Computer Specification (Version 4.0). EPA.

Girrbach, C. (2010). How Starbucks Saves Millions a Year in Energy with LED Lighting. Retrieved December 13, 2010, from http://www.greenbiz.com/blog/2010/12/02/how-starbuckssaves-millions-year-energy-led-lighting

Hans-Paul Siderius, R. H. (2007). An Energy Efficiency Index for Televisions. International Energy Agency.

IDC. (2009). Consumer Portable PCs Limit Volume Decline, But Shipment Value Suffers, According to IDC. Retrieved October 25, 2010, from

http://www.idc.com/about/viewpressrelease.jsp?containerId=prUS21879209\&sectionId=null\&el ementId=null\&pageType=SYNOPSIS

International Parking Institute. (2010). Internal Membership Survey.

iSuppli (a). (2010). LCDs Face LED Backlight Supply Shortage as Shipments More than Double in 2010. Retrieved October 26, 2010, from http://www.isuppli.com/Display-Materials-andSystems/News/Pages/LCDs-Face-LED-Backlight-Supply-Shortageas-Shipments-More-thanDouble-in-2010.aspx

iSuppli (b). (2010). LED Backlighting Used in One in Five LCD-TVs Sold in U.S. During Q3. (iSuppli) Retrieved December 6, 2010, from http://www.isuppli.com/Display-Materials-andSystems/News/Pages/LED-Backlighting-Used-in-One-in-Five-LCD-TVs-Sold-in-US-DuringQ3.aspx

iSuppli (c). (2010). Vizio Takes Lead in U.S. LCD-TV Market in 2009; Samsung Holds FlatPanel Top Spot. (iSuppli) Retrieved December 6, 2010, from http://www.isuppli.com/displaymaterials-and-systems/news/pages/vizio-takes-lead-in-us-lcd-tv-market-in-2009-samsung-holdsflat-panel-top-spot.aspx

Itron, Inc. (2006). California Commercial End-Use Survey Results.

Kalloniatis, M. (2005). Principles of Vision. U.S. National Library of Medicine .

Lazarev, A. (2009). Materials for Light Efficient LCD. Society for Information Displays. 
LEDs Magazine (a). (2010). Best Buy installs LED replacement lamps from CRS Electronics. Retrieved from http://www.ledsmagazine.com/news/7/9/22

LEDs Magazine (b). (2009). LED backlighting market for LCD panels to see rapid growth. Retrieved October 25, 2010, from Industry News: http://www.ledsmagazine.com/news/6/6/13

LEDs Magazine (c). (2010). LCD backlights and lighting drive largest growth yet seen in HBLED market. Retrieved November 3, 2010, from LEDs Magazine:

http://www.ledsmagazine.com/features/7/3/5

Lighting Reseach Center (a). (2003). What is a Ballast? Rensselaer Polytechnic Institute.

Lighting Research Center (b). (2002). Lighting Answers: MR16 Lamps. Retrieved December 15, 2010, from Rensselaer Polytechnic Institute:

http://www.lrc.rpi.edu/programs/nlpip/lightinganswers/mr16/abstract.asp

Lighting Research Center (c). (1994). Specifier Reports: Reflector Lamps - Energy Efficient Replacements for 75-watt, 100-watt and 150-watt incandescent reflector lamps. Rensselaer Polytechnic Institute.

Monahan, D. R. (2010, August 16). Walker Parking Consultants. [Interview].

Narukawa, Y. (2010). White light emitting diodes with super-high luminous efficacy. Journal of Physics D: Applied Physics .

Navigant Consulting, Inc (a). (2008). Energy Savings Estimates of Light Emitting Diodes in Niche Lighting Applications. U.S. Department of Energy.

Navigant Consulting, Inc (b). (2002). U.S. Lighting Market Characterization - Volume 1: National Lighting Inventory and Energy Consumption Estimate. Washington DC: U.S. Department of Energy.

NEMA (a). (2006). 2000 to 2005 IRL and GFSL Historical Shipments. NEMA.

NEMA (b). (2003). Special Statistical Report for the Large Lamp Section: PAR/R Lamp Survey. NEMA.

NEMA (c). (2010, December 2). Incandescent Lamp Index Declines to Record Low During Third Quarter of 2010. Retrieved January 3, 2011, from NEMA News: http://www.nema.org/media/pr/20101202a.cfm

NEMA (d). (2004). High-Intensity Discharge Lamp Survey. Energy Conservation Program for Commercial and Industrial Equipment: High-Intensity Discharge (HID) Lamps Rulemaking , Docket \# EE-DET-03-001. 
NLPIP. (1994). Reflector Lamps. Specifier Reports .

NMR Group, Inc. (2010 (a)). Results of the Mulitstate CFL Modeling effort. Somerville, MA.

NMR Group, Inc. (2010 (b)). The Market for CFLs in Massachusetts.

Nystedt, D. (2010). Samsung Builds 3D TV Home System, Thinnest LED TV Ever. Retrieved October 28, 2010, from

http://www.pcworld.com/article/186158/samsung_builds_3d_tv_home_system_thinnest_led_tv_ ever.html

Responsible Purchasing Network. (2009). Responsible Purchasing Guide for LED Exit Signs, Street Lights, and Traffic Signals. Retrieved January 10, 2011, from http://www.seattle.gov/purchasing/pdf/RPNLEDguide.pdf

RLW Analytics Inc. (a). (2000). California Statewide Lighting and Appliance Saturation Study Final Report. California Investor Owned Utilities.

RLW Analytics Inc. (b). (2007). Single Family Residential Existing Construction Stock Assessment. Northwest Energy Efficiency Alliance.

RLW Analytics Inc. (c). (2007). Single Family Residential New Construction Characteristics and Practices Study. Northwest Energy Efficiency Alliance.

RLW Analytics, Inc. (d). (2005). California Statewide Lighting and Appliance Efficiency Saturation Study. California Investor Owned Utilities.

SEMI. (2010). Growth continues in some sectors of the HB LED market. Retrieved October 26, 2010, from http://www.semi.org/en/IndustrySegments/ctr_028782?id=highlights

Sharp Electronics Corporation. (2009, September 23). Average TV size up to 60-inch by 2015 says Sharp. Retrieved January 10, 2011, from http://flowingdata.com/2009/09/23/tv-size-overthe-past-8-years/

State Governments. (2010). California, Pennsylvania, Michigan, Nebraska. [Interview].

Steele, R. (2010). LCD Backlights and Lighting Drive Largest Growth Yet Seen in HB-LED Market. Retrieved October 26, 2010, from http://www.ledsmagazine.com/features/7/3/5

Strategies Unlimited. (2009). LED Replacement Lamps Market Analysis and Forecast. Strategies Unlimited.

Texas Instruments. (2009). How DLP Technology Works. Retrieved October 26, 2010, from http://dlp.com/technology/how-dlp-works/default.aspx 
TIAX LLC(a). (2010). Commercial Miscellaneous Electric Loads: Energy Consumption Characterization and Savings Potential in 2008 by Building Type. U.S. Department of Energy.

TIAX LLC(b). (2007). Energy Consumption of Consumer Electronics in U.S. Residences. Consumer Electronics Association (CEA).

U.S. Census Bureau (a). (2010). American Factfinder: 2009 Population Estimates Table.

U.S. Census Bureau (b). (2010). Current Industrial Reports (1980-2001).

United Kingdom Department for Environment, Food and Rural Affairs. (2010). Task 3: Review of Sales and Inventory Estimates. UK Department for Environment, Food and Rural Affairs.

Webber, et al. (2006). After-hours power status of office equipment in the USA. Lawrence Berkeley National Laboratory.

Wesselink, et al. (2009). Sectoral Emission Reduction Potentials and Economic Costs for Climate Change. Ecofys.

Xenergy Inc. (2003). NSTAR Residental High Use Program Operating Hours Realization Rate Study. 
